Portland State University

PDXScholar

1988

\title{
A Comparative Study of the Characteristics of High Technology Start-Up Firms
}

Sandra J. Kiehl

Portland State University

Follow this and additional works at: https://pdxscholar.library.pdx.edu/open_access_etds Let us know how access to this document benefits you.

\section{Recommended Citation}

Kiehl, Sandra J., "A Comparative Study of the Characteristics of High Technology Start-Up Firms" (1988). Dissertations and Theses. Paper 1247.

https://doi.org/10.15760/etd.1246

This Dissertation is brought to you for free and open access. It has been accepted for inclusion in Dissertations and Theses by an authorized administrator of PDXScholar. Please contact us if we can make this document more accessible: pdxscholar@pdx.edu. 
A COMPARATIVE STUDY OF THE CHARACTERISTICS OF

HIGH TECHNOLOGY START-UP FIRMS

by

SANDRA J . KIEHL

A dissertation submitted in partial fulfillment of the requirements for the degree of

\author{
DOCTOR OF PHILOSOPHY \\ in \\ SYSTEMS SCIENCE
}

\author{
Portland State University \\ (C) 1988
}


TO THE OFFICE OF GRADUATE STUDIES:

The members of the Committee approve the dissertation of Sandra J. Kiehl presented November 4, 1988.

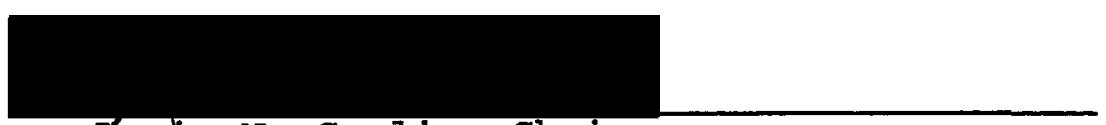

Lewis N. Goslin, Chair

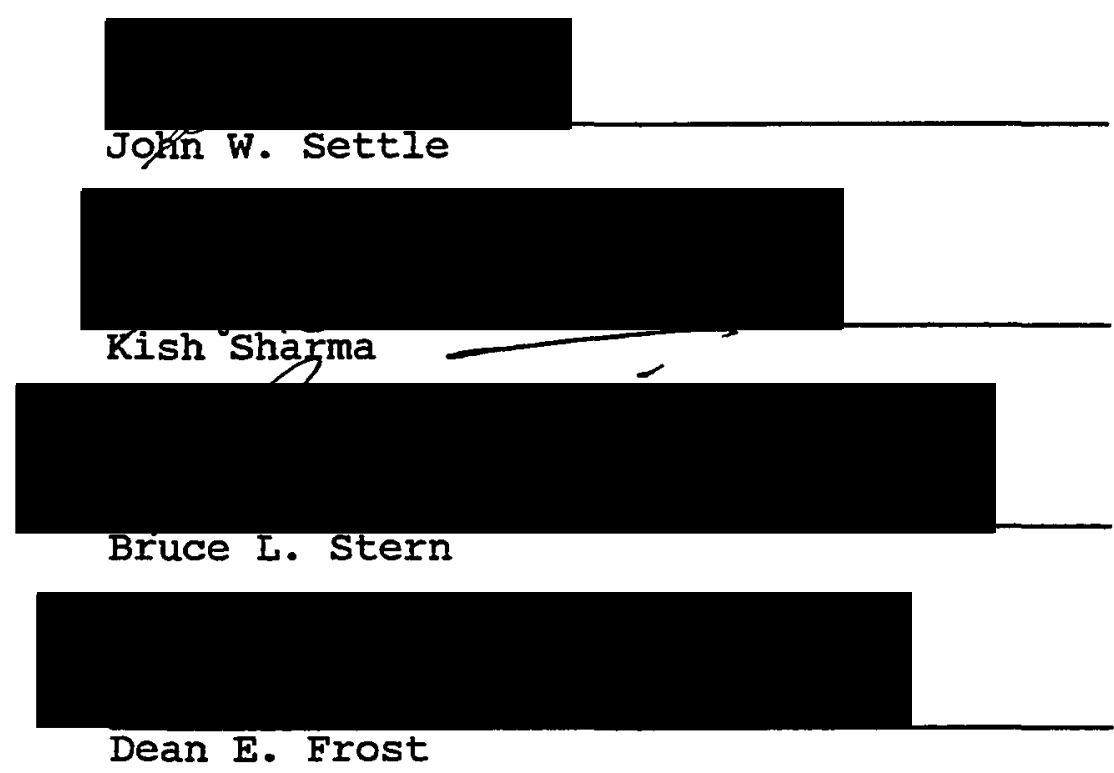

APPROVED:
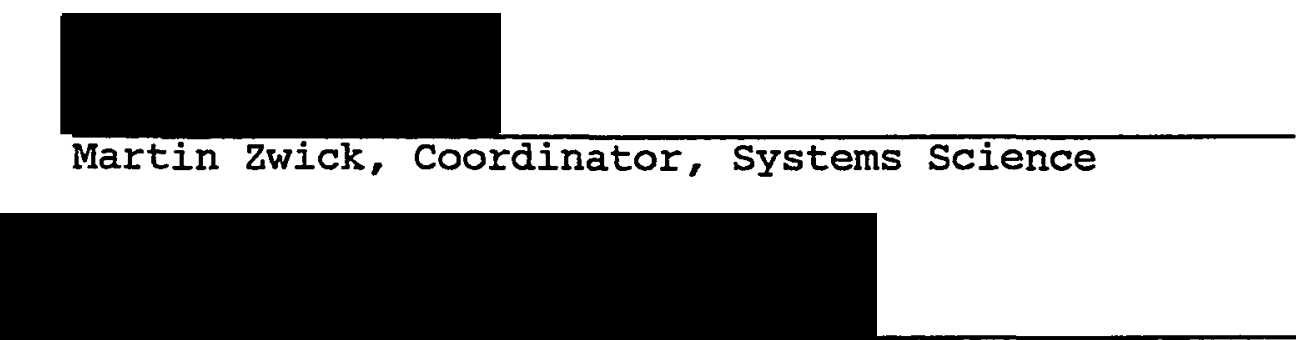

Bernard Ross, Vice Provost for Graduate Studies 
AN ABSTRACT Of THE DISSERTATION OF Sandra J. Kiehl for the Doctor of Philosophy in Systems Science presented November 4,1988 .

Title: A Comparative Study of the Characteristics of High Technology start-Up Firms.

APPROVED BY THE MEMBERS OF THE DISSERTATION COMMITTEE:

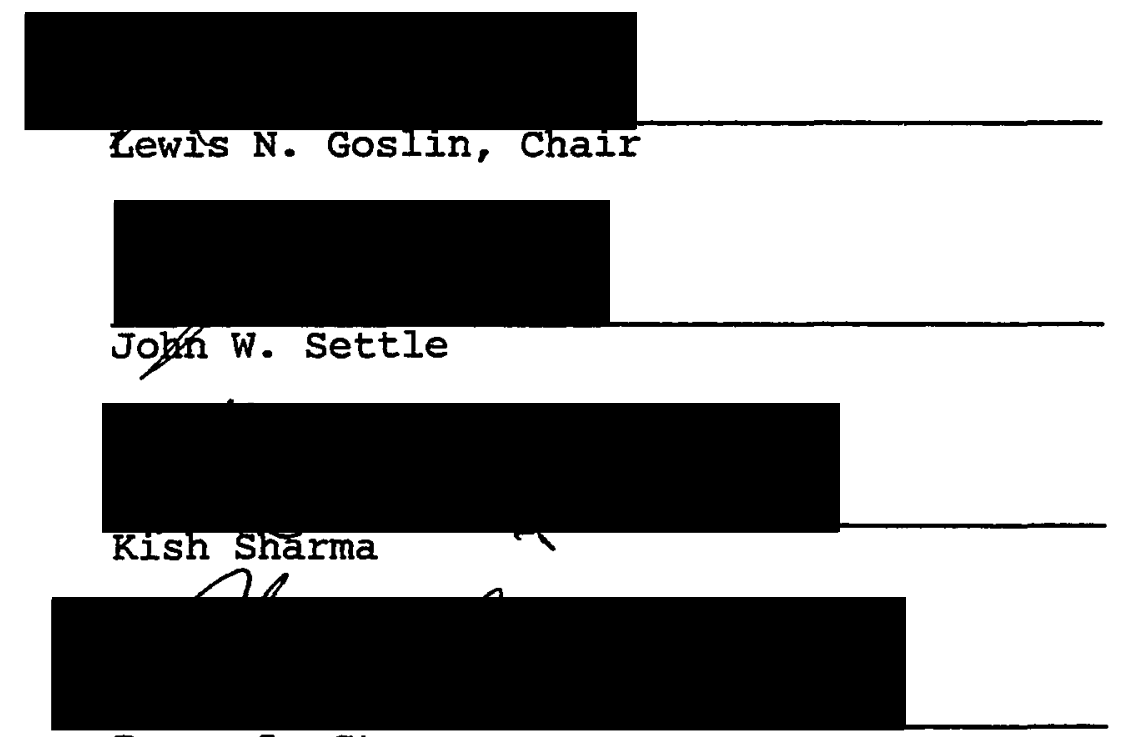

Bruce L. Stern

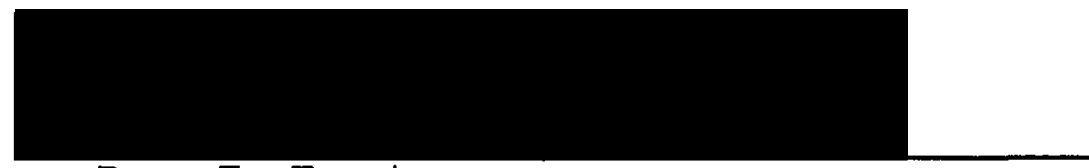

Dean E. Frost

A sample of two hundred and twenty-five high technology start-up firms located nationwide provided a base for the analysis of characteristics of start-up success. 
The analysis provides insights into management capabilities which may be generalized to a larger population.

For comparison purposes, the sample was divided into two groups: (1) those firms which have not received a venture capital infusion from a formal venture capital company and (2) those firms which have received one or more infusions of venture capital. Aspects of organizational climate, top management team approach, marketing strategy and focus, business planning and the intent to go public as a means of addressing future financing needs were examined. Hypothesis testing was accomplished through the employment of ANOVA and Chi-Square. Based upon the results of the testing of each of the hypotheses, the following conclusions are drawn:

1. Based upon those aspects examined, both the funded and unfunded firms embrace practices which strongly manifest those of an organic organization. The strong propensities toward both open communication channels and participatory decision making are indicative of the lack of formal structure present in these organizations. In addition, creativity is strongly supported, as it should be, by the notion that failure is viewed in a positive context as a necessary component of both being creative and making technological advancements.

2. The team approach to management is practiced by both funded and unfunded firms, although the venture capital funded firms have a hjgher quality top management team when 
quality is defined by aggregate primary past functional experience. The funded firm has a larger team which, in turn, brings more years of experience, a higher aggregate level of organizational responsibility, and more diversity of functional capability. This diversity provides balance in terms of complementary functional skills. Additional strength is added to the top management team of the funded firms due to a higher percentage of members whose prior experience is directly related to the functional capacity in which they now serve. Similarly, the funded firm is more likely to have management team members whose previous experience was in a firm whose core technology was the same or very similar to that of the start-up.

3. There do not appear to be significant differences between the venture capital funded and unfunded firms regarding the various marketing oriented characteristics. Both groups tend to be market driven with a solutions orientation.

4. The high technology start-up firm which has received venture capital funding is more likely to go public than the unfunded firm.

5. Business planning is practiced by the majority of all high technology start-up firms, although the funded firms do so to a greater extent. Not only do virtually all funded firms prepare business plans, but the plans 
themselves appear to be more extensive. Additionally, the primary purpose for which the funded firm prepares the plan is for venture capital acquisition. On the other hand, the unfunded firms perform business plan preparation to a lesser extent, but do so because of operating necessity.

The results of this study have implications for the nascent entrepreneur in the high technology arena and researchers alike toward the end of providing a more complete understanding of some of the critical components essential to the success of a start-up. 
TABLE OF CONTENTS

Page

LIST OF

TABLES

vi

CHAPTER

I INTRODUCTION $\ldots \ldots \ldots \ldots \ldots \ldots \ldots \ldots \ldots \ldots \ldots \ldots$

High Technology - An Economic Strategy 1

Definition of Terms ............... 2

High Technology

Start-Up

Venture Capital

Primary Firm Characteristics ........ 7

Management Depth

Marketing Expertise

Financial Control

Purpose of the study ............. 10

Delimitations of the study ......... 12

II REVIEW OF THE IITERATURE ............. 14

Introduction .................. 14

Importance of High Technology ........ 14

Real output Growth

New Job Creation

Strategic Impact on the Economy

Characteristics of the Successful High

Technology start-up Firm ........

Management Depth

Marketing Expertise

Financial control 
Conclusion $\ldots \ldots \ldots \ldots \ldots \ldots \ldots \ldots \ldots \ldots$

Statements of the Hypotheses ....... 49

III RESEARCH DESIGN AND METHODOLOGY .......... 52

Research Design ................ 52

Population Definition

Data Collection Method

Sampling Method

Sample Size

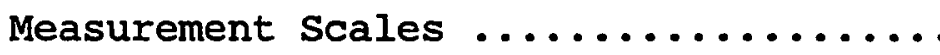

Independent Variable

Dependent Variables

Operationalization of Variables ...... 64

Hypothesis 1

Hypothesis 2

Hypothesis 3

Hypothesis 4

Hypothesis 5

Hypothesis 6

Hypothesis 7

Statistical Techniques ........... 79

Hypothesis Testing .............. 82

Notation

Statistical Computations

Hypothesis 1

Hypothesis 2

Hypothesis 3

Hypothesis 4

Hypothesis 5

Hypothesis 6

Hypothesis 7

Summary ......................... 92

IV ANALYSIS OF RESEARCH FINDINGS .......... 93

Characteristics of the sample ....... 93

Characteristics of the Entire Sample

Characteristics of the Unfunded Firms 
Characteristics of the Funded Firms Hypothesis Test Findings ........... 97

$\begin{array}{ll}\text { Hypothesis } & 1 \\ \text { Hypothesis } & 2 \\ \text { Hypothesis } & 3 \\ \text { Hypothesis } & 4 \\ \text { Hypothesis } & 5 \\ \text { Hypothesis } & 6 \\ \text { Hypothesis } 7\end{array}$

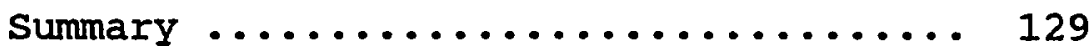

V SUMMARY, CONCLUSIONS AND RECOMMENDATIONS .. 132

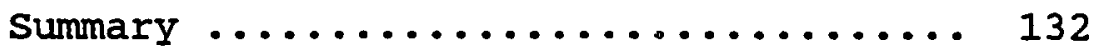

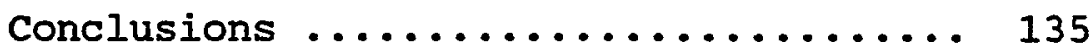

Recommendations for Further Research .. 141

BIBLIOGRAPHY $\ldots \ldots \ldots \ldots \ldots \ldots \ldots \ldots \ldots \ldots \ldots \ldots \ldots \ldots \ldots$

APPENDICES $\quad \ldots \ldots \ldots \ldots \ldots \ldots \ldots \ldots \ldots \ldots \ldots \ldots \ldots \ldots \ldots \ldots$

Appendix A ............................... 151

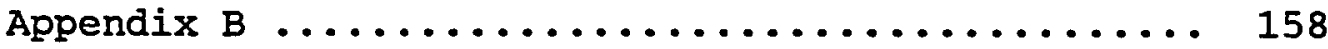

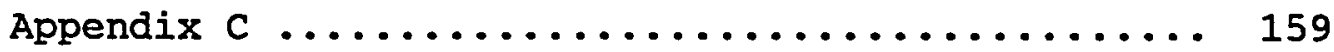

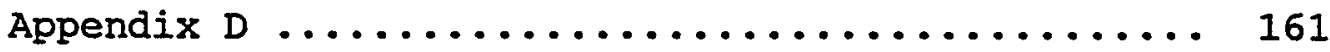

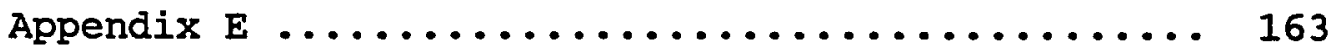

Appendix F ............................ 167

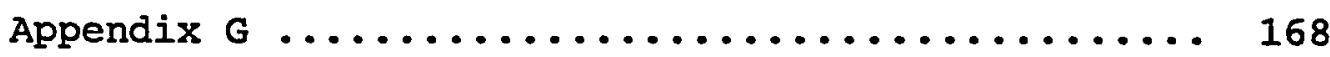

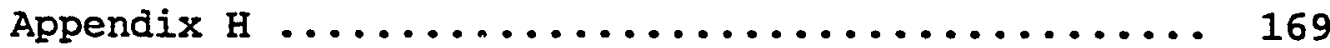

Appendix I .......................... 170

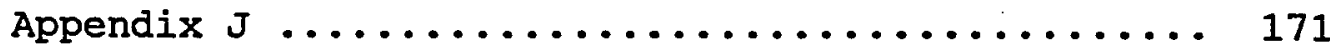

Appendix K ............................. 172 


\section{IIST OF TABLES}

I Hypothesis I - Variable Definitions ..... 66

II Hypothesis II - Variable Definitions ..... 68

III Hypothesis III - Variable Definitions .... 70

IV Hypothesis IV - Variable Definitions ..... 71

V Hypothesis V - Variable Definitions ..... 73

VI Hypothesis VI - Variable Definitions ..... 74

VII Hypothesis VII - Variable Definitions .... 78 HYPOTHESIS 1

VIII Component 1 - Open Communication

Flow - Anova Results .......... 98

IX Component 2 - Decision Making

Style - Anova Results ......... 99

$X$ Component 3 - Tolerance of Failure -

Anova Results .............. 100

XI Component 4 - Policies Consistent

With Corporate Goals - Anova

Results ................. 100

XII Component 5 - Integrity More Important

Than Profit - Anova Results .... 101

VIII Organizational Climate sum of Scores -

Anova Results .............. 101

HYPOTHESIS 2

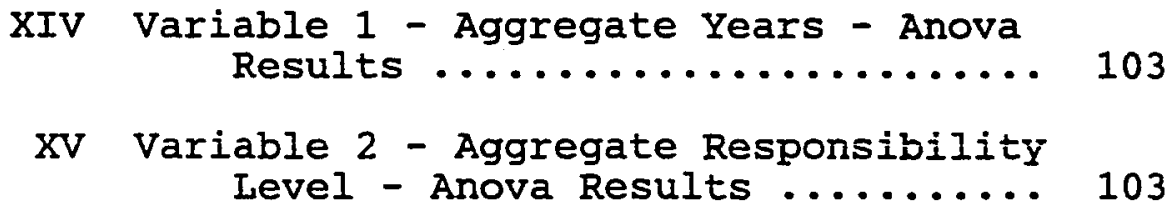


XVI Variable 3 - Aggregate Annual Sales Volume (Milizons of Dollars)

- Anova Results ................ 104

XVII Variable 4 - Number of Top Management Team Members - Anova Results .... 105

XVIII Variable 8 - Number of Different Prior Functional Areas - Anova Results 106

XIX Variable 5 - Members serving in same Functional Capacity - Anova Results ................. 106

XX Variable 6 - Members Experienced With a Like Technology - Anova Results

HYPOTHESIS 3

XXI Component 1 - Product will Not Sell Itself - Anova Results ........ 109

XXII Component 2 - Knowledgeable About Competitors - Anova Results .... 110

XXIII Component 3 - Employees Very Customer Focused - Anova Results ....... 110

XXIV Component 4 - Market Demand Primary To Technological Sophistication Anova Results ............. 111

XXV Strategy Sum of Scores -Anova Results 112 HYPOTHESIS 4

XXVI Component 1 - Customer Feedback Essential To New Product Development - Anova Results .... 114

XXVII Component 3 - Intimately knowledgeable About Customers' Business - Anova Results ...................... 115

XXVIII Component 4 - Focus on Sharp Unique Market Segmentation - Anova Results .................. 115

XXIX Solutions orientation sum of scores Anova Results .............. 116 
HYPOTHESIS 5

XXX Component 1 - Do Not Compete with Very Large Companies - Anova

Results .................

XXXI Component 2 - Do Not Strive To Be Low Cost Producer - Anova Results 118

XXXII Component 3 - Unique Product Deters Entry - Anova Results ......... 119

XXXIII Component 4 - Product Does Not Appeal To a Broad Commodity Market Anova Results ............... 120

XXXIV Component 6 - Market Differs From Larger Market As A Whole - Anova Results .............. 120

XXXV Niche Focus Sum Of Scores - Anova Results .................. 121

HYPOTHESIS 6

XXXVI Probability of Going Public in Two Years - Anova Results ......... 122

XXXVII Years Elapsed Between Founding \& Going Public - Cross Tabulation Results ................... 123

HYPOTHESIS 7

XXXVIII Number of Pages in Business Plan Anova Results ............... 124

XXXIX Business Plan Pages - Cross Tabulation Results ................. 125

XXXX Most Important Business Plan Component - Cross Tabulation Results ................... 126

XXXXI Least Important Business Plan Component - Cross Tabulation Results ................ 127

XXXXII Business Plan Component Weightings Anova Results ............. 128 
CHAPTER I

INTRODUCTION

The goal of this research study is to examine high technology start-up firm characteristics. For comparison purposes, the firms in the study are divided into two groups: (1) those firms which have not received a venture capital infusion, and (2) those firms which have received one or more infusions of venture capital.

The topics covered in Chapter I include: high technology - an economic strategy, definition of terms, primary firm characteristics, purpose of the study, and delimitations of the study.

\section{HIGH TECHNOLOGY - AN ECONOMIC STRATEGY}

In recent years the economic development strategies of state and local governments have become diversification strategies. For example, the state of Massachusetts has focused on the development of the high technology industry to attenuate the economic ills caused by the decline in its traditional heavy industrial base; and the state of oregon has encouraged growth in high technology in an effort to expand an economic base which has been firmly grounded in the lumber industry, which no longer employs as many people 
as it once did. Additionally, Black asserts these economic strategies are based on a shift from an industrial to an information economy. Economic development strategies such as these have moved away from the recruitment of the smokestack manufacturing industries to the high technology industries (Black, 1986: 9).

During the past decade, the literature has supported the notion that high technology industries are and will continue to be the engine that arives the economic growth of the United States for the duration of this century (Miller et al, 1985: 114; Howell, 1985: 17; Krishna et al, 1986: 47). Concomitantly, new business start-ups in the high technology arena are more pervasive than at any previous point in history.

\section{DEFINITION OF TERMS}

Before proceeding, it is important to understand the meaning of the terms "high technology" "start-up", and "venture capital".

\section{High Technology}

There is virtually little agreement on the explicit definition of high technology. When most individuals refer to high technology they generally mean micro-electronics. While the computer and electronics segment of the industry has provided the overwhelming portion of jobs and revenue growth, high technology encompasses much more. 
Biotechnology, chemicals and advanced materials such as polymers, microwave communications and fiber optics increasingly are part of the high technology mix.

Douglas Green, publisher and president of Mass High Tech, a New England high technology industry journal, defines high technology as any company in electronics, semiconductors, software, chemicals, biotechnology, photovoltaics or advanced communications that employs engineers in research and development (Radding, 1986: 4). zalud offers much the same breakdown, but with a refinement in the biotechnology arena claiming that priority areas involve applications in agriculture, livestock production, medicine, chemistry and pharmaceuticals (zalud, 1986: 90).

Webre and Bodde have been somewhat more precise by defining a high technology industry as one with a ratio of R\&D that is one-third higher than the overall average of the manufacturing industries, and with a ten-year growth in employment that is higher than the manufacturing average. These criteria, once again, produce a similar result regarding industry types -- drugs, industrial organic chemicals, office and computing machines, communications equipment, electronic components, air craft missiles and instrumentation (Webre et al, 1986: 28).

It should be noted that according to a recent research study by Gomez-Mejia \& Balkin, the definition provided by Webre \& Bodde may be somewhat conservative in at least one 
of its criteria. The research found that high technology companies reinvest about four times more than traditional companies (Gomez-Mejia et al, 1985: 31).

The Bureau of Labor and Statistics has defined high technology industries as those with R\&D expenditures and technical employees nearly twice as high as the total U.S. manufacturing average. The BLS has a second category called "high-tech intensive industries" defined as having R\&D spending and technical employment above the national average.

The thread common to all of the stated firm types is that they all operate close to the state of the art or the frontier of technology (Bleicher et al, 1983: 70).

For the purposes of this research study, high technology is defined as any firm in electronic hardware, software, fiber optics, lasers, AI, robotics, biotechnology, advanced materials, aerospace, chemicals, factory automation, electronic subassemblies/components, test and measurement, telecommunications, high technology services, energy and medical instrumentation. These firm types were chosen on a convenience basis relative to the availability of the sampling frame used. Further discussion of the sampling frame is found on pages fifty-two and fifty-three.

Start-Up

The term start-up also has a variety of definitions. Cooper defines start-up as a stage of development during 
which the strategic decision is made to found a firm and to position it within a particular industry with a particular competitive strategy (Schendel et al, 1979: 317).

Kozmetsky defines the start-up as the company in the organization phase or within the first year of business. At this point in time, product development will still be in process. Typically the management team will be in place, some marketing research will have been done and the business plan will have been prepared (Kozmetsky et al, 1985: 9). Stacey disagrees with the rather narrow scope of the foregoing definitions. He bases his disagreement on the premise that the committed entrepreneur does not necessarily approach the financial institutions for a serious injection of capital within the first two years of business. As a result, the start-up would be any business up to three years old. Additionally, he implies that the firm may also be producing and marketing a particular product from the outset (Stacey, 1986: 159).

Stacey's definition includes what the previous two authors would consider to be the early growth stage, when the firm is manufacturing and selling its product and when it has growing accounts receivables and inventories. A key point made by Kozmetsky is that the firm that can be classified as profitable has passed the start-up stage (Kozmetsky et al, 1985: 9; Schendel et al, 1979: 317). 
For the purposes of this research study, a start-up is defined as a firm which is one-to-five years old based on the date of founding. This extension of the time frame, as defined above, is based on personal knowledge of several high technology entrepreneurs whose companies spent two to three years in the product development stage. Those firms include, for example, Iattice Semiconductor, Ateq Corporation, Pacific Biotechnology Research, and Richware.

\section{Venture Capital}

Webster defines a venture as "an undertaking involving chance, risk or danger, especially a speculative business enterprise." It follows from this definition that venture capital financing was originally regarded as early stage financing of small but rapidly growing firms. Early stage financing is that which takes place prior to actual production and commercialization of the firm's product.

Since 1974, however, venture capital investments have been made in all phases of business development, from the point when the entrepreneur is attempting to prove a concept to the point when the firm is preparing to go public (Pratt, 1982: 4). Liles offers four explanations of situations in which venture capital financing is utilized. These explanations illustrate the diversity of situations calling for potential infusions of venture capital. They include: "(1) providing capital for any high-risk financial venture, (2) providing seed capital for a start-up situation, 
(3) investing in a firm that is unable to raise capital from conventional sources, and (4) investing in large publicly traded corporations where the risk is significant" (Liles, 1974: 461).

Venture capital may be in the form of equity, debt or convertible debt, although equity is the most common form. Further, venture capital may be obtained from a variety of sources. Those sources include, for example, private and public investment firms, Small Business Investment Corporations, institutions, banks and informal investors. The private and public investment firms, also known as professionally managed formal venture capital companies, are the major source of venture capital (Walker et al, 1986: 401).

It is convenient for the purposes of this study to define venture capital as equity financing obtained from a formal venture capital company, since they are easily identified and meet the required conditions for this examination.

\section{PRIMARY FIRM CHARACTERISTICS}

The aggregate of the current business literature on high technology start-up firms indicates that in addition to technological competency, there are three primary 
characteristics which are vital for the success of the high technology start-up:
- management depth,
- marketing expertise, and
- financial control.

Management Depth

While management depth may not necessarily be required initially to create a climate of innovation and creativity, it is required to sustain that climate and add the cohesion necessary to meet the goals of the start-up. Management is responsible for providing leadership, instilling a sense of commonality of purpose among all employees, building a sense of trust and respect, and ensuring the free flow of communication and ideas. Success depends on the ability of management to balance stability and conservatism, represented by the value system of the corporate culture, with continued innovation precipitated by the dynamic environment of high technology (Stacey, 1986: 160; Schendel et al, 1979: 322; Stevenson et al, 1986: 12; Maidique, 1984: 21).

\section{Marketing Expertise}

Technologically advanced products are not an end in themselves. The key point to be made here is that technology does not drive the market. Rather, the best market should be found and the product should be tailored to 
it. The innovative product is not the "better mousetrap", which can be defined as the best and most technologically sophisticated product (Bellack, 1985: 80). It is different in principle, and, more importantly, it provides a solution addressing a current need. Drucker asserts that products must have a market in the present; the firm should innovate for an existing market not for a potential future market (Rutigliano, 1986: 41). Grant Rollin, a partner in the High Technology Group of Deloit, Haskins \& Sells, also supports this notion when he observes that the firms receiving venture capital funding are those which are market-driven rather than technology-driven. The most successful startups, from his perspective, are those which determine what the market wants and then develop it (Schoch, 1985: 81).

The ability to provide solutions implies marketing adeptness. The entrepreneur must ascertain market needs not only at the outset, but on a continuing basis as the high technology marketplace represents a constantly changing environment.

\section{Financial Control}

Inadequate capital is one of the primary reasons for the failure of a new venture. Undercapitalization contributes to failure primarily due to the fact that the entrepreneur must spend an inordinate amount of time seeking capital infusions to relieve short-term cash flow problems. As a result, two additional problems are created: would-be 
investors are not as likely to invest if the firm is in financial crisis; and the firm as a whole may lose its sense of focus due to the loss of focus on the part of the driver of the firm's culture (that is, in the general practices and attitudes of the wider organization). To alleviate the pressures of undercapitalization, sound financial control should commence at the business planning stage and continue for the life of the firm.

Bleicher has indicated that high technology businesses require "instruments for management which do not rely as heavily on traditional techniques of controlling, finance and marketing as compared to more mature businesses" (Bleicher et al, 1983: 71). For example, the focus should be on teamwork rather than hierarchy, problem solving rather than routinization, and technological environmental scanning (looking for substantial technological potential), rather than marketing surveys.

\section{PURPOSE OF THE STUDY}

The purpose of this research study is to develop an understanding of the characteristics of the successful high technology start-up firm. There appears to be an absence of systematic, formal, empirical research which gives credibility to the notions presented in the current literature. These notions include: the team approach, an informal structure, and a solutions orientation as well as a 
variety of others which are discussed in Chapter II. The wisdom behind these notions appears to be, for the most part, very solid and based on experience, but the reader of the current business literature must trust the authors of that literature because there is, for the most part, no explicit presentation of the results of a specific studies. Hence, empirical research is needed to affirm or disprove the tenets and prescriptions advanced in the current business literature.

Answers to the pivotal questions require a determination of those factors inherent in the high technology start-up's structure, systems and strategies that contribute to management depth, marketing skill and financial control. Additionally, much of the current literature seems to imply that the venture capital funded start-up firm has a greater degree of management depth, marketing expertise and financial control than does the start-up which has not received any venture capital infusions. The reasoning behind this implication appears to be based on the additional accountability imposed by the expectations of the venture capital firm. It is, therefore, prudent to examine not only the high technology start-up arena as a whole, but to contrast and compare venture capital funded start-ups with unfunded start-ups (those which have not received at least one venture capital 
infusion) with respect to the aforementioned characteristics.

DELIMITATIONS OF THE STUDY

1. The meanings of high technology, start-up and venture capital are limited to the definitions provided for in the Definition of Terms Section.

2. The subject is examined relative to the organization which is created. This study does not address the personal or psychological characteristics of the individuals who found the start-up, nor does it address the environment surrounding the start-up venture.

3. The characteristics of the high technology start-up firm are examined on both an aggregate and a comparative basis. The criterion for comparison is whether or not the high technology start-up firm has received at least one round or infusion of venture capital financing as defined in the Definition of Terms section. Those start-ups which have received at least one round of venture capital financing are referred to as funded firms. Those start-ups which have not received any venture capital financing are referred to as unfunded firms.

4. While technological competency is considered quite important to the success of the high technology start-up 
firm, this research study does not address it per se. Technological competency is addressed as it relates to the quality of the top management team (see pages 60 and 61), and as it relates to the preparation of the business plan (see page 46 ). 
CHAPTER II

REVIEW OF THE LITERATURE

INTRODUCTION

The purpose of the literature review is to ascertain ideas and theories applying to those factors inherent in the success of high technology start-up firms. These ideas have been applied to designing a research instrument for the purpose of determining the relevancy of those notions advanced in the literature. (see Appendix A.) The fields of management, marketing and finance are the sources of concepts relating to the factors of success in high technology start-up firms.

This chapter discusses the following topics:

- Importance of High Technology, and

- Characteristics of the Successful High Technology start-Up Firm.

IMPORTANCE OF HIGH TECHNOLOGY

The high technology industry is critical to the economy of the United States because of its:

- Real Output Growth,

- New Job Creation, and

- Strategic Impact on the Economy. 
Real Output Growth

The economy of the United States is currently being characterized as a growth economy, with high technology industries being widely regarded as the prime movers of this growth. The rate of growth of real output in high technology industries was more than double that of the total U.S. industrial real output during the 1970-1980 period. High technology industries also experienced growth in average labor productivity which was six times faster than that of total U.S. business (Krishna, 1986: 47). Firms in the high technology industries now account for over one half of all private R\&D spending in the U.S., over one-third of all U.S. exports and one-sixth of the country's manufacturing exports (Webre et al, 1986: 28).

\section{New Job Creation}

All of the employment growth in the United States during the ten year period ending in 1985 had occurred in small companies. The nation's largest 1000 companies have eliminated one million jobs; however, smaller organizations have added 20 million jobs (Farrell, 1986: 42). Over the last twenty years, forty million jobs have been created, and the high technology industries have specifically accounted for five to six million of these jobs (Drucker, 1985: 3). In addition, studies have shown that for every new manufacturing job created in high technology two new service jobs are created (Goldman, 1984: 6). Conservatively, one 
can estimate that twenty-five percent of new job creation is based, either directly or indirectly, on the high technology industries.

Strategic Impact on The Economy

High technology industries are considered strategic because they stimulate technological progress across a broad range of industries. As a result, they contribute more to general economic growth than is measured by the value of their own output (Webre et al, 1986: 28).

The success of high technology industries is considered important to the nation for two reasons: (1) the benefits of high technology research extend well beyond the companies that sponsor it, and (2) high technology products drive technological change in a variety of technical sectors (Webre et al, 1986: 28).

From a qualitative standpoint, high technology is important in that it creates the news and excitement in what is now characterized as the entrepreneurial economy. The entrepreneur is commonly defined as one who starts his/her own new small business. But not every small business owner can be considered an entrepreneur. J.B. Say, the French economist, said around 1800, "The entrepreneur shifts economic resources from an area of lower and into an area of higher productivity and greater yield". In The Theory of Economic Dynamics, Joseph Schumpeter refined Say's definition by stating that dynamic disequilibrium is brought 
on by the innovating entrepreneur who sees change as the norm and as healthy. While say essentially said that the entrepreneur is one who does something better, Schumpeter focused on the notion that the entrepreneur does something different. The entrepreneur always searches for change, responds to it, and exploits it as an opportunity (Drucker, 1985: 28).

Currently we are in the third wave of entrepreneurship and innovation in the history of the modern industrialized world. The 1880's and 1920's also saw explosions of startups. The 1880's and '90's witnessed the second Industrial Revolution, while the 1920's saw the emergence of the great entrepreneurs of the auto industry, new technologies and new products. Today's boom is substantially different because of both its unprecedented size and scope and its global impact. A 1985 study by Arthur Young \& Company found that in the high technologies, the small firms are outperforming larger companies at a rate of 24 times as many innovations per R\&D dollar (Farrell, 1986: 42).

\section{CHARACTERISTICS OF THE SUCCESSFUL HIGH TECHNOLOGY START-UP FIRM}

The high technology venture has been characterized as "risky business". The high-tech entrepreneurs are seen as inventors bent on building a better mousetrap, as opposed to entrepreneurs or innovators (Drucker, 1985: 13). What then are the factors which distinguish the successful high 
technology entrepreneurship from the highly risky speculative venture?

The three primary factors which are vital for high technology ventures are those that have been crucial to large corporations over the decades: (1) management depth, (2) innovative products coupled with marketing expertise, and (3) adequate capital coupled with financial control (Chemical Week, 1984: 44; Drucker, 1985: 189). Much of what is presented in the current literature focuses on the forging of new businesses built around fast-paced innovation. However, would-be entrepreneurs oftentimes race so hard to beat the competition and are so infatuated with their own technology that they ignore the basic precepts of management, marketing and financial control (Business Week, 1984: 78 ).

The ensuing discussion will address the successful high technology start-up firm characteristics as they have been defined either anecdotally or empirically in the literature. These characteristics will be discussed within the framework of:

- Management Depth

- Marketing Expertise, and

- Financial Control.

Management Depth

Management is seen as the most important of the three factors. A bankroll and an innovative, high-tech idea are 
necessary but not sufficient for success (Chemical Week, 1984: 44). Given the product and the capital, the main obstacle to success has been the lack of a viable, organized operating presence in which people know where they are going, what they are supposed to do, and what the results should be. This operating presence manifests itself in a particular combination of characteristics inherent in the start-up firm. These characteristics will be discussed in terms of:
- Leadership Style / Culture,
- Team Approach,
- Informal Climate, and
- Organizational structure.

Leadership style / Culture. While all companies, in fact, need leaders, leadership is particularly important when the future is blurry and when change is occurring rapidly. Equally important are those strategies and management practices that can reinforce strong leadership (Maidique et al, 1984: 18).

The founder of the firm should exhibit strong leadership manifested in a "hands-on" leadership style. $\mathrm{He} /$ she serves as a role model for the organization, and instills a sense of integrity whereby honesty, fairness and openness are not sacrificed for short-term business objectives. The founder/leader is seen to be the creator of the culture (Maidique et al, 1984: 25). Stacey observes 
that an important feature of successful start-ups is the way in which the founder's dedication pervades the whole workforce; the employees in turn become totally enthusiastic about the business. The drive of all the employees of this type of company is to promote their organization and service its interests as best as they can (Stacey, 1986: 160).

Small size allows the entire organization to focus on opportunities. The culture of the start-up, with its shared sense of the need to survive, can create a cost consciousness and dedication which are difficult to achieve in the large organization where each employee knows that his/her contributions are but a small part of the whole (Schendel et al, 1979: 322).

The founder as an entrepreneur is a person who perceives opportunity, finds the pursuit of the opportunity desirable and believes that success is possible. The entrepreneur's belief in success is founded on the uniqueness of the idea, the strength of the product and a combination of other factors known mainly to the entrepreneur. These factors may include a special knowledge of the market or the ability to work hard and quickly. These same beliefs must be built into the organization if the entrepreneurial success of the founder is to be continued. The key to accomplishing this perpetuation is the building of an adaptive organization (Stevenson et al, 1986: 12). 
Team Approach. Most successful entrepreneurs have not only technical skills, but are competent in a variety of business functions or seek out complementary skills (Vesper, $1980: 37)$. The team approach is the means by which the high technology start-up firm builds the aggregate of necessary functional skills. Much of the current literature leads one to believe that the importance of having the management team in place at the outset has only surfaced since the electronics industry wavered in the mid-1980's. However, as early as 1982, when venture capital funds were in abundance, venture capital companies were looking for not only product but management as well. According to a member of the Rain Tree Group, a Massachusetts venture capital firm, "There is certainly enough money around for good deals, but the difficulty is finding the right package, or combination of management talent and product" (Johnson, 1982: 78).

The right people are well-rounded entrepreneurs who, as a team, have business skills which include marketing, finance, planning and operating expertise. In addition to these business skills, the team members should exhibit personal strengths such as integrity, enthusiasm, a will to win and persistance (Moser, 1984: 20). Whether the experience is gained in large or small companies is not as critical as variety (Bruno et al, 1985: 62). Additionally, the business skill package found to be the most desirable by the venture capitalist industry is one which is based upon 
previous experience in the particular field which the startup intends to enter (Vesper, 1980: 37).

Looking back a century, the importance of quality management to investors is demonstrated by the cases of Thomas Edison and Alexander Graham Bell. In 1881, Edison was seeking funds to build a manufacturing facility. While Edison was considered to be a great creative force, he was also considered to be an eccentric with unorthodox business methods. As a result, investors were unwilling to risk funds for capital acquisition in spite of the fact that they eagerly bought his patents (Josephson, 1959:247).

During the same time period, the Bell Telephone company was formed. Once again the inventor's business acumen was questioned. As a result, the two principle investors became partners with Bell and formed the firm. While both had high regard for Bell and faith in the future of his creations, their intent was to maximize return for dollars invested. These men, in addition to two others which they hired, handled the business while Bell remained the creative force (Bruce, 1973: 258).

According to Alfred D. Chandler, Straus professor of business history at the Harvard Business School, "the key entrepreneurial act has been creating an organization" (Inc., 1985: 53). Exploiting the technology is a necessary but insufficient condition for being a successful 
entrepreneur. You must create an organization - not a bureaucracy, but a team.

Levy observed that if the high technology start-up is to be successful in the face of intense international competition, it will need more than scientific creativity in its markets. It will need "cráck" management who are as comfortable with organization, finance, long-range planning and decision making as they are with technology (Levy, 1982: 47). Research by Roberts, Cooper and Bruno suggests that the successful new high technology firms are started by multiple founders (Schendel et al, 1979: 321); however, regardless of the number of founders, the successful high technology venture typically has a top management team in place before start-up. If the founders of the firm do not have all of the expertise required for this team and are seeking venture capital, the venture capitalist will require that the expertise be obtained and will provide the necessary recruiting services for the start-up (Chemical Week, 1984: 46).

It has been suggested by schilit that the expertise of the management team can be enhanced by choosing members for the Board of Directors who possess expertise that the management team may lack. Outside directors with backgrounds in finance, banking, marketing and international business can be particularly helpful in monitoring the environment and planning for growth (Schilit, 1986: 45). 
A directly opposing view is held by Marshall and Forbes of Royal Bank Venture Capital Limited, who propose that the single key success factor is management. They assert that poor management cannot be compensated for through the use of any external means. They claim that this approach will exacerbate rather than attenuate any management problems (Marshall et al, 1983: 107).

The members of the management team, while having diverse backgrounds, should embrace a common value system. This value system should be congruent with the previously stated value system of the founder/s. Charles Schwab, founder and CEO of the "high-tech" brokerage firm Charles Schwab \& Co., affirmed this notion when he stated in a recent interview, "When I bring new people on board, I try to get them to be in concert with my thinking,...." (Willis, 1986: 19).

The effective use of management teams is becoming very apparent in high technology companies. Companies such as Compaq Computer, AST Research and Quantum Corporation have avoided the "one-man show" syndrome by assembling top management teams that look beyond the narrow boundaries of specific functional areas to the global concerns of the company as a whole (Schlitit, 1986: 44). Referencing Peters and Waterman's In Search of Excellence, Henz asserts that by nature of the circumstances, the high technology venture which advances from a pioneering stage to a rapid growth 
stage in the business life cycle does, in fact, exhibit the hands-on, value-driven attribute. Establishing a corporate culture requires a hands-on attitude on the part of the entire management team, which is seen as a close knit group generally possessing a camaraderie and consensus on goals (Henz, 1986: 30).

The team should show a cohesion around its focus, with each member having a defined role and the experience and personality to fill it. Experience has shown that successful start-ups, having been correctly assembled at the outset usually by one highly committed individual who has intimate knowledge of the strengths, weaknesses and capabilities of each member, are those where the management team stays together (Stacey, 1986: 158).

From the venture capitalists' point of view, there are a variety of sound reasons supporting the team concept. They include, for example: (1) more balance regarding functional capability, (2) a larger manpower effort, (3) ability to grow larger without expending limited management talent seeking out additional key talent, (4) ability to absorb the loss of a given member without drastically affecting the performance of the firm, and (5) an indication of the ability to attract and manage people (Vesper, 1980: 41). Research has indicated that high technology ventures are more likely to have teams, and those ventures requiring 
more start-up capital are more likely to have teams in place at start-up (Cooper, 1970: 70).

Informal climate. Many founders of high

technology start-ups have scientific and engineering

backgrounds, and are not necessarily practical business

people. The informal atmosphere and management climate that encourage active participation throughout the entire organization have been directly attributed to these backgrounds (Howell, 1985: 21). Lipton has observed that relatively few have IVY League MBA's, and many have spent their entire lives avoiding wearing a tie (Lipton, 1982: 34).

Because high technology start-ups are on the cutting edge of new technologies, scientists and engineers, in general, are as important as key executives in the more traditional firms. A large percentage of the scientists and engineers come into high technology from the academic ranks, further contributing to the relaxed work environment. For example, at Tandem Computers Inc., CEO James Treybrig attributes their rapid success to the creation of an unstructured environment where people can enjoy working. A Friday afternoon "beer bust" is a custom. All employees from the president to assemblers drink beer and talk informally. The underlying motivation for the beer bust and the lack of time clocks, badges, and organizational charts 
is the promotion of both communication and equity across all levels of the company (Gomez-Mejia et al, 1985: 32). Creativity is considered the lifeblood of any high technology business. To foster creative solutions there should be no hierarchy to problem solving. Solutions may come from anyone, anywhere in the organization. A strong spirit of cohesion must exist where individuals are willing to share experienced and points of view, and to criticize and approve (Bleicher et al, 1983: 76).

Organizational structure. In the case of the start-up firm, organizational structure, systems and procedures are usually informal or nonexistent; therefore, implementation of strategy is normally accomplished through specific individual task assignments, and the leadership style of the entrepreneur (Schendel et al, 1979: 308).

To succeed, the energy and creativity of the entire organization must be drawn upon. Anything that restricts the flow of ideas, or undermines the trust, respect and sense of commonality of purpose is a potential danger. High technology start-ups, therefore, pay little attention to seniority, rank and functional specialization (Maidique, 1984: 21).

The chain of command in the high technology start-up is short and decision methods are informal and intuitive. According to William G. MCGowan, founder and CEO of the highly successful MCI Communications, the structure and 
style of the high technology organizational must allow for the speed and dexterity to change directions quickly (Levy, 1982: 48). While decisions may not be carefully documented, they are timely. Management generally has a first-hand feel for the realities of both customers and operations. Day-today contact is the basis for decision rather than the abstractions of reports. The ability to change directions quickly is manifested in the informal decision processes in which relatively few executives must be convinced and in the start-up venture's lack of commitment to the status quo (Schendel et al, 1979: 324).

The structure of the high technology start-up firm can be described as organic as opposed to mechanistic. Burns and stalker define these two types of organizations or systems in the following fashion:

A mechanistic system is appropriate to stable conditions. It is characterized by:

(1) the pursuit of technical improvement of means, rather than the accomplishment of the ends of the concern, (2) the precise definition of rights and obligations and technical methods attached to each functional role,

(3) hierarchic structure of control, authority and communication, (4) a reinforcement of the hierarchic structure by the location of knowledge actualities exclusively at the top of the hierarchy, where the final reconciliation of distinct tasks and assessment of relevance is made, (5) a tendency for interaction between members of the concern to be vertical, i.e. between superior and subordinate, and

(6) a tendency for operations and working behavior to be governed by the instructions and decisions issued by superiors. 
The organic organization is appropriate to a dynamic environment which constantly gives rise to new problems and unforseen events. It is characterized by:

(1) the contributive nature of special knowledge and experience to the common task of the concern, (2) the realistic nature of the individual task, which is seen as set by the total situation of the concern,...

(3) the spread of commitment to the concern beyond any technical definition,

(4) the shedding of responsibility as a limited

field of rights, obligations and methods......, (5) a network structure of control, authority and communication. The sanctions which apply to the individual's conduct in his/her working role derive more from presumed community of interest with the rest of the working organization in the survival and growth of the firm, and less from a contractual relationship between himself and a non-personal corporation.......

(6) ....knowledge about the technical or commercial nature of the here and now task may be located anywhere in the network;....... and

(7) a lateral rather than a vertical direction of communication through the organization...

(Burns et al, 1980: 127).

In the organic organization institutionalized shared common beliefs about values replace rigid rules. The culture of the institutionalized beliefs becomes the way of "how we do things"; thus the formal and informal organizations become indistinguishable from one another. Summary. This section has focused on the management characteristics of the successful high technology start-up firm. Those characteristics include: strong leadership, a hands-on leadership style, a value-driven corporate culture, a functionally well-rounded management team, an informal 
environment, participatory decision making, and open communication channels.

\section{Marketing Expertise}

The primary notion set forth in the literature is that the high technology start-up firm should have the following market orientations:

- Market Driven Innovative Products,

- Solutions - Not Wizardry,

- Narrow Focus, and

- First-Hand Customer Knowledge.

Market Driven Innovative Products. While many may debate over whether the high technology start-up should be driven strategically by product or by market, Farrell concludes that the theory underlying the debate is too sophisticated for the entrepreneur. He characterizes the entrepreneur as one with both a high customer focus and a high market focus. A customer without a product is not a customer, and a product without a customer is not a product. What counts, he says, is the entrepreneur's vision of the connection between the two. The entrepreneur must have a clear picture of a specific set of customers who need and will pay for a specific set of products and/or services (Farrel1, 1986: 48).

Drucker supports the customer/product balance when he states, "Unless the results of innovation can have a payoff and market in the present, don't innovate. You don't 
innovate for something you'll have only in the future. There must be receptivity and a current need" (Rutigliano, 1986: 41). The downfall of many new high technology startup firms can be traced to their managements' assumption that creating a useful new product will automatically bring into being a market for that product (Chemical Week, 1984: 45). Maintaining a strong marketing orientation is a prevalent theme throughout the current literature (Schlitit, 1986: 46; Maidique et al, 1984: 19; Yeskey, 1986: 20). The start-up venture should be founded on a perceived customer need and catering to that need should be uppermost in the founders' minds (Henz, 1986: 30). A successful product must have a clearly discernible unique selling quality. This quality of differentiation must manifest itself in the product price, quality, design, after sales support or even its image. It must be a quality for which the customer is willing to pay (Pearsen, 1986: 110).

The high technology start-up must constantly consider its market and have the flexibility to adapt to new opportunities as the market changes. To be successful, the management team must always be planning on a contingency basis for the effects of competition, new technology, changing work practices and a variety of other issues which require a continuous review of company objectives (Stacey, $1986: 159)$ 
Solutions - Not Wizardry. According to Aggarwal, technology-based products must serve basic customer needs to be successful. The successes of the past, including electricity, photocopying, computers and penicillin have satisfied customer needs at low costs and may have helped reduce human drudgery. The high technology failures of the last decade did not satisfy basic needs at low cost; rather, they tried to satisfy some artificial or marginal needs at a high expense (Aggarwal et al, 1984: 48).

Taking this one step further, high technology oftentimes serves basic customer needs in a rather indirect way by providing practical solutions to business productivity problems. The "better mousetrap" new technology is no longer sought after unless it provides a solution to the potential customer. New technology should be used to extend human capability rather than to create devices that will simply imitate human skills as in the case of the talking dashboard (Horton, 1985: 3). What customers do not want is more technology.

According to John Gingerich, executive VP of Measurex Corporation, the natural tendency of a high technology company is to step into a product-driven mode of operation. The trick is to make the transition from a product-driven to a solutions-driven orientation very early in the life of the company (Yeager, 1984: 64). 
Ken Ostrow, president and founder of Impact Systems Inc., claims that his firm did not start with a predetermined technology. This firm started by first targeting a solution and then choosing a technology that got the market interested. The technology was definitely secondary to the promised economic return (Yeager, 1984: $68)$.

The solutions-oriented approach also has advantages when considering the product life cycle. Most high technology products have life cycles of only two or three years. The reason for these short product life cycles is that the competition is robust. If a company wants to compete successfully, products must constantly be improved or replaced with new products (Gomez-Mejia et al, 1985: 32 ). The solutions approach tends to lengthen product life cycles. Users are reluctant to change to a new technology unless there is significant evidence that the new solution is superior to the existing one. In addition, solutionsoriented products tend to penetrate the mainstream of a customer's business, thereby increasing the risk of changing vendors or technology. The benefits to the producing company are twofold: (1) more time to enjoy the fruits of the product, and (2) more time to make new product decisions (Yeager, 1985: 69).

Narrow Focus. Research has indicated that narrow specialization or focus leads to greater growth (Vesper, 
1980: 174). It then follows, as many writers advise, that the start-up should choose a niche and generally avoid competing with the large corporation. Direct competition is possible only where the small firm has a definite competitive advantage or where the large firm is doing a poor job or is complacent (Schendel et al, 1979: 323; Moser, 1984: 19; Dewar, 1982: 76,77).

Henz suggests that the successful start-up is one which "sticks to the knitting". It is one which concentrates on a single product or service (Henz, 1986: 30). If a product does change, it will be the result of a clearer understanding of what the customer wants (Drucker, 1985: 189).

Niche marketing does put a premium on real "new generation" products that meet a defined need. Innovation is in demand because customers are disenchanted with mere product line extensions. An additional problem with line extensions is that competitors are able to match them too easily. This type of an environment demands breakthrough products that can be customized for market niches. They must be different in principle - not packaging (Yeskey, $1986: 24)$.

The best opportunities are "off the beaten path". The me-too marketers with the look-alike products think that the market is so large that a small piece of it is all that is needed for success. What they have found is the customer 
needing a better reason than product availability to make a purchase decision. Following the leader is not a good basis to compete. You have to be better than the leader and you have to be there first. According to Mitch Kapor, chairman and CEO of Lotus, companies need to invent new marketplaces because they will not survive by trying to take sales away from their competitors (Bellack, 1985: 79).

The personal investment policy of Bill Davidow, a successful venture capitalist whose start-up company investments include Tandem Computers Inc., Businessland Inc., and Valid Logic Systems Inc., reflects an opinion held by many in the venture capital arena: seek companies highly focused on making unique contributions to markets they can control. Having invested in a few failures, Davidow attributes these failures to the inability of the start-up's management to focus narrowly (Morris, 1986: 30 ).

In his recent book, Marketing High Technology, Davidow cites the conclusions of the Boston Consulting Group's work on business strategies. The conclusion of the Boston Consulting Group was that one of the most successful competitive strategies is to divide the market into a "sufficiently isolated segment which can be dominated". Davidow adds that the company need not be large to be profitable, but it must be large in its own protected market segment. The market segment must be isolated from 
competitors by barriers to entry or by complacency of the competition (Davidow, 1986: 15).

The research of Maidique and Hayes supports the notion that the most successful high technology firms are highly focused. These firms realize the great bulk of their sales either from a single product or from a closely related set of products (Maidique et al, 1984: 19). Vesper is also very supportive of the highly focused niche market orientation. He asserts that specialized technology and/or the discovery of a market vacuum will produce a better than average payoff (Vesper, 1980: 32). Part of this higher payoff is the result of reduced costs. According to Davidow, competing in a broad market requires a broad product line. A tighter focus decreases costs as a result of a narrow product line and reduced R\&D expenditures (Davidow, 1986: 21) .

First-Hand Customer Knowledge. "What is our business is not determined by the producer but by the customer. Management must make a conscious effort to get honest answers from the consumer himself rather than attempt to read his mind" (Drucker, 1985: 193).

According to Jerry Wasserman, VP of Arthur D. Little Inc., too many of the high technology start-ups are created on a bright idea by a bright engineer who develops a good product for a limited application. A problem arises because the engineer thinks that he knows his markets (Industry 
Week, 1985: 53). In all likelihood, market research was not done, and the entrepreneur probably does not understand the market or know what is needed to solve its problems (Bellack, 1985: 80).

A good example of the misinformed entrepreneur is Allen H. Michels, founder and president of Convergent Technologies. Convergent had a very successful first product offering, went public two years after founding, and was seemingly successful. The following year the firm lost $\$ 30$ million on their lap-top computer product line. No marketing research had been done, and when the firm attempted to introduce three more products, the market did not respond as had been expected. After the fact, Michels continued to maintain that good products will sell themselves (Business Week, 1984: 83).

Bleicher maintains that high technology firms do not rely as heavily on traditional techniques of marketing as do the more mature businesses. Most high technology firms pay little attention to market research. The president and CEO of one of the leaders in the word-processing industry has been quoted as saying that if he had paid attention to the marketing surveys, he would not have founded his business in the first place (Bleicher et al, 1983: 71).

Yeskey alleges that American industrials, in general, are not strategic marketing organizations. Coopers \& Lybrand's Management Consulting Services Division, with whom 
Yeskey is a director, has found that research sophistication is still in a formative stage among industrials which still rely on plant capacities and sales goals rather than studies of the marketplace. The challenge for industrials and start-ups alike appears to be the same - listen to the marketplace and plan products accordingly (Yeskey, 1986: 24).

In general, the current literature indicates that marketing research should be done by the high technology start-up; however, it is also suggested that market research involving a truly innovative product is difficult to perform (Bleicher et al, 1983: 71). The problem with the literature's suggestions is that arguments on both sides of the market research issue are based primarily on anecdotes rather than empirical evidence.

Summary. The successful high technology start-up firm will have both an innovative product and an intense market focus. The product must possess a factor of differentiation for which the customer is willing to pay. The successful start-up firm must identify a unique market niche and provide a product which offers a solution rather than merely a newer technology. First-hand customer knowledge is a prerequisite for this solutions-orientation.

\section{Financial Control}

While a preponderance of the literature addresses management depth and marketing expertise as those 
characteristics which venture capitalists deem to be the necessary prerequisites for venture capital infusions, a review of the current literature has yielded little regarding the practice of sound financial control in the successful high technology start-up. The existing literature does focus on the following:

- Sources of Capital,

- Undercapitalization, and

- Planning.

Sources of Capital. The bulk of the capital for start-up creation comes from the savings of the entrepreneur, his family or friends or from personal bank loans. These sources account for sixty to ninety percent of the initial financing for the new start-up firms in the United States. The remaining ten to forty percent of the financing needs comes primarily form SBIC's, various federal agencies, venture capital firms, and banks. Informal risk capital investors, known as "business angels" also provide start-up capital. These wealthy individuals generally provide funds in the $\$ 50,000$ range (Greene, 1985: 57; Shapero, 1982: 18).

Banks and venture capital firms, however, generally balk at providing funds unless they see that the entrepreneur's commitment includes investment of his own savings (Schilit, 1986: 45). Banks, for example, also want to see more than two years of operating history. They are 
interested in companies with products rather than concepts. Hence, they are almost impossible to deal with as a potential source for initial funding (Mark, 1983: 86; Juillard, 1986: 90).

The standards for obtaining venture capital are very high. It is estimated that of every 200 firms that solicit venture capital funding only three or four are successful in receiving it. of those firms that did not receive funds in 1983, sixty-nine percent were high technology oriented. Greene estimates that less than five hundred firms a year receive funding from venture capitalists. Historically onethird of these investments have been made in start-up firms (Greene, 1985: 57; Moser, 1984: 18). However, in 1985 only fourteen percent of the venture capital investments were considered to be "seed money" for start-up creation (Bryant, 1986: 38). The primary reason for the limited venture capital funding at the creation stage is the undefined nature of the product and its potential. Venture capital financing does, however, become significant as the product approaches commercialization (Marshall et al, 1983: 106). The other attributes possessed by those high technology firms which have received funding from venture capitalists include: a revenue potential of $\$ 50$ to $\$ 100$ million annually; the ability to generate about $\$ 20$ million in profits, with a seven percent after-tax margin within five years; and a rate of return on the investment that will 
be at least twenty percent greater than would be realized through other risk-free alternatives. In addition, the entrepreneur/s should demonstrate a willingness to take the start-up public in the future (Moser, 1984: 19). The lofty prerequisites of the venture capitalist explain the fact that only two percent of those seeking venture capital funds are successful in obtaining them.

Undercapitalization. Research has indicated that the larger the amount of start-up capital and the larger the founding team, the greater the likelihood of success (Roberts, 1970: 25). Undercapitalization, whether the result of inadequate start-up capital or inadequate cash flow projections, is the basis of failure for many start-up firms with outstanding products or services (Hartman, 1983: $43)$.

The undercapitalized start-up firm is in a state of continual crisis (Schilit, 1986: 45). This crisis mode dictates that the entrepreneur spend twenty to thirty percent of his time searching for funds needed to alleviate these short-term cash flow problems. While the entrepreneur's attention is diverted by the search for funds, the start-up firm as a whole can loose sight of its chief objectives (Andrews, 1986: 32). In order to avert failure due to undercapitalization, the current literature prescribes sound planning and financial control (Andrews, 1986: 34; Schilit, 1986: 45; Stacey 1986: 158). 
Planning. A principal distinction made by the strategic management paradigm is between the day-to-day management of operations and the management of strategy. The entrepreneur in the start-up venture clearly performs both of these functions. However, due to time pressures and limited resources, he is usually so heavily involved with operating management tasks that he spends little time with strategic management tasks.

The demands of day-to-day operations put pressure on management to set aside blocks of time for strategic planning. Unlike large organizations, the emphasis is not upon deciding how to allocate resources or upon planning as a communication mechanism. The principal focus is on mechanisms for problem identification and for assessment of current strategy. (Schendel et al, 1979: 323).

There has not been much explicit research on the process of establishing a competitively viable business. For the larger start-up venture, particularly those seeking venture capital funds, there is usually a new business plan describing the way in which the firm is to compete. For the larger group of new ventures, those start-ups without the discipline of seeking outside capital, the process of deciding upon a basis of competition seems to be informal and intuitive. It is oftentimes based on the entrepreneur's personal "feel" for the market (Schendel et al, 1979: 321). 
According to Vesper, the influence of planning on success has been uncertain. Typically the firm which is seeking external funding has been forced into developing detailed plans which include not only the detailed steps to be taken but also forecasts of future events. On the other hand, those firms not seeking outside funds generally go into action and plan as needed from step to step (Vesper, 1980: 51).

Good financial planning commences with the preparation of the business plan (Stacey, 1986: 159). According to Timmons, "an effective business plan will convince the investor that you have defined a high-growth opportunity, that you have the entrepreneurial and management talent to exploit the opportunity, and that you have a rational, coherent and believable program for doing so" (Timmons, 1980: 28)

Philip Thurston of the Harvard Business School suggests that planning does not come easily for many entrepreneurs (Thurston, 1983: 168). Yet, as other authors point out, a major cause of failure for the start-up firm is lack of planning (Mancuso, 1983: 2). Development of a plan and follow through on that plan are seen as the best means of enhancing the start-up's success.

Technical and scientific entrepreneurs tend to downgrade the business plan based on several invalid reasons. Those reasons include, for example, placing 
unwarranted faith in the technologically advanced product without considering marketability and marketing know-how, viewing the business plan as a negotiating and selling tool for raising money and not considering it relevant beyond that, and believing that the most important task for the start-up is to raise money as an indication of the viability of their idea. In their enthusiasm for seeking out potential investors, little time is spent preparing the business plan and the net result is a deficient plan and no capital; and the entrepreneurs do not consider possible fatal flaws in their plans and do not think to seek expert outside review toward the end of identifying those possible flaws (Timmons, 1980: 30$)$.

As was previously mentioned, the business plan is defined by many to be a document developed to demonstrate that the future prospects for a business are good enough to convince a venture capitalist to back the business with equity dollars. While this appears to be a commonly held notion, the business plan serves three main purposes for the start-up firm: (1) it is, in fact, a sales tool used to sell the start-up firm, its management and its product to venture capitalists, (2) from the venture capitalist's perspective, the business plan plays an important role in the assessment of risk and return associated with the new venture, and (3) most importantly, the business plan and its preparation imposes a discipline on the start-up's management to 
consider the entire undertaking in a structured manner and consider the financial implications of proposed actions. The emphasis is on completely understanding the business, as the business plan is a synthesis of what is likely and what is possible in marketing, manufacturing, engineering and finance. The building of the plan and the thought processes that precede the writing force the entrepreneur to take an objective and critical look at his/her firm (Seddon, 1984: 5; Larson, 1987: 64; Thurston, 1983: 174; Mancuso, 1983: 3). Assuming the undertaking is viable, the plan then serves as a dynamic working document for management (Moser, 1984: 20).

The primary planning error in high technology start-up companies is failing to precisely define the market which they are going to target. The problems inherent in this failure are two-fold: (1) if you cannot precisely define the customer, you cannot develop a product that meets his needs, and (2) if you cannot define the market, you cannot define the barriers to entry and subsequently cannot determine the cost of entry (Davidow, 1986: 138).

Regardless of the reason for business plan development, the current literature suggests the following as essential components of the plan:

(1) statement of corporate goals and objectives,

(2) description of the product including proprietary position, competitor's product comparison and regulatory agency requirements, 
(3) description of product R\&D which includes plans for new product design, engineering and technological improvements,

(4) management plan which delineates the management team members and their associated roles and responsibilities in addition to descriptions of expertise and experience offered by each member,

(5) description of technological competencies relative to the proposed product technology - it is desirable to demonstrate that members of the top management team have served in the same or similar functional capacities within firms producing or utilizing the same or similar technologies,

(6) market analysis which includes identification and analysis of customers and competition,

(7) market size and share descriptions which include, for example, trends, segment descriptions and estimated market share based on sales projections,

(8) marketing strategy description which includes detail on pricing, promotion, distribution, service and warranty policies,

(9) financial projections regarding both profit and cashflow, and

(10) manufacturing process description, if applicable, which includes materials requirements, the 
make/buy decisions, labor requirements, quality control issues, and production methods (Thurston, 1983: 188; Rich et al, 1985: 62; Schoch, 1985: 80-81; Timmons, 1980: 34; Mancuso, 1983: 30-37). From the venture capitalist's perspective, the first real screen of the business plan is the management team's resumes, which ideally reflect profit and loss experience and evidence of success. Detail of past experience is most desirable. Secondly, the market opportunity should be clearly identified with hard analysis and well-referenced data. The potential investor needs to believe that the start-up has targeted an attractive market and developed a plan to capture an unfair share of it. Financial projections tend to be lower on the scale of importance. Oftentimes they are discounted by fifty percent because there is no adequate explanation as to how the projections are going to be met (Schoch, 1985: 82).

Summary. While a variety of capital sources exist, the high technology entrepreneur faces considerable problems when trying to access these sources. These problems subsequently tend to increase the likelihood of undercapitalization. The solution prescribed by the literature is sound business planning, not only for the possible acquisition of venture capital, but as the first and ongoing exercise of sound management practice. 
CONCLUSION

The current literature on the characteristics of the successful high technology start-up firm indicates that the management practices are not necessarily traditional, the marketing orientation is very focused, and the financial control mechanisms emulate those of the typical successful firm.

The key factors associated with the successful high technology start-up firm include:

1. An organizational climate and culture that recognize and support creativity,

2. Management practices that promote open communication channels and participatory decision making,

3. Policies that motivate the achievement oriented engineer/scientist to focus on corporate goals,

4. A top management team that collectively has functional experience in management, marketing and finance in addition to technological competence,

5. Strategies that are market-driven rather than technology-driven, and

6. Sound financial planning and control practices focusing on both the long and short terms, and including a written plan (Vesper, 1980: 37; Johnson, 1982: 78; Bleicher et al 1983: 76; Maidique et al, 1984: 19; Stacey, 1986: 159). 
The current business literature oftentimes implies, in the perception of this researcher, that the venture capital funded firm possesses certain qualities to which success is attributed. It appears to be further implied that some firms do not receive venture capital funding due to the relative lack of these qualities. Given that the venture capitalist is interested in investing in successful or potentially successful firms, the funded firm is used as a proxy for success.

STATEMENTS OF THE HYPOTHESES

Based upon the preceding review of the literature, the following seven hypotheses regarding management depth, marketing skill, and financial control are proposed. (It should be noted that the terms organic, quality, market driven, solution, and market niche, as used in the following hypotheses, are concepts which are operationally defined in Chapter III.)

\section{Management Depth}

H1: The high technology start-up firm which has acquired venture capital funding maintains an organizational climate which is more organic than does the high technology start-up firm which has not acquired venture capital funding.

H2: The top management team of the high technology start-up firm which has acquired venture capital 
funding has a higher quality top management team than does the high technology start-up firm which has not acquired venture capital funding.

\section{Marketing Skill}

H3: The strategy of the high technology start-up firm which has acquired venture capital funding will tend to be more market driven than will the high technology start-up firm which has not acquired venture capital funding.

H4: The high technology start-up firm which has acquired venture capital funding is more likely to create products which provide solutions to new problems or superior solutions to existing problems rather than products which are either "better mousetraps" or look-alike technology than is the high technology start-up firm which has not acquired venture capital funding.

H5: The high technology start-up firm which has acquired venture capital funding focuses more narrowly on a market niche which it can control than does the high technology start-up firm which has not acquired venture capital funding. 
Financial Control

H6: The high technology start-up firm which has acquired venture capital funding is more likely to plan on going public than the high technology start-up firm which has not acquired venture capital funding.

H7: The high technology start-up firm which has acquired venture capital funding is more likely to have prepared a formal business plan than those high technology start-up firms which have not acquired venture capital funding. 
CHAPTER III

RESEARCH DESIGN AND METHODOLOGY

The purpose of this chapter is to discuss the research design, variable measurement scales, operationalization of variables, statistical techniques, and hypothesis testing procedures.

\section{RESEARCH DESIGN}

\section{Population Definition}

The population selected for the purposes of carrying out this research study is defined as: the founders of U.S. based, privately held high technology start-up firms established during the five-year period of 1983-1987. The sampling frame used in this endeavor is the Corporate Technology Directory (CTD) published by Corporate Technology Information Services, Inc. (Corp Tech) in Wellesley Hills, Massachusetts. This sampling frame represents a population of approximately 3,400 high technology start-up firms.

The Corporate Technology Directory is produced from information maintained in a computerized data base. While the directory itself is published yearly, the data base is continually updated by corp Tech. By virtue of the fact 
that the data base represents the most current information, the sampling frame was selected directly from the computerized data base in March, 1988.

The sampling frame was provided in zip code order and contained: CEO/President name, firm name, and firm address. The sector ID's used by Corp Tech differentiate among several segments of the high technology arena. Those segments include: hardware, software, fiber optics, lasers, AI, robotics, biotechnology, advanced materials, aerospace, chemicals, factory automation, subassemblies/components, test and measurement, telecommunications, high technology services, energy and medical.

The directory does not explicitly state the name/s of the founder/s of the individual firms. Accordingly, the name of the CEO/President was used as the sampling unit. This procedure is justified based upon a previous study (Goslin \& Kiehl, 1988) of seventy-six high technology startup firms located in the Pacific Northwest in which 97.4 percent of the respondent CEO/Presidents were, in fact, also founders of their respective firms. In those cases where the CEO/President was not one of the original founders, he/she was asked to either respond to the best of his/her ability or forward the measurement instrument to one of the founders. 
Data Collection Method

Due to the fact that secondary data sources relevant to this research topic do not appear to exist, primary data collection was undertaken. Data was collected through the use of a mail survey. A mail survey was selected for data collection because a nationwide sample was desired, and it was felt that the cost per response would be the most reasonable for this type of interrogation method vis a vis telephone or personal interviewing. The survey instrument is included in Appendix A. This instrument is intended to measure both demographic characteristics and attributes of firm behavior in an effort to assess the differences between venture capital funded and unfunded high technology start-up firms regarding the characteristics of management, marketing and finance which have been identified in the hypotheses.

\section{Sampling Method}

A probability sample of 1350 founders of high technology start-up firms was drawn from the previously defined sampling frame through the use of a systematic random sampling design. Given the expectation of a response rate of approximately twenty percent, the large sample size insured the attainment of an adequate final sample size necessary to properly test the hypotheses. It should be noted that the status of the firms regarding venture capital funding was not known prior to the mailing. It was felt that a twenty percent response rate would result in a 
sufficient number of firms in each group (venture capital funded and unfunded). The responses associated with the previously mentioned Goslin and Kiehl study resulted in sixty-four percent of the study firms being funded with the remainder being unfunded (Goslin and Kiehl, 1988).

\section{Sample Size}

For the purposes of this research study, the key variable concerns the presence or absence of venture capital financing. Based on this dichotomy, all hypotheses are tested to demonstrate that a greater proportion of the venture capital funded high technology start-up firms possessed a particular hypothesized attribute to a greater degree than the unfunded firms. As a result, the proportional formula for determining sample size was used to determine the maximum sampling error. The exact formula used was $\left[\left(z^{2}\right) * P(1-P)\right] /\left(E^{2}\right)$, where the $z$-value represents the level of confidence, $P(1-P)$ represents the variance and $E$ represents the maximum allowable sampling error (Tull et al, 1984: 415).

When measuring proportional attributes of a population, the population variance is $P(1-P)$. Given that the population variance is unknown, as it is was at the commencement of this research study, it is suggested as being prudent to use a P-value of .5 (Emory, 1980: 164). This will result in the use of a variance of .25 , which is the maximum value that the variance formula will allow; 
therefore, it is deemed to be the most conservative subjective estimate.

A decision was made to use a confidence level of ninety percent. The ninety percent confidence level implies that the probability is ten percent or less that the maximum allowable sampling error, as defined in the ensuing discussion will be exceeded.

Based on a sample size of 226 and the use of the proportional formula for determining sample size, the maximum allowable sampling error is 5.5 percent, which is an acceptable midrange sampling error for descriptive studies.

In order to achieve the desired response rate, two mailings were done. The first mailing was sent to the 1350 high technology start-up firms which were included in the sampling frame provided by Corp Tech. Each potential respondent was sent a packet which included a cover letter explaining the nature of the study and requesting his/her participation, a copy of the survey instrument, and a "Results Request" form to be completed given that the respondent desired a summary of the research results. As a result of the first mailing, 261 questionnaires were returned by the US Postal Service as being nondeliverable. The primary reasons given for the returned mail were "no forwarding address" and "addressee unknown". One can only assume that the firms involved in these returns have become defunct. 
Given the nondeliverable rate of nineteen percent, the resulting response rate for the first mailing was approximately sixteen percent, resulting in 177 completed questionnaires. Because the desired response rate was not achieved, a second mailing was undertaken exactly one month after the initial mailing. Each packet contained a followup letter, a fresh copy of the questionnaire and an additional "Results Request" form. The second mailing went to the remaining 911 potential respondents.

A response rate of five percent was achieved for the second mailing. This resulted in an aggregate response rate for the two mailings of twenty-one percent. Consequently no additional mailings were done, as the desired response rate had been attained. The final sample size was then 226 with sixty-three percent of the firms being funded and the remainder being unfunded.

\section{MEASUREMENT SCALES}

\section{Independent Variable}

The independent variable is the basis for comparison of attributes of the high technology start-up firms. As previously discussed, the independent variable in this research study is venture capital funding. Venture capital funding is measured by a ratio scale, which indicates the actual number of rounds of venture capital which the firm has received. The hypotheses specify comparisons between 
funded and unfunded high technology start-up firms. As such, it is necessary to measure venture capital funding through the use of a dichotomous measure by defining an unfunded firm as one having $(0)$ rounds of funding and a funded firm as one having (1-4) rounds of funding.

Two additional ratio scale measurements are utilized for those firms which have received at least one round of venture capital financing. The first measurement indicates the dollars received per round and the second measurement indicates the related equity cost for each round of venture capital financing to a maximum of four rounds. These latter two measurements are used to calculate a ratio, equity cost / dollars received, indicating the percent of equity given up for each dollar of venture capital financing received. While the "equity cost / dollars received" ratio can provide additional information about the funded firms, not all firms are willing to disclose this information. Measurement of the number of rounds of venture capital funding is, therefore, the major means of acquiring the appropriate data for the purposes of hypotheses testing.

\section{Dependent Variables}

The dependent variables necessary to test the hypotheses are defined by the current business literature as:

1. organizational climate,

2. quality of the top management team, 
3. strategy,

4. solutions orientation,

5. market niche strategy,

6. plan to go public, and

7. business plan.

The selection of the dependent variables and the subsequent selection of the means of operationalizing the dependent variables are based on this researcher's perception of importance as indicated by the prevalence of these notions in the current business literature. In those cases where a dependent variable or concept is defined by multiple operational measures no attempt is made to give each component measure other than an equal weighting. (See HYPOTHESIS TESTING section.) The rational for this approach is based on the fact that any weighting scheme is purely subjective at this point - that is, no theoretical or empirical basis for weighting exists. Equal weighting is, therefore, deemed to be the most reasonable approach.

Organizational climate is measured by Likert scales which indicate the degrees to which the firm possesses the following attributes:

- vertical and horizontal communication flow,

- firm policies (e.g. ethics, profit sharing, integrity) which are very consistent with corporate goals,

- informal participatory decision making, 
- tolerance of failure, and

- a value system whereby integrity is more important than profit.

Quality of the top management team is measured by the respondent's assessment of the prior functional experience of each member of the top management team. The variables used to measure quality include: prior, primary functional experience, size of the organization where the experience was gained, years of experience, and level of organizational responsibility.

The selection categories for the primary functional experience include management, marketing/sales, finance/accounting, engineering/science, manufacturing/operations (if applicable), R\&D (if applicable), and an "Other" category to capture all other possible functional experiences. A nominal scale is used to measure these categories.

A ratio scale is used to measure the size of the organization worked for in terms of incremental steps of $\$ 1$ million dollars of annual sales revenues. Years of experience is measured via a ratio scale, and level of organizational responsibility is defined by a seven-point interval scale reflecting a range of responsibility levels. As a guideline, the following is suggested to the respondents (see Appendix A): CEO = "1", vice president of a 
functional area $=" 3 "$, departmental manager $=" 5 "$, and group supervisor $=" 7 "$.

Two additional nominal scale measurements are used to specify whether or not each individual team member: (1) has served in the same or similar functional capacity as that in which he/she now serves, and (2) has had his/her primary past experience in a firm which utilized or produced the same or a similar technology.

Strategy is measured by Likert scales which indicate the degrees to which the respondent possesses the following opinions about the firm:

- our product is so good that it will sell itself,

- we are knowledgeable about competitor activities,

- our employees are very customer focused, and

- we believe that market demand is primary to technological sophistication.

Likert scales are used to measure perceptions regarding strategy as well as the majority of the following dependent variables because it is relatively easy for the subjects to respond. They are merely asked to express relative aggreement or disagreement with respect to a given statement. It should be noted that a single subject's Iikert scale score is meaningless if it stands alone. However, in studies such as the present one, the scores gain meaning by virtue of the use of comparison groups. 
While the Iikert scale is both easy to construct and easy to use, it has been found that the results obtained are comparable to those obtained, for example, by an anchored semantic differential scale (Tull et al, 1976: 359; Schoner et al, 1975: 271).

Solutions orientation is also measured by Likert scales which indicate the degrees to which the respondent has the following beliefs about the firm:

- customer feedback is essential to product development,

- our employees are very customer focused,

- we are intimately knowledgeable about our customers' business, and

- we maintain sharp vertical market segmentation. Market niche strategy is measured by Likert scales which indicate the following respondent perceptions about the firm:

o our intent is to avoid direct competition with larger companies,

- our firm strives to be low cost producer,

- uniqueness of our product deters entry by others,

- our product appeals to a broad market, and

- we have identified customer needs or characteristics that differ from the larger market as a whole. 
Plan to go public is commonly known as the intent to make a public stock offering. It is measured by the use of a Iikert scale which indicates the probability of the firm going public within the next two years. A two year time frame is used in an effort to elicit a more concrete response. An additional ratio scale measurement is used to determine the time frame, relative to the year of founding, within which the firm may go public. A maximum time period of five years is used.

Formal business plan represents the firm's strategic plan, and is also used as a selling document in the search for funding. The development of a formal business plan is measured in several ways. A ratio scale is used to determine the number of pages there are in the respondent's business plan. Additionally, a nominal scale is used to determine the primary purpose of developing the business plan. The nominal scale categories include: operating necessity, venture capital requirement, market strategy and definition, and "other___.

To increase the amount of information regarding business plan preparation, a ten-point rating scale is used to measure the respondent's perceptions of the three most important business plan components specified in the following list:

- product definition.

- management team, 
- product R\&D,

- market analysis,

- marketing strategy,

- profit and cashflow projections,

- manufacturing (if applicable),

- market size / share, and

- technological competency.

In addition, two nominal scale measures are used to ascertain the respondent's perceptions regarding both the most important component and least important component relative to those specified above.

\section{OPERATIONALIZATION OF VARIABLES}

\section{Hypothesis 1}

The high technology start-up firm which has acquired venture capital funding maintains an organizational climate which is more organic than does the high technology start-up firm which has not acquired venture capital funding.

Five statements are posed to respondents in order to ascertain their perceptions of the organizational climate of their respective firms. The respondents are asked to indicate the extent to which they agree or disagree with the statements using the following Iikert scale:

1. Strongly disagree

2. Somewhat disagree

3. Neither

4. Somewhat agree 
5. Strongly agree

The five statements, as they are posed in the survey instrument, defining organizational climate include:

H1.1. Open communication flow, both horizontal and vertical, is never encouraged.

H1.2. Our decision making style is very participatory.

H1.3. Our culture does not include a tolerance of failure as a part of learning.

H1.4. Our policies (e.g. ethics, profit sharing, integrity) are very consistent with corporate goals.

H1.5. Profit is much more importart than integrity. Based on the preceding questions, the organic organizational climate is strongly characterized by responses of $1,5,1,5$, and 5 respectively. On the other hand, the mechanistic organizational climate is strongly characterized by responses of $5,1,5,1$, and 1 to the same five statements.

In order to test hypothesis 1, the responses to the aforementioned statements are coded to insure consistency between extremes on the Iikert scale, as defined above, and definitions of organic and mechanistic organizational climates. The actual coding scheme is as follows:

1. The organic organizational climate is represented by a "5" on the Likert scale. 
2. The mechanistic organizational climate is represented by a "1" on the Likert scale.

3. Statements $\mathrm{H} 1.1$ and $\mathrm{H} 1.3$, as stated above, are reverse coded, i.e. "1" becomes "5", "2" becomes "4" and so on.

4. Questions H1.2, H1.4, and H1.5 are coded exactly as they have been answered.

Table I summarizes the variables necessary to test hypothesis 1 .

\section{TABLE I}

\section{HYPOTHESIS 1 - VARIABLE DEFINITIONS}

Variable Description

v1.1 Open communication flow

v1.2 Participatory decision making

v1.3 Tolerance of failure

v1.4 Policies consistent with corporate goals

v1.5 Integrity more important than profit

Hypothesis 2

The top management team of the high technology startup firm which has acquired venture capital funding has a higher quality top management team than does the high technology start-up firm which has not acquired venture capital funding.

A matrix, as is illustrated in Appendix A, is used to acquire the bulk of the necessary data regarding the prior, primary functional experience of the top management team. For each team member, designated as CEO, B, C and D, the respondent is asked to provide the number of years experience, the level of organizational responsibility and 
the annual sales volume of the firm in which the experience was gained. These three items of data are to be within one of the seven aforementioned functional areas for each team member specified. Appendix A contains an example of this response scheme on page 150 .

For the purposes of data analysis, four variables are assigned to each team member, based upon the specified functional area and three items of data within that area. These variables are summarized in Table II.

Two additional ratio scale variables are generated from the data provided in the matrix. They are: number of top management team members and number of functional areas represented by the team's prior experience.

Two supplementary questions are also posed in order to determine whether or not the prior experience of each team member, as defined by the matrix: (1) is directly related to the functional capacity in which he/she now serves, and (2) was gained in a firm which utilized or produced a like technology. The two questions posed to garner this information are:

H2.1. Please specify those members of your top management team who now serve in the same or a similar functional capacity as that specified above. 'sase circle the appropriate team members. )
CEO
$\mathbf{B}$
C
D 
H2.2. Please specify those members of your top

management team whose previous experience (as

defined in the matrix above) was in a firm

utilizing or producing the technology that

supports your product. (please circle the

appropriate team members.)

$\begin{array}{llll}\text { CEO } & B & C & D\end{array}$

The resulting variables are also summarized in Table II.

Each of these variables is coded utilizing a ' $O$ ' if the team member is not circled, and $a$ ' 1 ' if the team member is circled.

TABLE II

\section{HYPOTHESIS 2 - VARIABLE DEFINITIONS}

Variable
v2.1A
v2.2A
v2.3A
v2.4A
v2.5A
v2.6A
v2.1B - v2.6B
v2.1C - v2.6C
v2.1D - v2.6D
v2.7
v2.8

Description

CEO Function

CEO Years

CEO Level of Responsibility

CEO Annual Sales Volume

CEO Same Functional Capacity

CEO Same or Similar Technology

Team Member B

Team Member $\mathrm{C}$

Team Member D

Number of team members

Number of functional areas

represented by prior experience

Hypothesis 3

The strategy of the high technology start-up firm which has acquired venture capital funding will tend to be more market driven than will the high technology start-up firm which has not acquired venture capital funding. 
Four statements are posed to the respondents in order to ascertain their perceptions regarding the strategy of their respective firms. Once again, the respondents are asked to indicate the extent of agreement or disagreement based on a Iikert scale. The response categories are defined as they have been with in conjunction with hypothesis 1, with a response of "1" indicating strong disagreement and "5" indicating strong agreement.

The four statements used on the survey instrument to define strategy are:

H3.1. Our product is so good that it will sell itself.

H3.2. Our firm is extremely knowledgeable about competitor activities.

H3.3. Our employees are very customer focused.

H3.4. We do not believe that market demand is primary to technological sophistication.

As worded on the survey instrument, a market driven strategy is characterized by responses of $1,5,5$, and 1 on statements $\mathrm{H} 3.1$ through $\mathrm{H} 3.4$ respectively.

Once again, the responses are coded for consistency such that a market driven strategy corresponds to the Likert scale extreme of "5". The net result is that questions H3.1 and H3.4 are reverse coded for the purposes of data analysis. 
Table III summarizes the variables necessary to test hypothesis 3 .

\author{
TABLE III \\ HYPOTHESIS 3 - VARIABLE DEFINITIONS \\ Variable Description \\ v3.1 Product does not sell itself \\ v3.2 Knowledgeable about competitor activities \\ v3.3 Employees are customer focused \\ v3.4 Market demand is primary to technological \\ sophistication
}

Hypothesis 4

The high technology start-up firm which has acquired venture capital funding is more likely to create products which provide solutions to new problems or superior solutions to existing problems rather than products which are either "better mousetraps" or lookalike technology than is the high technology start-up firm which has not acquired venture capital funding.

Four statement are posed in order to test respondent perceptions regarding the presence or absence of a solutions orientation. Once again, Likert scales are used with "1" indicating strong disagreement and "5" indicating strong agreement. The statements as they appear on the survey instrument include:

H4.1. Customer feedback is not essential to our product development.

H4.2. Our employees are very customer focused.

H4.3. Our firm is intimately knowledgeable about our customers' business. 
H4.4. Our firm's focus is on sharp unique market segmentation.

It should be noted that questions $\mathrm{H} 4.2$ and $\mathrm{H} 3.3$ are one in the same, as a customer focus is a necessary component of both a market driven strategy and a solutions orientation. As worded on the survey instrument, a solutions orientation is strongly characterized by responses of 1,5 , 5, and 5 on statements H4.1 through H4.4 respectively. The "better mousetrap" or technological sophistication orientation is characterized by a reversal of the responses, i.e. $5,1,1$, and 1 , to these statements. Here again, the responses are reverse coded where necessary for consistency. In this case, a solutions orientation is represented by a "5" on the Iikert scale, and the technological sophistication orientation is represented by a "1". Table IV summarizes the variables necessary to test hypothesis 4 .

TABLE IV

\section{HYPOTHESIS 4 - VARIABLE DEFINITIONS}

Variable Description

v4.1 Customer feedback essential to product development

v4.2 $=v 3.3=$ Employees customer focused

v4.3 Intimately knowledgeable about customers'

v4.4 Focus on sharp unique market segmentation 
Hypothesis 5

The high technology start-up firm which has acquired venture capital funding focuses more narrowly on a market niche which it car control than does the high technology start-up firm which has not acquired venture capital funding.

Six statements are posed to the respondents in order to determine the respondents' perceptions of the market focus of their respective firms. Once again, the same Likert scale, with "1" representing strongly disagree and "5" representing strongly agree, as delineated previousiy is used. The six statements as they appear on the survey instrument are:

H5.1. We compete directly with very large companies. H5.2. We strive to be low cost producer.

H5.3. Uniqueness of our product deters entry by others.

H5.4. Our product appeals to a broad commodity market.

H5.5. Our firm's focus is on sharp unique market segmentation.

H5.6. Our market has needs or characteristics that differ from the larger market as a whole.

A narrow focus on a market niche is strongly represented by responses of $1,1,5,1,5$, and 5 on statements $\mathrm{H} 5.1$ through $\mathrm{H5} .6$ respectively. Reverse coding of statements $\mathrm{H} 5.1, \mathrm{H} 5.2$ and $\mathrm{H} 5.4$ results in a Likert scale value of "5" defining a narrow focus on a market niche. 
Table $V$ summarizes the variables necessary to test hypothesis 5 .

\section{TABLE V}

\section{HYPOTHESIS 5 - VARIABLE DEFINITIONS}

\begin{tabular}{cl} 
Variable & \multicolumn{1}{c}{ Description } \\
v5.1 & $\begin{array}{l}\text { Do not compete directly with very large } \\
\text { companies }\end{array}$ \\
v5.2 & $\begin{array}{l}\text { Do not strive to be low cost producer } \\
\text { v5.3 }\end{array}$ \\
Uniqueness of product deters entry \\
v5.4 & $\begin{array}{l}\text { Product does not appeal to a broad } \\
\text { commodity market }\end{array}$ \\
v v4.4 $=$ Focus on sharp unique market \\
segmentation \\
Our market differs from the larger \\
market as a whole
\end{tabular}

Hypothesis 6

The high technology start-up firm which has acquired venture capital funding is more likely to plan on going public than the high technology start-up firm which has not acquired venture capital funding.

Plan on going public is measured in two fashions. The first method is by means of a Likert scale, and the second is through the use of a ratio scale. The questions posed for the purpose of testing hypothesis 6 are:

H6.1. What is the probability of your firm going public in the next two years?

1. Definitely will not

2. Probably will not

3. Not sure

4. Probably will

5. Definitely will 
H6.2. We expect to go public within years of founding .

$$
\begin{array}{llllll}
1 & 2 & 3 & 4 & 5 & \mathrm{~N} / \mathrm{A}
\end{array}
$$

The assumption that is made regarding the wording of both questions is that the fewer the number of years specified, the more likely it is that the event of going public will actually occur. The variables necessary to test hypothesis 6 are summarized below.

TABLE VI

$$
\text { HYPOTHESIS } 6 \text { - VARIABLE DEFINITIONS }
$$

Variable Description

v6.1 Probability of going public in two years or v6.2 Years elapsed between founding and going public

\section{Hypothesis 7}

The high technology start-up firm which has acquired venture capital funding is more likely to have prepared a formal business plan than those high technology start-up firms which have not acquired venture capital funding.

Five questions are posed to examine business planning in the high technology start-up firm. The first of the five questions is the only one necessary to test hypothesis 7. That question, as it appears on the survey instrument, is: H7.1. How many $81 / 2 \times 11$ pages are there in your business plan? 
The basic information needed is whether or not the respondent firm has prepared a business plan, which requires either a "yes" or "no" response. Since the question as posed on the survey instrument collects ratio scale data, for the purposes of testing the hypothesis a "0" response corresponds to a "no" and any response greater than "0" corresponds to a "yes".

Further comparisons of the firms are made on the following interval cuts of the data:

1. 10 or fewer pages,

2. 11 - 25 pages,

3. 26 - 50 pages, and

4. 51 or more pages.

Questions $H 7.2$ through $H 7.4$ collect additional exploratory data regarding business plan preparation. The current business literature is unclear as to which components are the most important. There appear to be two opposing viewpoints: on one hand, it is said that every component is of equal importance. On the other hand, it is said that the management and marketing components are the most important, from the venture capitalist's point of view. The intent here is to determine, from the respondent's point of view, both the most important and least important components. Additionally, the findings are compared to determine differences, if any, between venture capital 
funded and unfunded high technology start-up firms. The three questions posed to collect this data are:

H7.2. Which component of your business plan do you consider to be the most important?

1. Product definition

2. Market analysis ( customers and competition)

3. Marketing strategy (pricing, promotion, distribution, etc.)

4. Product R\&D

5. Manufacturing (if applicable)

6. Profit and cashflow projections

7. Management team

8. Market size / share

9. Technological competency

H7.3. Which component of your business plan do you consider to be the least important ?

1. Product definition

2. Market analysis ( customers and competition)

3. Marketing strategy (pricing, promotion, distribution, etc.)

4. Product R\&D

5. Manufacturing (if applicable)

6. Profit and cashflow projections

7. Management team 
8. Market size / share

9. Technological competency

H7.4. Please divide 10 points among three of the business plan components listed below so that the division will reflect the three most important to you.

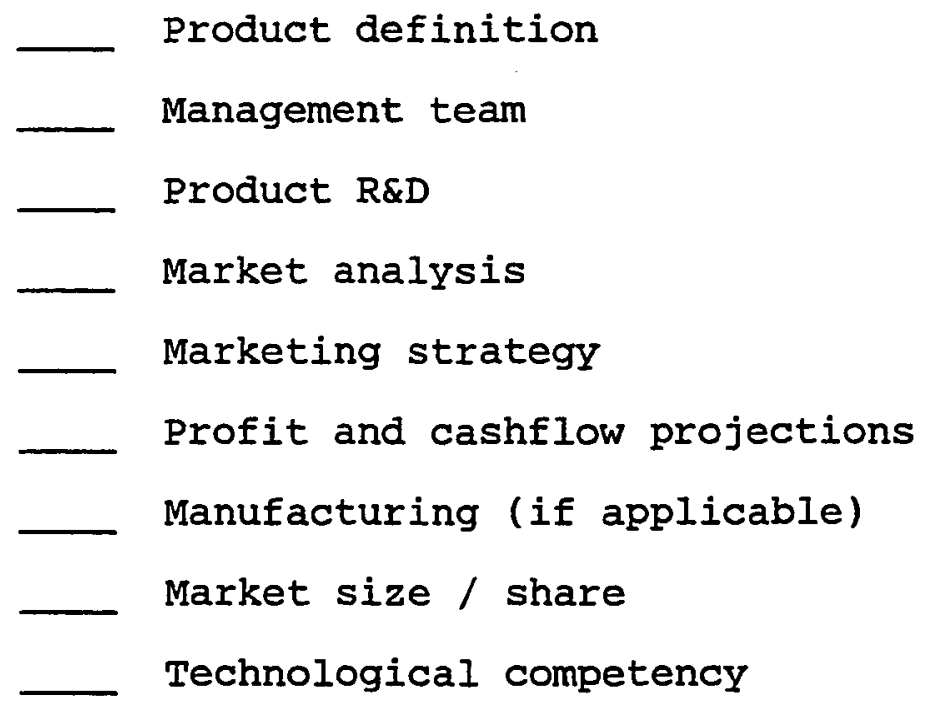

Nominal scale data, indicating both the most and least important business plan components are elicited by questions H7.2 and H7.3. Question H7.4 collects interval scale data which reflects not only a rank ordering of the three most important components, from the respondent's point of view, but also weights those choices such that, for example, one particular component can be said to be two or three times as important as another.

An attempt is being made to ascertain those components of the business plan on which the most resources are expended during preparation and correspondingly which 
components comprise the bulk of the final plan. An assumption is made here that resources and final business plan emphasis is based on the respondent's perceptions of the importance of the various components.

The fifth question regarding business planning is posed in order to determine the purpose for which the business plan, if any, was prepared. Nominal scale data is collected by means of the following question:

H7.5. For what primary purpose did you develop your business plan?

1. Operating necessity

2. Venture capital requirement

3. Market strategy and definition

4. Other

(please specify)

TABLE VII

HYPOTHESES 7 - VARIABLE DEFINITIONS

Variable Description

v7.1 Number of pages in business plan

v7.2 Most important business plan component

v7.3 Least important business plan component

v7.4.1 Product definition weighting

v7.4.2 Management team weighting

v7.4.3 Product R\&D weighting

v7.4.4 Market analysis weighting

v7.4.5 Marketing strategy weighting

v7.4.6 Profit and cashflow projections weighting

v7.4.7 Manufacturing weighting

v7.4.8 Market size / share weighting

v7.4.9 Technological competency weighting

v7.5 Purpose of business plan development 
The variables necessary to test hypothesis 7 and its related questions are detailed in Table VII.

\section{STATISTICAL TECHNIQUES}

The statistical techniques used in this research study include ANOVA, Chi-square and Pearson Correlation. Each technique is discussed in a general fashion, followed by a detailed discussion of application to the individual statements of the hypotheses.

For those hypothesis tests involving Likert scale variables, testing takes place on two levels. First, the individual Likert scales used to measure an attribute are examined to determine differences at a component level. Secondly, a sum of scores for each attribute is developed and tested to determine the attribute at the holistic level.

Once again, close examination of the individual Likert scales indicates, at first blush, that not all scoring is in one direction. This is contrary to the logic underlying the use of a sum of scores, but necessary for the continuity of the survey presentation. All scoring is standardized as to the direction before analysis is undertaken.

In order to make inferences about the differences between population means, the null hypothesis of no difference between means is assumed. The ANOVA statistical technique is used to determine the probability that the means of the interval and ratio scale variables for venture 
capital funded firms and unfunded firms deviate from one another due to the effects of the presence or absence of venture capital infusions rather than sampling variation. In other words, can the observed differences be reasonably attributed to chance or is there reason to suspect true differences between the two groups ? (Tull et al, 1984: 471)

When utilizing univariate ANOVA, the variability in the sample is divided into two parts - variability of observations within a group and variability between the two groups. If the variability within groups is minimal and the group means vary a great deal, than the means are probably not equal.

The observed F-value is developed based on the ratio of the variability between groups / the variability within groups. Additionally, a critical F-value is determined based on the degrees of freedom and the chosen level of significance. The degrees of freedom depend upon both the number of groups and the number of cases in the sample. If the observed F-value is greater than the critical F-value at the chosen level of significance, it would indicate that there is a difference between the groups and the null hypothesis should be rejected.

In addition, Pearson correlation coefficients are calculated for all pair combinations of independent variables utilized to measure each particular attribute in 
question. The intent here is to determine the extent to which autocorrelation is present.

For those hypothesis tests utilizing nominal scale variables, the Chi-square statistic is employed. Chi-square is used in this case to determine if venture capital funded and unfunded high technology start-up firms differ in the way that they are distributed into the discrete nominal categories used in each particular hypothesis test. Chisquare is a test of independence, and is used in conjunction with crosstabulation or contingency tables. Two variables are independent if the probability that a case falls into a particular cell is the product of the marginal probabilities of the categories defining that particular cell.

To construct a Chi-square test of independence the following general procedure is used:

1. For each cell of the contingency table, the probability of a case falling into a cell ${ }_{i j}$ of the table is estimated by $P_{i j}($ row $=i$ and column $=j$ ) $=($ count in row $i / N) *($ count in column $j / N)$.

2. The null hypothesis is a test of independence between venture capital funding and the particular variable associated with the hypothesis being tested.

3. Determine the expected number of cases in each cell $l_{i j}$ using the formula $E_{i j}=N\left(P_{i j}\right)=[$ (count in 
row i) *(count in column $j)] / N$, where $N=$ total sample size.

4. Calculate $x^{2}=\left[E_{i} E_{j}\left(O_{i j}-E_{i j}\right)^{2}\right] / E_{i j}$, where $O_{i j}=$ the actual number of cases or observations in $\operatorname{cell}_{i j}$.

5. Determine the degrees of freedom based upon the number of rows ( $R$ ) and columns $(C)$ in the contingency table. For an $\mathrm{R} \times \mathrm{C}$ table, the degrees of freedom are $(R-1) *(C-1)$.

6. The probability of obtaining the calculated $x^{2}$ value given the associated degrees of freedom is then determined. If the probability is small enough, the null hypothesis is rejected (Tull et al, 1984: 483).

\section{HYPOTHESIS TESTING}

The intent of this research study is to draw inferences to the population of high technology start-up firms. The general question to be answered by the tests of the hypotheses is not whether the sample measures of central tendency for the various attributes are, in fact, different, but whether the two population measures of central tendency are different in each case.

\section{Notation}

To ease the task of representing the hypothesis tests in an operational form, the following notation is used. The 
hypotheses themselves are denoted, as previously, by $\mathrm{Hi}$, where $i$ equals the hypothesis number as it appears in the Statements of the Hypotheses section in Chapter II. The variables used in testing each hypothesis are denoted slightly differently than they are in Tables I through VII. For the purposes of the ensuing discussion, variables are denoted by $v_{a} i \cdot j$, where a equals either venture capital funded (F) or unfunded ( $U$ ), $i$ equals the hypothesis being tested, and $j$ equals a unique variable number as defined in the aforementioned tables. When the mean value for a particular variable is discussed, it is denoted by an upper case "V", e.g. $v_{a} i \cdot j$.

\section{Statistical Computations}

All descriptive statistical calculations and hypothesis testing are accomplished through the employment of the Statistical Package for the Social sciences (SPSS ${ }^{X}$ ). The IBM 4381 mainframe computer at Portland State University is used to execute SPSS $^{x}$.

\section{Hypothesis 1}

$\mathrm{H} 1$ is tested through the use of ANOVA. As was previously mentioned, testing takes place on two levels. The individual Likert scale means for variables $v_{F} 1.1$ through $v_{F^{1}} 1.5$ and $v_{U} 1.1$ through $v_{U} 1.5$ are compared respectively to determine whether true differences exist between the venture capital funded and unfunded groups of 
firms. Secondly, the sum of scores means for $v_{F} 1 . j$ and $v_{U} 1 . j$, where $j$ varies from 1 to 5 , are calculated and compared. The SPSS ${ }^{x}$ procedure, ANOVA, actually develops the means and performs the necessary statistical calculations. H1 hypothesizes that the venture capital funded firm has an organizational climate which is more organic than that of the unfunded firm. It is expected that descriptive statistics will indicate mean values of $V_{F^{1}} \cdot j$ and $v_{U^{1}} \cdot j$ which are not equal, and will also indicate that both are closer to a Likert scale value of "5", representing an organic organizational climate, rather than a "1", representing a mechanistic organizational climate.

For the purposes of testing $\mathrm{Hl}$, it is operationalized as follows: $\mathrm{H} 1: \mathrm{V}_{\mathrm{F}^{1}}>\mathrm{V}_{\mathrm{U}^{1}}$. The null hypothesis is then the hypothesis of no difference, $\mathrm{H} 0: \mathrm{V}_{\mathrm{F}^{1}}=\mathrm{V}_{\mathrm{U}^{1}}$. It is expected that the observed F-value developed by the ANOVA statistical procedure is less than or equal to the critical F-value at the .10 level of significance. The null hypothesis should not be rejected indicating that there is no significant difference between the groups' perceptions regarding their organizational climate. The expected result of no significant difference is based on previous research by Goslin and Kiehl (Goslin and Kiehl, 1988). (See Appendix B for a summary of expected results of all hypothesis tests.) 
Hypothesis 2

$\mathrm{H} 2$ is also tested through the use of ANOVA. Multiple tests are performed to ascertain differences, if any, between funded and unfunded firms regarding years of experience, responsibility levels and annual sales volumes on an aggregate team basis.

For each team, the following aggregates are calculated:

1. Total years experience $=\mathrm{TY}=\mathrm{v} 2.1 \mathrm{~A}+\mathrm{v} 2.1 \mathrm{~B}+$ $v 2.1 C+v 2.1 D$.

2. Total responsibility levels $=\mathrm{TL}=\mathrm{v} 2.2 \mathrm{~A}+\mathrm{v} 2.2 \mathrm{~B}+$ $v 2.2 C+v 2 \cdot 2 D$.

3. Total sales volume $=\mathrm{TS}=\mathrm{v} 2 \cdot 3 \mathrm{~A}+\mathrm{v} 2 \cdot 3 \mathrm{~B}+\mathrm{v} 2 \cdot 3 \mathrm{C}+$ v2.3D.

The initial assessment of top management team quality is equated to aggregate analysis of these team totals, i.e. the greater the TY and the TL and the TL, the higher the quality.

In terms of the mean TY, TL and TS, it is expected that $\left(T Y_{F}>T Y_{U}\right)$ and $\left(T L_{F}>T L_{U}\right)$ and $\left(T S_{F}>T S_{U}\right)$. It should be pointed out that v2.2A, v2.2B, v2.2C and $v 2.2 \mathrm{D}$ are recoded with $1=7,2=6,3=5$ and so forth to provide continuity regarding the direction of the hypothesized relationship.

The null hypcthesis in the case of each measure is 
that of no difference, and it is expected to be rejected at the .10 level of significance.

The second aspect of quality to be tested regards the number of members on the top management team, v2.7. The mean size of the top management team of the funded firm is expected to be larger than that of the unfunded firm. The null hypothesis, HO: $\mathrm{V}_{F} 2.7=\mathrm{V}_{U} 2.7$, is one of no difference. It is expected that this null hypothesis will be rejected at the .10 level of significance, and these results will support hypothesis 2 .

The third aspect of quality to be examined is the number of functional areas represented by the prior experience, v2.8. Once again, the mean number of areas for funded firms, $V_{F} 2.8$ is expected to be larger than the mean for unfunded firms, $V_{U} 2.8$. The null hypothesis of no difference is expected to be rejected at the .10 level of significance.

The fourth aspect of quality to be tested is whether or not each of the team members serves in a similar capacity as in his/her prior experience. While nominal scale data was collected, it is used to build a ratio scale measure reflecting the total number of team members for whom the response to $\mathrm{v} 2.5$ was "1". The team total is represented by $T F=v 2.5 A+v 2.5 B+v 2.5 C+v 2.5 D$. The null hypothesis is that of no difference, $\mathrm{HO}: T F_{F}=T F_{U}$. It is expected to be rejected at the .10 level of significance. 
A similar technique is used to test the final aspect of quality regarding the total number of team members whose prior experience was in a firm utilizing or producing a like technology. This team total $=\mathrm{TT}=\mathrm{v} 2.6 \mathrm{~A}+\mathrm{v} 2.6 \mathrm{~B}+\mathrm{v} 2.6 \mathrm{C}+$ v2.6D. Here again, the null hypothesis, $H 0: T_{F}=T_{T}$, is expected to be rejected at the .10 level of significance.

Given that all of the hypothesis tests have the expected results, as delineated above, hypothesis 2 is expected to be accepted, as it will be shown that the funded firms do have a higher quality top management team.

\section{Hypothesis 3}

H3 is also tested through the use of ANOVA. As with hypothesis 1 , the Likert scale means for $v_{F} 3.1$ through $v_{U} 3.6$ and the sum of scores means for $v_{F} 3 \cdot j$ and $v_{U^{3}} \cdot j$ are developed. Descriptive statistics are expected to indicate that $V_{F^{3}} \cdot j>V_{U}{ }^{3} \cdot j$ for all individual Likert scales and the sum of scores.

To test hypothesis 3 , once again the null hypothesis is one of no difference, $\mathrm{HO}_{\mathrm{O}} \mathrm{V}_{\mathrm{F}}{ }^{3}=\mathrm{V}_{\mathrm{U}}{ }^{3}$. It is expected that the observed F-value will be greater than the critical Fvalue at the .10 level of significance. The null hypothesis is to be rejected thereby indicating that there are significant differences between the venture capital funded and unfunded high technology start-up firms. The funded firms tend to be more market driven than the unfunded firms. 
Hypothesis 4

H4 is also tested through the use of ANOVA. As with previous hypotheses, the Likert scale means and the sum of score means for $\mathrm{v}_{\mathrm{F}} 4.1$ through $\mathrm{v}_{U^{4}} .4$ are calculated. It is expected that $\mathrm{V}_{\mathrm{F}^{4}}>\mathrm{V}_{\mathrm{U}} 4$ for all individual Iikert scales and the sum of scores.

The higher $V_{F^{4}}$ indicates that the funded firms have more of a solutions orientation based on the previously discussed notion that a "5" on the Likert scale represents a solutions orientation, whereas a "l" represents a technological orientation.

To test hypothesis 4 , the null hypothesis is one of no difference, $\mathrm{HO}: \mathrm{V}_{F^{4}}=\mathrm{V}_{U^{4}}$. It is expected that the observed F-value developed by ANOVA is greater than the critical Fvalue at the .10 level of significance. The null hypothesis is to be rejected indicating, once again, that there are significant differences between the venture capital funded firms and the unfunded firms. In this case, the funded firms are expected to be more likely to have a solutions orientation than are the unfunded firm.

\section{Hypothesis 5}

ANOVA is utilized to test the Likert scale means and the sum of scores means of $v_{F} 5.1$ through $v_{U} 5.4$. Here again, it is expected that $V_{F}{ }^{5}>V_{U}$ for both the individual Iikert scales and the sum of scores. The null hypothesis of no difference, $H O: V_{F^{5}}=V_{U^{5}}$, is expected to be rejected at the 
.10 level of significance as the observed F-value is greater than the critical F-value.

Based upon these expectations and the premise that a "5" on the Likert scale corresponds to a niche focus, the venture capital funded start-up firm does focus more narrowly on a market niche than does the unfunded firm.

\section{Hypothesis 6}

H6 is tested through the use of ANOVA. The probability of a start-up firm going public within the next two years is expected to be greater for those high technology start-up firms which have received venture capital funding than for the unfunded firms. In other words, the mean probability value of $v_{F} 6.1$ is expected to be greater than that of $\mathrm{V}_{U} 6.1$.

The null hypothesis, $H 0: V_{F} 6.1=V_{U} 6.1$, is that of no difference. Based upon the expectation that the observed Fvalue will be greater than the critical F-value at the .10 level of significance, the null hypothesis will be rejected. The notion that the venture capital funded firm is more likely to go public than the unfunded firm will then be accepted.

Hypothesis 6 is also tested through the use of Chisquare. Utilizing v6.2, years elapsed between founding and going public, it is expected to be shown that a greater proportion of the funded firms expect to go public within five years of founding. In this case, the null hypothesis 
is that of independence, i.e. there is no relationship between venture capital funding and v6.2.

It is expected that the calculated Chi-square, based on five degrees of freedom ( 2 rows and 6 columns in the contingency table) will have a level of significance which is less than .10. Given this result, the null hypothesis of independence will be rejected, and it is shown that there is a relationship between venture capital funding and v6.2, years elapsed between founding and going public. Additionally, the contingency table will indicate that a greater percentage of venture capital funded firms expect to go public within the five year time frame.

\section{Hypothesis 7}

H7 is tested through the use of ANOVA and Chi-square. Utilizing ANOVA, it is expected to be shown that the $V_{F} 7.1>$ $\mathrm{V}_{\mathrm{U}} 7.1$ for those firms in both groups which have, in fact, developed business plans. The null hypothesis in this case is that of no difference, $\mathrm{HO}_{0} \mathrm{~V}_{\mathrm{F}} 7.1=\mathrm{V}_{U} 7.1$. Once again it is expected that the observed F-value will be greater than the critical F-value at the .10 level of significance. The null hypothesis will then be rejected. At this particular point, it will be known that the venture capital funded firms have larger business plans than the unfunded start-up firms.

Utilizing Chi-square along with its associated contingency table, it is expected to be shown that there is 
a relationship between venture capital funding and v7.1. In order to test the null hypothesis of independence, v7.1 is recoded in the following fashion: a value of $(0)$ pages corresponds to the absence of a business plan, and a value of (1+) pages corresponds to the presence of a business plan.

It is expected that the calculated Chi-square, based on one degree of freedom (two rows and two columns in the contingency table), will have a probability or level of significance which is less than .10. Based upon this finding, the null hypothesis of independence is rejected and hypothesis 7 is accepted.

Chi-square is also used to examine the exploratory questions regarding the most and least important components, from the respondents' perception, of the business plan. The intent is to determine not only the most and least important components, but also whether these perceptions are, in any way, related to the presence or absence of venture capital funding.

In the case of each of these variables, v7.2 and v7.3, a contingency table is produced based on eight degrees of freedom (two rows corresponding to funded and unfunded and ten columns corresponding to the nine business plan components as delineated on page 74 , plus an "all important" category). 
ANOVA is used to examine v7.4.1 through v7.4.9, which represent the weightings assigned to the various business plan components according to perceived importance. The null hypothesis is one of no difference, $H 0: V_{F} 7.4 \cdot j=V_{F} 7.4 . j$, where $j$ equals 1 to 10 . The intent here is to determine whether or not there are differences in perceived importance among components between the funded and unfunded groups of firms.

Chi-square is used to examine the purpose for which the business plan was developed. Once again, the null hypothesis is that of independence. The calculated Chisquare, based on three degrees of freedom, is expected to have a level of significance which is less than or equal to .10. As a result, the null hypothesis is to be rejected, and it is shown that the purpose for developing a business plan is markedly different based on the presence or absence of venture capital financing. Further it is expected that the venture capital funded firms will indicate a venture capital requirement as the primary purpose, and the unfunded start-up firms will indicate operating necessity as that purpose.

\section{SUMMARY}

To test the hypotheses, a sampling frame of 1350 CEO/Presidents of high technology start-up firms was used. 
A systematic random sampling design was utilized to select the firms from the Corp Tech data base.

Data collection was accomplished through the use of a mail survey. Two mailings were undertaken to achieve a final sample size of 226 respondents.

Hypothesis testing includes the use of ANOVA to test for differences between venture capital funded and unfunded firms with regard to the hypothesized characteristics. Additionally, the Chi-square statistic is utilized in those cases where nominal scale data have been collected to measure association between variables. 
CHAPTER IV

\section{ANALYSIS OF RESEARCH FINDINGS}

The purpose of this chapter is to discuss the results of the statistical analysis of the data. General characteristics of the sample are first discussed to provide a context within which the individual hypotheses are to be addressed. The individual statistical test results regarding each of the seven hypotheses are then discussed.

\section{CHARACTERISTICS OF THE SAMPLE}

The primary demographic characteristics collected include: the state in which the respondent firm is located, the age of the firm, and whether or not the firm has received at least one infusion of venture capital financing. Additional measures of dollars received and percent of equity given up for each of the first three rounds of venture capital financing were also collected for those firms which have, in fact, been venture capital financed.

\section{Characteristics of the Entire Sample}

Examination of the entire sample indicates two major geographic pockets of respondent firms. One pocket exists on the west coast and includes the states of California, Oregon and Washington. This pocket accounts for 
approximately forty percent of the entire sample. The second geographic pocket of respondent firms includes those states on the east coast, specifically the north eastern states. Included in this group are: Connecticut, Massachusetts, Maryland, New Hampshire, New Jersey, New York, Pennsylvania, Rhode Island and Vermont. This pocket comprises about thirty percent of the sample. (Further discussion of geographic pockets can be found in the Recommendations for Further Research section of Chapter V.) The remaining thirty percent of the sample includes firms in the south, southeast, southwest and midwest. A total of thirty-two states are represented in the sample. Regarding age, the majority of the sample, sixty percent, falls into the four to five years old category. One the other hand, slightly less than ten percent of the firms are 1 year old, with the remaining firms being two to three years old. The mean age of the respondent firms is 3.6 years.

The sample reflects an uneven split between venture capital funded firms and unfunded firms. The funded firms represent approximately one-third of the sample, with the unfunded firms representing the remaining two-thirds. Appendix $C$ contains the supporting detailed demographic breakdown of the sample as a whole. 
Characteristics of the Unfunded Firms

Here again, the same two geographic pockets exist, with the states of California, Oregon and Washington representing slightly more than forty percent of the respondent unfunded firms. The east coast pocket of Connecticut, Massachusetts, Maryland, New Hampshire, New Jersey, New York, Pennsylvania, Rhode Island and Vermont accounts for twenty-five percent of the unfunded respondents. The respondents in this group represent thirty-one of the thirty-two state sample total. See Appendix D for a state by state breakdown of the unfunded firms.

The mean age of the unfunded firms is 3.5 years. The majority of these firms, about seventy percent, fall into the four to five years old category. Eleven percent of this group is in the one year old category, with the remaining nineteen percent being three to four years old. The details of these breakdowns can be found in Appendix D.

\section{Characteristics of the Funded Firms}

The same two pockets of geographic concentration exist for the funded firm group. The west coast pocket represents forty-three percent of this group, while the east coast pocket represents thirty-seven percent. This group has respondents in only twenty of the thirty-two states represented in the total sample. Appendix E details the complete geographic breakdown of funded firms. 
Here again, the majority of the funded firms, sixty percent, are four to five years old, with only six percent being in the one year old category. The mean age of the funded firms is 3.7. years. See Appendix E for the detailed breakdown.

An examination of dollars received and equity given up for each of the first three rounds of venture capital yields the following findings. The number of rounds of venture capital financing ranged from one to seven, with two being the median number. Eighty-eight percent of these firms received one to three rounds. Appendix E summarizes the complete funding findings.

First Round Financing. Three-fourths of the funded firms received less than $\$ 3$ million in first round financing. Thirty-six percent of the group received less than $\$ 1$ million, and twenty-five percent received $\$ 1$ 1.99 million. The maximum dollars obtained in this round were 25 million. The mean number of dollars obtained was $\$$ 2.4 million, while the median was $\$ 1.1$ million.

The mean and median percent of equity given up for this first round was forty percent. Thirty percent of the group gave up twenty-five percent or less, and forty-six percent gave up twenty-six to fifty percent.

Second Round Financing. The mean second round dollars received was three million, while the median was $\$ 2$ million. In this round, thirty-two percent of the firms 
received $\$ 1$ million or less, forty percent received $\$ 1$ to 3 million, with the remaining twenty-eight percent receiving up to $\$ 21$ million.

The mean equity cost of second round financing was thirty percent and the median cost was twenty-one percent. Sixty-eight percent of the firms paid eleven to thirty percent of equity for this second round financing.

Third Round Financing. Sixty percent of those firms receiving a third round of financing obtained $\$ 1$ to 3 million. The maximum dollars received were 18.23 million resulting in a mean of $\$ 3.7$ million, while the median was only $\$ 2.6$ million.

The equity given up was twenty percent or less for eighty-one percent of the firms. The mean equity cost was nineteen percent, but the large concentration of respondents in the aforementioned narrow range resulted in the median being slightly lower at fifteen percent. Details of financing dollars and equity are found in Appendix E.

\section{HYPOTHESIS TEST FINDINGS}

Hypothesis 1

The high technology start-up firm which has acquired venture capital funding maintains an organizational climate which is more organic than does the high technology start-up firm which has not acquired venture capital funding.

It was expected that the research hypothesis would be rejected and the null hypothesis accepted, i.e. there would be no difference between venture capital funded firms and 
unfunded firms regarding their organizational climates. Concomitantly, it was expected that both firms groups, funded and unfunded, would tend to perceive their firms as more organic than mechanistic.

The profiles contained in Appendix $\mathrm{F}$ appear to confirm the expectations regarding hypothesis 1 . The Iikert scale means for each component measure and the sum of scores are within a percentage of a point of each other. Additionally, all are greater than four on a Likert scale where five represents the extreme "organic" end of the continuum.

Six tests were performed to validate the expectations. Table VIII contains the detailed findings when this hypothesis was tested based on only component one, open communication flow.

TABLE VIII

HYPOTHESIS 1 - COMPONENT 1 OPEN COMMUNICATION FLOW - ANOVA RESULTS

\begin{tabular}{|c|c|c|c|c|c|}
\hline Source & D.F. & $\begin{array}{l}\text { Sum of } \\
\text { Squares }\end{array}$ & $\begin{array}{c}\text { Mean } \\
\text { Squares }\end{array}$ & $\begin{array}{c}F \\
\text { Ratio }\end{array}$ & $\begin{array}{c}\mathbf{F} \\
\text { Prob. }\end{array}$ \\
\hline Between Groups & 1 & .062 & .062 & .068 & .794 \\
\hline Within Groups & 219 & 199.512 & .911 & & \\
\hline Total & 220 & 199.574 & & & \\
\hline Unfunded: & Mean $=4$ & 5159 & Standard D & Deviation & $=1.0204$ \\
\hline unded: & Mean $=4$ & 5506 & Standard D & Deviation & .8328 \\
\hline
\end{tabular}


As can be seen from the table, the mean Likert scale values are very close to the "organic" end of the continuum. In addition, the $F$ probability or observed significance level of .794 indicates that the results are not statistically significant at the .10 level. As such, the null hypothesis that all population means are equal must be accepted, and the research hypothesis is rejected.

The testing of component two, decision making style, yielded similar results. Table IX summarizes the results of the statistical analysis.

TABLE IX

HYPOTHESIS 1 - COMPONENT 2

DECISION MAKING STYLE - ANOVA RESULTS

Source

Between Groups

Within Groups

Total

Unfunded:

Funded:

$\begin{array}{rrrrr}\text { D.F. } & \begin{array}{c}\text { Sum of } \\ \text { Squares }\end{array} & \begin{array}{c}\text { Mean } \\ \text { Squares }\end{array} & \begin{array}{c}F \\ \text { Ratio }\end{array} & \begin{array}{c}\text { Prob. } \\ 1\end{array} \\ 1.889 & 1.889 & 2.123 & .146 \\ 219 & 194.916 & .890 & & \\ 220 & 196.805 & & & \end{array}$

$$
\begin{array}{ll}
\text { Mean }=4.2391 & \text { Standard Deviation }=.9783 \\
\text { Mean }=4.0482 & \text { Standard Deviation }=.9434
\end{array}
$$

While the mean scores for the two firm groups do differ, the results are not statistically significant at the .10 level. The null hypothesis of no difference is, therefore, accepted. The research hypothesis is not supported, as there is no significant difference between the means. Here 
again, the means are closer to the "organic" end of the scale.

Components three through five all yielded similar results. The detailed findings of each test of hypothesis 1 are found in Tables $\mathrm{x}$ through XII.

TABLE X

HYPOTHESIS 1 - COMPONENT 3

TOLERANCE OF FAILURE - ANOVA RESULTS

Source

Between Groups

Within Groups

Total

Unfunded:

Funded:
D.F. $\quad \begin{array}{llcc}\text { Sum of } & \text { Mean } & \text { F } & \text { F } \\ \text { Squares } & \text { Squares } & \text { Ratio } & \text { Prob. }\end{array}$ $\begin{array}{lllll}1 & .003 & .003 & .002 & .964\end{array}$ $220 \quad 280.633 \quad 1.276$

$221 \quad 280.636$

\begin{tabular}{|c|c|c|c|c|c|}
\hline & \multicolumn{3}{|c|}{$\begin{array}{l}\text { HYPOTHESIS } 1 \text { - COMPONENT } 4 \\
\text { POLICIES CONSISTENT WITH CORPORATE } \\
\text { GOALS - ANOVA RESULTS }\end{array}$} & & \multirow[b]{2}{*}{$\begin{array}{c}\mathbf{F} \\
\text { Prob. }\end{array}$} \\
\hline Source & $\underline{\text { D.F. }}$ & $\begin{array}{l}\text { Sum of } \\
\text { Squares }\end{array}$ & $\begin{array}{c}\text { Mean } \\
\text { Squares }\end{array}$ & $\begin{array}{c}F \\
\text { Ratio }\end{array}$ & \\
\hline Between Groups & 1 & .591 & .591 & .722 & .396 \\
\hline Within Groups & 219 & 179.120 & .8179 & & \\
\hline Total & 220 & 179.711 & & & \\
\hline Unfunded: & Mean $=4$. & 3116 & tandard De & viation $=$ & .8944 \\
\hline Funded: & Mean $=4$. & 2048 & tandard $D$ & viation $=$ & .9208 \\
\hline
\end{tabular}


The final test of hypothesis 1 is that involving the sum of scores means. Given the preceding results for the five components, it is no surprise that the results of this primary test of hypothesis 1 do, in fact, support the

TABLE XII

$$
\begin{aligned}
& \text { HYPOTHESIS } 1 \text { - COMPONENT } 5 \\
& \text { INTEGRITY MORE IMPORTANT THAN } \\
& \text { PROFIT - ANOVA RESULTS }
\end{aligned}
$$

Source

Between Groups

Within Groups

Total

Unfunded:

Funded:
Sum of Mean D.F. Squares Squares Ratio Prob.

$\begin{array}{lllll}1 & .195 & .195 & .252 \quad .616\end{array}$

\begin{tabular}{|c|c|c|c|c|c|}
\hline \multicolumn{6}{|c|}{ TABLE XIII } \\
\hline \multicolumn{6}{|c|}{$\begin{array}{l}\text { ORGANIZATIONAL CLIMATE SUM OF SCORES } \\
\text { ANOVA RESULTS }\end{array}$} \\
\hline Source & D.E. & $\begin{array}{l}\text { Sum of } \\
\text { Squares }\end{array}$ & $\begin{array}{l}\text { Mean } \\
\text { Squares }\end{array}$ & $\begin{array}{c}\bar{F} \\
\text { Ratio }\end{array}$ & $\begin{array}{c}E \\
\text { Prob. }\end{array}$ \\
\hline Between Groups & 1 & .454 & .454 & 1.360 & .245 \\
\hline Within Groups & 215 & 71.703 & .334 & & \\
\hline Total & 216 & 72.157 & & & \\
\hline Unfunded: & Mean $=4$ & 567 & andard $\mathrm{D}$ & iation $=$ & .5381 \\
\hline Funded: & Mean $=4$ & 627 & andard $\mathrm{D}$ & riation $=$ & .6362 \\
\hline
\end{tabular}

$219 \quad 169.335 \quad .773$

$220 \quad 169.530$ 
expectation of no statistically significant difference between the two firm groups. Table XIII summarizes the results of this final test of the hypothesis.

Here again, the means tend toward the "organic" end of the scale. The F probability of .245 indicates that the results are not statistically significant. The null hypothesis is accepted, and the research hypothesis is, as expected, not supported.

\section{Hypothesis 2}

The top management team of the high technology startup firm which has acquired venture capital funding has a higher quality top management team than does the high technology start-up firm which has not acquired venture capital funding.

The expected result of the funded firms having a higher quality top management team did, for the most part, receive sound support throughout all of the hypothesis tests. The only test which did not, necessarily support the hypothesized relationship is that concerning the aggregate number of years of prior primary experience. Examination of total years yielded results which did support the direction of the hypothesized relationship. The funded firms possess a mean total of 36.5 while the unfunded firms have a mean of 31.1 years. These results were, however, not statistically significant at the .10 level, as the $F$ probability was .13 . As such, there is no significant difference between the firm groups regarding longevity of prior primary experience. Table XIV details the results of this test. 
The aggregate level of responsibility yielded test results which supported the hypothesized relationship. The aggregate mean for the funded firms is 21.6 , while the mean for the unfunded firms is 15.5. As the results in Table XV indicate, the difference between these means is

TABLE XIV

$$
\begin{gathered}
\text { HYPOTHESIS } 2 \text { - VARIABLE } 1 \\
\text { AGGREGATE YEARS - ANOVA RESULTS }
\end{gathered}
$$

Source

Between Groups

Within Groups

Total

Unfunded:

Funded:

$\begin{array}{rrrrr}\text { D.F. } & \begin{array}{l}\text { Sum of } \\ \text { Squares }\end{array} & \begin{array}{c}\text { Mean } \\ \text { Squares }\end{array} & \begin{array}{c}F \\ \text { Ratio }\end{array} & \begin{array}{c}F \\ \text { Prob. }\end{array} \\ 1 & 1003.57 & 1003.57 & 2.276 & .134 \\ 145 & 63923.10 & 440.85 & & \\ 146 & 64926.67 & & & \end{array}$

Mean $=31.111 \quad$ Standard Deviation $=21.880$

Mean $=36.474 \quad$ Standard Deviation $=19.510$
TABLE XV

HYPOTHESIS 2 - VARIABLE 2

AGGREGATE RESPONSIBILITY LEVEL ANOVA RESULTS

Source

Between Groups

within Groups

Total

Unfunded:

Mean $=15.467$

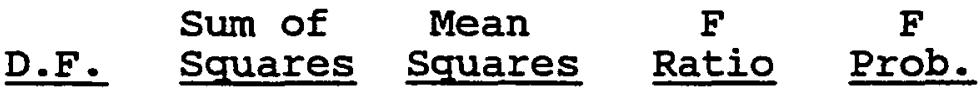
$\begin{array}{lllll}1 & 1333.90 & 1333.90 & 22.918 & .000\end{array}$ $145 \quad 8439.38 \quad 58.20$ $146 \quad 9773.28$

Funded:

$$
\text { Mean }=21.649 \quad \text { Standard Deviation }=6.784
$$


statistically significant at the .10 level. The null hypothesis of no difference is rejected, and the hypothesized relationship is supported.

Testing based on the aggregate annual sales volume of the team also produced results in support of hypothesis 2 . There is a dramatic difference in the aggregates with the funded firms having a mean aggregate of $\$ 2882$ million and the unfunded firms having a mean only one-third as large at $\$ 922$ million. As shown in Table XVI, the difference is statistically significant, and the null hypothesis of no difference must be rejected. Here again, hypothesis 2 is supported as expected.

TABLE XVI

HYPOTHESIS 2 - VARIABLE 3

AGGREGATE ANNUAL SALES VOLUME (MILLIONS OF DOLLARS) ANOVA RESULTS

Source

Between Groups

within Groups

Total

Unfunded:

Funded:

$\begin{array}{rrr}\text { D.F. } & \begin{array}{l}\text { Sum of } \\ \text { Squares }\end{array} & \begin{array}{c}\text { Mean } \\ \text { Squares }\end{array} \\ 1 & 134097 \mathrm{~K} & 134097 \mathrm{~K} \\ 145 & 4161056 \mathrm{~K} & 28696 \mathrm{~K} \\ 146 & 4295053 \mathrm{~K} & \end{array}$

F $\quad F$

Ratio Prob. $4.673 \quad .032$

The mean number of members on the top management team is approximately one-third greater for the funded firms at 3.6. The unfunded firms have a mean of 2.8 members on their 
top management teams. These results, as detailed in Table XVII, are also statistically significant at the .10 level. The null hypothesis of no difference is rejected, and hypothesis 2 is generally supported.

TABLE XVII

HYPOTHESIS 2 - VARIABLE 4

NUMBER OF TOP MANAGEMENT TEAM MEMBERS

ANOVA RESULTS

Source

Between Groups

Within Groups

Total

Unfunded:

Funded:

\begin{tabular}{rrr} 
D.F. & $\begin{array}{l}\text { Sum of } \\
\text { Squares }\end{array}$ & \multicolumn{1}{c}{$\begin{array}{c}\text { Mean } \\
\text { Squares }\end{array}$} \\
1 & 23.760 & 23.760 \\
145 & 150.498 & 1.038
\end{tabular}

$146 \quad 174.268$

In addition to having a larger top management team, the findings also indicate that there is more functional diversity on the team of the funded firm. The top management team of the funded firm has aggregate prior experience representing a mean of 3.1 different functional areas. The unfunded firm's aggregate experience is in 2.4 functional areas. These findings, shown in Table XVIII, are statistically significant at the .10 level. Support is, therefore, given to the hypothesized relationship.

The fourth aspect of quality examined regards whether or not the team members serve in the same or a similar 
capacity as that of their prior experience. The findings do support the hypothesized relationship. The funded firms have a mean number of 2.5 members and the unfunded firms have a mean of 1.9 top management team members who have had

TABLE XVIII

HYPOTHESIS 2 - VARIABLE 8

NUMBER OF DIFFERENT PRIOR FUNCTIONAL AREAS ANOVA RESULTS

\begin{tabular}{|c|c|c|c|c|c|c|c|}
\hline \multicolumn{2}{|l|}{ Source } & $\underline{\text { D.F. }}$ & \multicolumn{2}{|c|}{$\begin{array}{l}\text { Sum of } \\
\text { Squares }\end{array}$} & $\begin{array}{c}\text { Mean } \\
\text { Squares }\end{array}$ & $\begin{array}{c}\mathbf{F} \\
\text { Ratio }\end{array}$ & $\begin{array}{c}F \\
\text { Trob. }\end{array}$ \\
\hline Between Group & & 1 & & 901 & 16.901 & 16.436 & .000 \\
\hline Within Groups & & 145 & & 100 & 1.028 & & \\
\hline Total & & 146 & & 001 & & & \\
\hline Unfunded: & Mean & 2.4 & & St & Zard De & iation $=$ & 1.0612 \\
\hline Funded: & Mean & $=3.1$ & & & ndard DE & iation $=$ & .9342 \\
\hline
\end{tabular}

TABLE XIX

HYPOTHESIS 2 - VARIABLE 5

MEMBERS SERVING IN SAME FUNCTIONAL CAPACITY

ANOVA RESULTS

Source

Between Groups

Within Groups

Total

Unfunded:

Funded:

$\begin{array}{rrrrr}\text { D.F. } & \begin{array}{l}\text { Sum of } \\ \text { Squares }\end{array} & \begin{array}{c}\text { Mean } \\ \text { Squares }\end{array} & \begin{array}{c}\text { Ratio } \\ \text { Ratio }\end{array} & \begin{array}{c}F \\ \text { Prob. }\end{array} \\ 145 & 13.972 & 13.972 & 7.870 & .006 \\ 146 & 257.429 & 1.775 & & \end{array}$

$$
\begin{array}{ll}
\text { Mean }=1.9111 & \text { Standard Deviation }=1.3294 \\
\text { Mean }=2.5439 & \text { Standard Deviation }=1.3372
\end{array}
$$


primary experience directly related to their current functional capacity. The detail in Table XIX indicates that these results are statistically significant at the .10 level. The null hypothesis of no difference is, once again, rejected.

The final aspect of quality, the number of team members having prior experience in a firm utilizing or producing a like technology, also yielded statistically significant results in support of the hypothesized relationship. As shown in Table $\mathrm{xx}$, the funded firms have a

TABLE XX

HYPOTHESIS 2 - VARIABLE 6

MEMBERS EXPERIENCED WITH A LIKE TECHNOLOGY ANOVA RESULTS

\begin{tabular}{|c|c|c|c|c|c|}
\hline Source & D.F. & $\begin{array}{l}\text { Sum of } \\
\text { Squares }\end{array}$ & $\begin{array}{c}\text { Mean } \\
\text { Squares }\end{array}$ & $\begin{array}{c}F \\
\text { Ratio }\end{array}$ & $\begin{array}{c}F \\
\text { Prob. }\end{array}$ \\
\hline Between Groups & 1 & 9.796 & 9.796 & 4.944 & .028 \\
\hline Within Groups & 145 & 287.319 & 1.982 & & \\
\hline Total & 146 & 297.115 & & & \\
\hline
\end{tabular}

$\begin{array}{lll}\text { Unfunded: } & \text { Mean }=1.4000 & \text { Standard Deviation }=1.4206 \\ \text { Funded: } & \text { Mean }=1.9298 & \text { Standard Deviation }=1.3869\end{array}$

mean number of 1.9 members who have had their prior primary experience in a firm dealing with a like technology. The unfunded firms have a mean of 1.4 members having this type of experience. 
Considering all of the aspects of quality, strong support is given to the hypothesized relationship. While it is true that the difference in aggregate years experience is not statistically significant at the chosen level, it is not felt that the results are strongly contrary to the expectations. Taken on an aggregate basis, the null hypothesis of no difference must be rejected, and hypothesis 2 must be accepted.

Hypothesis 3

The strategy of the high technology start-up firm which has acquired venture capital funding will tend to be more market driven than will the high technology start-up firm which has not acquired venture capital funding.

It was expected that the venture capital funded firms tend to be more market driven than the unfunded firms. Examination of the strategy profiles in Appendix $G$ indicate that the results are somewhat mixed regarding the expectations. On an overall basis, the funded firms do appear to be more market driven than the unfunded firms as indicated by the sum of scores means of 3.9 and 3.5 respectivèly.

Additionally, the funded firms reflect higher Likert scale means for components one, product will not sell itself, and four, market demand is primary to technological sophistication. Contrary to expectations, components two, knowledgeable about competitor activities, and three, 
employees very customer focused, indicate results in the opposite than expected direction.

Testing hypothesis 3 by examining only component one resulted in the funded firms having a larger likert scale mean. Table XXI summarizes the ANOVA results. In addition to the relationship being in the desired direction, the findings are statistically significant at the .10 level. As such, the null hypothesis of no difference is rejected.

TABLE XXI

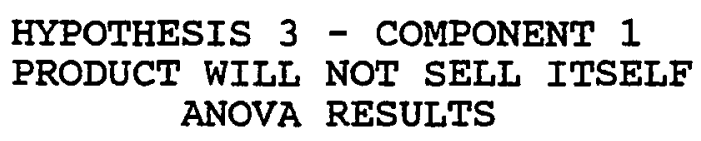

Source

Between Groups

Within Groups

Total

Unfunded:

Funded:

$\begin{array}{rrrr}\text { D.F. } & \begin{array}{l}\text { Sum of } \\ \text { Squares }\end{array} & \begin{array}{c}\text { Mean } \\ \text { Squares }\end{array} \\ 1 & 8.558 & 8.558 \\ 218 & 306.801 & 1.407 \\ 219 & 315.359 & \end{array}$

Mean $=3.5328$

Standard Deviation $=1.2664$

Mean $=3.9400$

Testing hypothesis 3 while utilizing components two and three on an individual basis yield relationships which are contrary to expectations. Considering only component two, the test yielded likert scale means of 4.0 for both funded and unfunded firms, while testing with component 
three resulted in mean scores of 3.6 for unfunded firms and 3.5 for funded firms.

\begin{tabular}{lccccc}
\multicolumn{5}{c}{ TABLE XXII } \\
HYPOTHESIS & 3 - COMPONENT 2 \\
KNOWLEDGEABLE ABOUT COMPETITORS \\
ANOVA RESULTS
\end{tabular}

Source

Between Groups

Within Groups

Total

Unfunded:

Funded:
TABLE XXIII

HYPOTHESIS 3 - COMPONENT 3

EMPLOYEES VERY CUSTOMER FOCUSED

ANOVA RESULTS
D.F. Squares Squares Ratio Prob.

$\begin{array}{llllll}1 & .514 & .514 & .659 & .418\end{array}$

$\begin{array}{lll}217 & 168.445 \quad .780\end{array}$

$218 \quad 168.959$ 
In each case, however, the results are not statistically significant based upon the F probabilities of .39 and .42 respectively. Tables XXII and XXIII summarize the results of these tests. In both of these cases, the null hypothesis of no difference is accepted.

Testing hypothesis 3 while utilizing only component four yielded results which do support the hypothesized relationship.

As is illustrated in Table XXIV, the Likert scale mean of 3.8 for the funded firms is, indeed, higher than the mean of 3.5 for the unfunded firms. Here again, the findings are statistically significant at the .10 level. In this case, the null hypothesis of no difference is rejected.

TABLE XXIV

HYPOTHESIS 3 - COMPONENT 4

MARKET DEMAND PRIMARY TO TECHNOLOGICAL SOPHISTICATION ANOVA RESULTS

Source

Between Groups

Within Groups

Total

Unfunded:

Funded:

$\begin{array}{rccc}\text { D.F. } & \begin{array}{c}\text { Sum of } \\ \text { Squares }\end{array} & \begin{array}{c}\text { Mean } \\ \text { Squares }\end{array} \\ 1 & 4.570 & 4.570 \\ 206 & 316.180 & 1.535 \\ 207 & 320.750 & \end{array}$



Ratio Prob.

$2.978 \quad .086$

320.750

Mean $=3.5078 \quad$ Standard Deviation $=1.2792$

Mean $=3.8125 \quad$ Standard Deviation $=1.1702$ 
The final test of hypothesis 3 is at the aggregate level, utilizing the component sum of scores. Table XXV shows that the relationship is in the desired direction with the funded firms having a mean score closer to the "market demand" end of the scale. Here again, the results are not statistically significant at the .10 level, and the null hypothesis of no difference must be accepted.

On an overall basis, the null hypothesis must be accepted and the research hypothesis must be rejected based on the results of both the primary hypothesis test and two of the four component tests, which are not statistically significant.

TABLE XXV STRATEGY SUM OF SCORES ANOVA RESULTS

Source

Between Groups

within Groups

Total

Unfunded:

Funded:

$\begin{array}{llcc}\text { Sum of } & \text { Mean } & F & F \\ \text { Squares } & \text { Squares } & \text { Ratio } & \text { Prob. }\end{array}$
D.F. Squares Squares Ratio Prob. $\begin{array}{lllll}1 & .773 & .773 & 2.247 & .136\end{array}$

$204 \quad 70.202 \quad .344$
$205 \quad 70.975$

Additionally, while the primary test did yield results in the desired direction, two of the four component tests did not. 


\section{Hypothesis 4}

The high technology start-up firm which has acquired venture capital funding is more likely to create products which provide solutions to new problems or superior solutions to existing problems rather than products which are either "better mousetraps" or lookalike technology than is the high technology start-up firm which has not acquired venture capital funding.

It was expected that the venture capital funded firm would have more of a solutions orientation than the unfunded firm. The profiles depicted in Appendix $\mathrm{H}$ illustrate that, for the most part, the exact opposite relationship holds. In all cases, except the perception of sharp vertical market segmentation, the Likert scale means for the unfunded firms indicate a greater tendency toward a solutions orientation.

Testing hypothesis 4 while utilizing only component one, customer feedback essential to new product development, resulted in the unfunded firms having a Likert scale mean of 4.7, and the funded firms having a mean of 4.6. Not only is the relationship in the opposite than expected direction, but the findings are also not statistically significant at the .10 level. The null hypothesis of no difference is accepted based on these results. Table XXVI details the findings of this test of hypothesis 4.

Tests utilizing components two, employees very customer focused, and three, intimately knowledgeable about customers' business, yielded similar results. As was previously detailed in Table XXIII, component two yielded Likert scale means which were only slightly unequal, and the 
difference was not statistically significant based upon an $F$ probability of .42 .

TABLE XXVI

HYPOTHESIS 4 - COMPONENT 1

CUSTOMER FEEDBACK ESSENTIAL TO NEW PRODUCT

DEVELOPMENT - ANOVA RESULTS

Source

Between Groups

Within Groups

Total

Unfunded:

Funded:
Sum of Mean $F \quad F$ D.F. Squares Squares Ratio Prob. $\begin{array}{lllll}1 & .796 & .796 & 1.117 & .292\end{array}$ $218 \quad 155.404 \quad .713$ $219 \quad 156.200$

The test involving only component three resulted in Likert scale means of 3.6 and 3.5 respectively for unfunded and funded firms. Here again, the findings are not statistically significant based on the resulting $F$ probability of .52 , and the nuil hypothesis must be accepted. Table XXVII details the examination of component three.

Testing hypothesis 4 while utilizing only component four, focus on sharp unique market segmentation, yielded results in the desired direction. The funded firms' Likert scale mean of 3.73 was greater than the unfunded firms' mean of 3.66. However, these results are deemed not statistically significant at the .10 level, as is evidenced 
by the detail of Table XXVIII. The null hypothesis of no difference must be accepted in this case.

TABLE XXVII

HYPOTHESIS 4 - COMPONENT 3

INTIMATELY KNOWLEDGEABLE ABOUT CUSTOMERS'

BUSINESS - ANOVA RESULTS

TABLE XXVIII

HYPOTHESIS 4 - COMPONENT 4

FOCUS ON SHARP UNIQUE MARKET SEGMENTATION

ANOVA RESULTS

Source

Between Groups

Within Groups

Total

Unfunded:

Funded:

$\begin{array}{rrccc}\text { D.F. } & \begin{array}{c}\text { Sum of } \\ \text { Squares }\end{array} & \begin{array}{c}\text { Mean } \\ \text { Squares }\end{array} & \begin{array}{c}\text { Ratio } \\ \text { Parob. }\end{array} & \begin{array}{c}F \\ \text { Prob. }\end{array} \\ 217 & .234 & .234 & .1793 & .672 \\ 218 & 282.652 & 1.3025 & & \end{array}$

Mean $=3.6642$ Standard Deviation $=1.1712$

Mean $=3.7317 \quad$ Standard Deviation $=1.0892$

Examination of the sum of scores, which reflects the aggregate perceptions regarding a solutions orientation, 
yielded differences in an opposite than expected direction. In addition, the findings, detailed in Table XXIX, are not statistically significant at the .10 level.

Based on all five tests of hypothesis 4 , the null hypothesis of no difference must be accepted. While small differences regarding the perception of having a solutions orientation appear to exist between the funded and unfunded firms, the firms have like propensities toward a solutions orientation.

TABLE XXIX

SOLUTIONS ORIENTATION SUM OF SCORES ANOVA RESULTS

Source

Between Groups

Within Groups

Total

Unfunded :

Funded:

$\begin{array}{rrr}\text { D.F. } & \begin{array}{l}\text { Sum of } \\ \text { Squares }\end{array} & \begin{array}{c}\text { Mean } \\ \text { Squares }\end{array} \\ 1 & .199 & .199 \\ 216 & 76.550 & .354 \\ 217 & 169.530 & \end{array}$

$$
\begin{aligned}
& \text { Mean }=4.0257 \\
& \text { Mean }=3.9634
\end{aligned}
$$$$
\text { Standard Deviation }=.6111
$$$$
\text { Standard Deviation = }
$$

\section{Hypothesis 5}

The high technology start-up firm which has acquired venture capital funding focuses more narrowly on a market niche which it can control than does the high technology start-up firm which has not acquired venture capital funding.

The comparison of funded and unfunded firms with respect to a market niche strategy yielded mixed results, 
which are illustrated by the profiles in Appendix I. The hypothesis test based on component one, do not compete with very large companies, produced unfavorable results with respect to expectations. The funded group did have a higher Likert scale mean of 2.4 compared to the mean of 2.3 for the unfunded firms; however, these low mean scores indicate that both groups tend to compete with very large companies. Once again, the results, shown in Table $\mathrm{XXX}$, are not statistically significant at the .10 level, and the null hypothesis of no difference is accepted.

TABLE XXX

$$
\begin{gathered}
\text { HYPOTHESIS } 5 \text { - COMPONENT } 1 \\
\text { DO NOT COMPETE WITH VERY LARGE COMPANIES } \\
\text { ANOVA RESULTS }
\end{gathered}
$$

Source

Between Groups

Within Groups

Total

Unfunded :

Funded:

$\begin{array}{rrr}\text { D.F. } & \begin{array}{r}\text { Sum of } \\ \text { Squares }\end{array} & \begin{array}{c}\text { Mean } \\ \text { Squares }\end{array} \\ 1 & .230 & .230 \\ 218 & 401.207 & 1.840 \\ 219 & 401.437 & \end{array}$

Standard Deviation $=1.3436$

Standard Deviation $=1.3784$

Testing based upon component two, do not strive to be low cost producer, resulted in findings which also do not support the hypothesized relationship. In this case, as shown in Table XXXI, the unfunded firms have a higher Likert 
scale mean of 3.2 compared to the mean of 3.0 for the funded firms.

TABLE XXXI

HYPOTHESIS 5 - COMPONENT 2

DO NOT STRIVE TO BE LOW COST PRODUCER ANOVA RESULTS

Source

Between Groups

Within Groups

Total

Unfunded:

Funded:

$\begin{array}{llccc}\text { D.F. } & \begin{array}{l}\text { Sum of } \\ \text { Squares }\end{array} & \begin{array}{c}\text { Mean } \\ \text { Squares }\end{array} & \begin{array}{c}F \\ \text { Ratio }\end{array} & \begin{array}{c}F \\ \text { Prob. }\end{array} \\ & .728 & .480 & .489\end{array}$

$217 \quad 328.944 \quad 1.516$

$218 \quad 329.672$

These means indicate an almost neutral position regarding a propensity toward being the low cost producer. Additionally, the results are not statistically significant at the .10 level. The null hypothesis of no difference must, therefore, be accepted in this case.

Component three, unique product deters entry by others, also yielded unexpected results. The funded firms appear to be more likely to produce a unique product which deters entry by others than the unfunded firms based upon Likert scale means of 3.2 and 3.0 respectively. Table XXXII details these results. These means, once again, fall on the scale neutral point, and the slight difference is not 
statistically significant at the .10 level. As such, the findings offer no support for research hypothesis 5.

TABLE XXXII

$$
\begin{aligned}
& \text { HYPOTHESIS } 5 \text { - COMPONENT } 3 \\
& \text { UNIQUE PRODUCT DETERS ENTRY } \\
& \text { ANOVA RESULTS }
\end{aligned}
$$

Source

Between Groups

Within Groups

Total

Unfunded:

Funded:

$\begin{array}{rrr}\text { D.F. } & \begin{array}{l}\text { Sum of } \\ \text { Squares }\end{array} & \begin{array}{c}\text { Mean } \\ \text { Squares }\end{array} \\ 1 & .924 & .924 \\ 217 & 332.427 & 1.532 \\ 218 & 333.351 & \end{array}$

$$
\text { Mean }=3.0365
$$

Standard Deviation $=1.2742$

$$
\text { Mean }=3.1707
$$

Components four, product does not appeal to a broad commodity market, and five, focus on sharp unique market segmentation, both appear to support the hypothesis in the desired direction. The Likert scale means, as shown in Tables XXXIII and XXVIII, are righer for the funded firms, but the difference is not statistically significant at the .10 level. The null hypothesis of no difference must be accepted.

Hypothesis testing based on component six, market differs from larger market as a whole, yields results which are also contrary to expectations. As Table XXXIV shows, the Likert scale mean of 3.5 for the funded firms is, indeed, lower than the 3.7 for the unfunded firms. Despite 
the difference, the null hypothesis of no difference is accepted as these findings are not statistically significant at the .10 level.

\begin{tabular}{|c|c|c|c|c|c|}
\hline \multirow[b]{2}{*}{ Source } & \multicolumn{4}{|c|}{$\begin{array}{l}\text { HYPOTHESIS } 5 \text { - COMPONENT } 4 \\
\text { DOES NOT APPEAL TO A BROAD COMMODITY } \\
\text { MARKET - ANOVA RESULTS }\end{array}$} & \multirow[b]{2}{*}{$\begin{array}{c}\text { F } \\
\text { Prob. }\end{array}$} \\
\hline & D.F. & $\begin{array}{l}\text { Sum of } \\
\text { Squares }\end{array}$ & $\begin{array}{c}\text { Mean } \\
\text { Squares }\end{array}$ & $\begin{array}{c}F \\
\text { Ratio }\end{array}$ & \\
\hline Between Groups & 1 & 1.348 & 1.348 & .712 & .399 \\
\hline within Groups & 216 & 408.946 & 1.893 & & \\
\hline Total & 217 & 410.294 & & & \\
\hline Unfunded: & Mean $=3$ & 7279 & andard D & Deviation & $=1.4219$ \\
\hline Funded: & Mean $=3$ & 8902 & :andard D & Deviation & $=1.2958$ \\
\hline
\end{tabular}

\section{TABLE XXXIV \\ HYPOTHESIS 5 - COMPONENT 6 \\ MARKET DIFFERS FROM LARGER MARKET AS}

A WHOLE - ANOVA RESULTS

Source

Between Groups

Within Groups

Total

Unfunded:

Funded:
Sum of Mean D.F. Squares Squares Ratio Prob.

$\begin{array}{lllll}1 & 2.328 & 2.328 & 1.879 & .172\end{array}$

$217 \quad 268.860$

1.239

$218 \quad 410.294$

Mean $=3.6642 \quad$ Standard Deviation $=1.0591$

Mean $=3.4512 \quad$ Standard Deviation $=1.1983$ 
Testing hypothesis 5 at the aggregate level, using the sum of scores, weakly supports the hypothesized direction of the relationship, but the difference is not statistically significant at the .10 level. Table XXXV summarizes these findings.

Based upon the complete findings, both the funded and unfunded firms are likely to somewhat niche focused; however, no evidence of support for the hypothesized difference exists. Hypothesis 5 is, therefore, rejected.

TABLE XXXV

NICHE FOCUS SUM OF SCORES

ANOVA RESULTS

Source

Between Groups

Within Groups

Total

Unfunded:

Funded:
D.F. $\quad \begin{array}{llcc}\text { Sum of } & \text { Mean } & F & F \\ \text { Squares } & \text { Squares } & \text { Ratio } & \text { Prob. }\end{array}$ $\begin{array}{lllll}1 & .005 & .005 & .013 & .911\end{array}$

$216 \quad 89.057 \quad .412$

$217 \quad 89.062$

\section{Hypothesis 6}

The high technology start-up firm which has acquired venture capital funding is more likely to plan on going public than the high technology start-up firm which has not acquired venture capital funding.

The expected result of the funded firms being more likely to go public than the unfunded firms received solid support through hypothesis testing. 
Examination of the probability of going public within the next two years yielded findings in the desired direction. As shown in Table XXXVI, the funded firms, with a Likert scale mean of 2.5 , appear to be more likely to go public than the unfunded firms, which have a mean of 2.0 . The F probability of .02 indicates that the results are statistically significant. The null hypothesis of no difference is rejected and the research hypothesis is supported based on these findings.

TABLE XXXVI

$$
\text { PROBABILITY OF GOING PUBLIC IN TWO YEARS }
$$
ANOVA RESULTS

Source

Between Groups

Within Groups

Total

Unfunded:

Funded:

\begin{tabular}{|c|c|c|c|c|}
\hline D.F. & $\begin{array}{l}\text { Sum of } \\
\text { Squares }\end{array}$ & $\begin{array}{c}\text { Mean } \\
\text { Squares }\end{array}$ & $\begin{array}{c}F \\
\text { Ratio }\end{array}$ & $\begin{array}{c}F \\
\text { Prob. }\end{array}$ \\
\hline 1 & 6.086 & 6.086 & 5.746 & .018 \\
\hline 165 & 174.741 & 1.059 & & \\
\hline 166 & 180.827 & & & \\
\hline
\end{tabular}

$$
\begin{array}{ll}
\text { Mean }=2.0000 & \text { Standard Deviation }=1.0249 \\
\text { Mean }=2.5185 & \text { Standard Deviation }=1.0514
\end{array}
$$

Utilizing the Chi-square statistic to examine the number of years elapsed, to a maximum of five, between founding and the intended year to go public also substantiated the expected results of hypothesis 6. Cross tabulation of venture capital funding and the number of years elapsed indicates that thirty-two percent of the 
funded firms expect to go public within four to five years of founding, while sixteen percent of the unfunded firms have this expectation. As Table XXXVII indicates, the findings were statistically significant at the .10 level, indicating that there is a relationship between funding and going public.

Based upon the results of these two tests, the null hypotheses are rejected, and it is shown that the venture capital funded firm is more likely to go public than the unfunded firm.

TABLE XXXVII

YEARS ELAPSED BETWEEN FOUNDING \& GOING PUBLIC CROSS TABULATION RESULTS

Years

$$
\begin{gathered}
1 \\
2 \\
3 \\
4 \\
5 \\
\text { N/A }
\end{gathered}
$$

Chi-square $=8.56348$
Funded

$\begin{array}{rrrr}0 & (0.0 \%) & 0 & (0.0 \%) \\ 1 & (1.3) & 0 & (0.0) \\ 1 & (1.3) & 2 & (1.7) \\ 5 & (5.3) & 6 & (4.2) \\ 22 & (26.7) & 18 & (12.5) \\ 55 & (65.3) & 116 & (81.7)\end{array}$

\section{Hypothesis 7}

The high technology start-up firm which has acquired venture capital funding is more likely to have prepared a formal business plan than those high technology start-up firms which have not acquired venture capital funding.

The results of ANOVA indicate that there is a statistically significant difference in the length of the 
business plan of the funded firm compared to the unfunded firm. The findings, as detailed in Table XXXVIII, show that the funded firm develops a business plan of forty-two pages, while the unfunded firm prepares one of only twenty-seven pages. These statistically significant results at the .10 level result in the rejection of the null hypothesis of no difference in the size of the business plan regardless of the presence or absence of venture capital funding.

Hypothesis 7 was also tested utilizing the Chi-square statistic. Two different cross tabulations were done toward this end. In the first case, the number of business plan

TABLE XXXVIII

NUMBER OF PAGES IN BUSINESS PLAN
ANOVA RESULTS

Source

Between Groups

Within Groups

Total

Unfunded:

Funded:
D.F. $\quad \begin{array}{llcc}\text { Sum of } & \text { Mean } & \mathbf{F} & \mathbf{F} \\ \text { Squares } & \text { Squares } & \text { Ratio } & \text { Prob. }\end{array}$

$\begin{array}{lllll}1 & 11589.5 & 11589.5 & 14.093 & .000\end{array}$

$217 \quad 178452.8 \quad 822.4$

$218 \quad 190042.3$

pages was recoded to reflect a breakdown into the following mutually exclusive categories: (0) no business plan, (1) 110 pages, (2) 11-24 pages, (3) 25-49 pages, and (4) 50 pages or more. The findings, as shown in Table XXXIX, indicate 
that there is a relationship between the size of the business plan and venture capital funding. The cross tabulation resulted in approximately eighty percent of the funded firms having business plans in excess of twenty-five pages, whereas only forty-five percent of the unfunded firms had business plans which exceeded twenty-five pages. These results are significant at the .00 level.

When the number of pages was recoded to reflect the presence or absence of a business plan, it was found that ninety-eight percent of the funded firms did, in fact, prepare a plan compared to eighty percent of the unfunded

TABLE XXXIX

BUSINESS PLAN PAGES

CROSS TABULATION RESULTS

Pages

0

$1-10$

$11-24$

$25-49$

$50+$
Funded

$2(2.4 \%) \quad 19 \quad(13.8 \%)$

$8 \quad(9.8) \quad 34 \quad(23.9)$

$\begin{array}{llll}7 & (8.5) & 24 & (16.7)\end{array}$

$\begin{array}{llll}39 & (46.3) & 37 & (26.1)\end{array}$

$\begin{array}{llll}28 & (32.9) \quad 28 & (19.6)\end{array}$

Chi-square $=24.9556 \quad$ Significance $=.0000$

firms. These findings were significant at the .01 level. As a result of the findings of both of these tests, the null hypothesis of independence must be rejected.

Based upon all three of the hypothesis tests regarding business planning, the hypothesized difference between funded and unfunded firms is accepted as expected. Not only 
are the funded firms more likely to prepare a business plan, but the plans which they develop are larger than those of the unfunded firms.

In conjunction with hypothesis 7 , four other business plan factors were examined: the perceived most important component, the perceived least important component, a weighted comparison of the components, and the purpose of plan preparation. Chi-square was utilized to determine whether or not there is a relationship between venture capital funding and the perceptions of the most and least important business plan components. Tables $\mathrm{xxxx}$ and $\mathrm{xxxxI}$ give complete breakdowns of the findings.

TABLE XXXX

MOST IMPORTANT BUSINESS PLAN COMPONENT CROSS TABULATION RESULTS

\section{Component}

Product Definition

Management Team

Product $R$ \& $D$

Market Analysis

Marketing Strategy \& Definition

Profit \& Cash flow Projections

Manufacturing (if appl.)

Market Size / Share

Technological Competency

All Important

Chi-square $=9.65846$
Funded

$7(8.6 \%) \quad 11 \quad(8.7 \%)$

$10 \quad(12.3)$

$4 .(4.9)$

$17(21.0)$

$17 \quad(21.0)$

$13(16.0)$

$1(1.2)$

$1(1.2)$

9 (11.1)

$2(2.5)$
Unfunded

$8(6.3)$

$7(5.5)$

$28 \quad(22.0)$

$30 \quad(23.6)$

$29 \quad(22.8)$

$4(3.1)$

$3(2.4)$

$7(5.5)$

$0(0.0)$

Regarding the perceived most important component, the three highest ranking components were: market strategy and definition, market analysis, and profit and cash flow 
projections. Additionally, the results were not statistically significant at the .10 level indicating that the perception of "most important" is dependent of venture capital funding.

Examination of the perceived least important component indicated that the prevalent choice was manufacturing followed by market size / share and product definition. Table XXXII summarizes the results of this cross tabulation. Here again, the results were not statistically significant at the .10 level. The null hypothesis of independence, therefore must be accepted.

TABLE XXXXI

\section{LEAST IMPORTANT BUSINESS PLAN COMPONENT CROSS TABULATION RESULTS}

Component

Product Definition

Management Team

Product $R \& D$

Market Analysis

Marketing Strategy \& Definition

Profit \& Cash flow Projections

Manufacturing (if appl.)

Market Size / Share

Technological Competency

All Important

Chi-square $=11.79021$
Funded

$16 \quad(19.8 \%) \quad 16 \quad(12.9 \%)$

$4(4.9) \quad 10 \quad(8.1)$

$6(7.4) \quad 9(7.3)$

$1(1.2) \quad 5(4.0)$

$0(0.0) \quad 4(3.2)$

$4(4.9) \quad 11(8.9)$

$\begin{array}{llll}28 & (34.6) & 27 & (21.8)\end{array}$

$11(13.6) \quad 26 \quad(21.0)$

$9(11.1) \quad 14 \quad(11.3)$

$2(2.5) \quad 2(1.6)$

Utilizing ANOVA, the weightings assigned to the various business plan components were examined. As Table XXXXII indicates, the only components for which a significant difference exists are management team and technological 
competency. All other tests yielded results which were not statistically significant at the .10 level. Appendix $J$ profiles the business plan component weightings.

The results of the cross tabulation involving venture capital funding and the purpose for which the business plan was prepared ran somewhat contrary to expected results. As Table XXXXIII illustrates, the greatest percentage of the unfunded firms did, in fact, prepare their business plans for the expected reason, operating necessity. The funded

\section{TABLE XXXXII}

BUSINESS PLAN COMPONENT WEIGHTINGS ANOVA RESULTS

Component

Product Definition

Management Team

Product $\mathrm{R} \& \mathrm{D}$

Market Analysis

Marketing Strategy \& Def. Profit \& Cash flow Proj. Manufacturing (if appl.) Market Size / Share Technological Competency
Funded Mean

1.1481

1.9259

.5556

1.4444

2.0617

1.3704

.1852

.3333

.9383
Unfunded Mean

Sig.

\begin{tabular}{rll} 
Mean & & Sig. \\
\hline .8800 & & .2098 \\
1.0720 & .0004 \\
.6480 & & .6245 \\
1.5120 & .7896 \\
2.0242 & .8891 \\
1.6800 & .2406 \\
.3520 & .2557 \\
.4240 & .5201 \\
1.3810 & .0657
\end{tabular}

firms indicated, in fifty-six percent of the cases, that the primary purpose for plan preparation was due to a venture capital requirement. The calculated Chi-square was statistically significant at the .10 level, resulting in the rejection of the null hypothesis of independence, and it is shown that there is a relationship between venture capital 
funding and the purpose for which a business plan is prepared.

TABLE XXXXIII

BUSINESS PLAN PREPARATION PURPOSE CROSS TABULATION RESULTS

Purpose

Operating Necessity

Venture Capital Requirement Market Strategy \& Definition

All of the Above

Other

Chi-square $=35.24338 \quad$ Significance $=.0000$

Funded Unfunded

$15 \quad(18.5 \%) \quad 48 \quad(40.0 \%)$

$\begin{array}{llll}45 & (55.6) & 29 & (24.2)\end{array}$

$12(14.8) \quad 39 \quad(32.5)$

$8(9.9) \quad 1 \quad(0.8)$

$1(1.2) \quad 3(2.5)$

SUMMARY

Of the seven hypotheses advanced in Chapter II, four were supported by statistically significant evidence in the desired direction and three were not. The four which were supported in the expected manner yielded the following results.

1. There is no significant difference between the organizational climates of the venture capital funded and unfunded firms.

2. The top management team of the funded firm is of a higher quality, with respect to the aggregate prior functional experience, than that of the unfunded firm.

3. The venture capital funded start-up firm is more apt to prepare a formal business plan, and this plan, in 
general, is more comprehensive for the funded firm than for its unfunded counterpart.

4. The funded high technology start-up firm is more likely to go public than the unfunded firm.

Three hypotheses were not supported in the expected manner. Due to findings which are not statistically significant, the following generalizations are made.

1. No significant difference exists regarding the respondents' perception of strategy. All firms perceived themselves to be equally market driven as opposed to technology driven.

2. All firms, regardless of funding, perceived themselves to be solutions oriented with a strong customer focused commitment.

3. All firms perceived themselves to be in a neutral position regarding market niche focus. No significant differences between the firm groups were found, and both groups perceived themselves to be at the midpoint between focusing on a niche and focusing on a broader market.

It should also be noted that the significance of all of these findings is enhanced by the fact that in those cases where a firm attribute is measured by multiple components, each component represents a unique dimension of the attribute in question. This is evidenced by the fact that autocorrelation effects among each particular attribute's component measures are weak. Appendix $K$ contains the 
correlation matrices associated with each of the research hypotheses. 
CHAPTER V

\section{SUMMARY, CONCLUSIONS AND RECOMMENDATIONS}

This chapter is intended to summarize the whole of this research study, present conclusions based on the findings, and make recommendations for future research regarding the high technology start-up firm.

\section{SUMMARY}

Characteristics of the successful high technology start-up firm have received much attention in the current business literature. Most of the discussion is based on personal experience and observation, and it tends to be discursive and anecdotal rather than being substantiated by the conciseness of structured empirical research.

The thesis of much of the literature is that the venture capital funded firm exemplifies the practices of the successful firm regarding management style, the team approach to management, the structure of the firm, market definition, strategy, financial control and planning. The questions that arise include: (1) Do the funded firms exhibit the qualities of a successful start-up as a result of the requirements and rigor of venture capital acquisition, or are the qualities inherent in the viable 
high technology start-up firm regardless of funding? and (2) Are the characteristics and practices of the successful start-up firm, as defined by the current business literature, embraced by the start-up firm as "the way we do business", or do these notions exist only in the theoretical context of "the best way to do business"?

The intent of this study was to shed light on both of these questions by contrasting and comparing the venture capital funded firm high technology start-up firm and the unfunded firm regarding several of the aforementioned characteristics. Aspects of organizational climate, top management team approach, marketing strategy and focus, business planning and the intent to go public as a means of addressing future financing needs were addressed.

The current business literature served as the source of the characteristics to be examined, the hypothesized differences between venture capital funded and unfunded firms, and the subsequent expectations regarding those differences.

In order to test the hypotheses, a nationwide survey was performed. Based on a sampling frame of 1350 high technology start-up firms, a final sample of 226 respondent firms was obtained. The respondents represented thirty-two states, and the sample was unevenly split regarding the acquisition of venture capital financing, with 142 firms being unfunded and 84 firms being funded. Data collection 
was accomplished through the use of a mail survey. Two mailings were undertaken to achieve a twenty-one percent response rate.

Hypothesis testing was accomplished, for the most part, through the employment of ANOVA. Most hypotheses were tested to determine if significant differences occurred between variable means for the venture capital funded and unfunded firms. In those cases involving nominal scale variables, the Chi-square statistic was utilized to test for independence between funding and the variable under question. In all cases, a significance level of .10 was selected as the criterion for acceptance or rejection of the null hypothesis.

The results of hypothesis testing did not necessarily support all expectations regarding differences between the firm groups. The discrepancies exist primarily with regard to perceptions of marketing traits. While the sample as a whole perceives itself as market driven and solutions oriented, some differences occurred between the groups, but they were not statistically significant. Examination of the attributes of a market niche focus also resulted in differences which were not statistically significant, in addition to the fact that neither group exemplifies a focus on a narrow market niche. 
CONCLUSIONS

Based upon the results of the testing of each of the seven hypotheses, the following conclusions are drawn.

1. There appears to be no question regarding the organizational climate of the high technology start-up firm. Based upon those aspects examined, both the funded and unfunded firms embrace practices which strongly manifest those of an organic organization. The strong propensities toward both open communication channels and participatory decision making are indicative of the lack of formal structure present in these organizations. Structure is, instead, imposed by the value system of the start-up, and that value system provides a context of integrity and equality within which all employees focus on the common goal of the firm. In addition, creativity is strongly supported, as it should be, by the notion that failure is viewed in a positive context as a necessary component of both being creative and making technological advancements.

These findings have implications for the nascent high technology entrepreneur to the extent that one must examine his/her management style to assess whether or not he/she can take a leadership role in creating the culture that is necessary to operate within the dynamic high technology arena.

2. The team approach to management is practiced by both funded and unfunded firms, although the venture capital 
funded firms have a higher quality top management team when quality is defined by aggregate primary past functional experience. The funded firm has a larger team which, in turn, brings more years of experience, a higher aggregate level of organizational responsibility, and more diversity of functional capability. This diversity provides balance in terms of complementary functional skills.

Additional strength is added to the top management team of the funded firms due to a higher percentage of members whose prior experience is directly related to the functional capacity in which they now serve. Similarly, the funded firm is more likely to have management team members whose previous experience was in a firm whose core technology was the same or very similar to that of the start-up.

Examination of the data beyond hypothesis testing substantiated the notion that the higher quality exhibited by the funded firms is a function of viewing the team as a whole, rather than assessing quality based on the average team member. When the notion of quality was assessed by comparing the average team member, it was found that: (1) regarding years of experience, the average funded firm team member has ten percent less than his/her counterpart; (2) regarding level of organizational responsibility, the funded firm team member worked at only a slightly higher level than the unfunded counterpart; and (3) regarding annual sales 
volume, the average team member in the funded firm had his/her previous experience in a firm which was twice as large as the unfunded team member. On this individual basis, only the difference in annual sales volume is statistically significant at the .10 level. For the most part, then, the individual team members "look" the same. As was discussed in the review of the literature, size of the firm in which previous experience was gained tends to be of lesser importance than the notions of diversity, compatible or like technologies, and sameness regarding functional capacities served in. It can be concluded that since the attributes regarding prior experience tend to exhibit equality when examined relative to the individual team member, the quality of the top management team is enhanced by the team concept.

These findings have implications particularly for those firms that intend to seek venture capital financing. The findings of this study support the notions presented in the current literature regarding the composition of the top management teams of the firms which do, in fact, receive funding. Assuming that the present study provides an accurate picture of the management teams of both the funded and unfunded firms, it appears that the unfunded firm attempting to acquire venture capital would have to make a concerted effort to shore up their management teams through the addition of members who would add functional diversity 
coupled with experience in a firm in the same technological arena as the start-up.

3. There do not appear to be significant differences between the venture capital funded and unfunded firms regarding the various marketing oriented characteristics. Both groups tend to be market driven with a solutions orientation. These two characteristics are in strong support of the literature.

The finding which may have implications for both the funded and the unfunded firms is that regarding a narrow focus on a market niche. Both groups strongly agree that their products do not have broad commodity market appeal, and their markets have unique characteristics which differentiate them from the larger market as a whole. On the other hand, both groups indicate that they tend to compete with larger firms based on a product that is not necessarily unique enough to create a barrier to entry. Additionally, they take a neutral stance regarding the use of low cost as a basis of competitive strategy.

It is these last three findings that raise some issues for both groups of firms. If the current business literature is correct regarding a narrow focus on a market niche, then the high technology start-up firms should reexamine their current strategies. If their product is not necessarily unique, what are the barriers to entry into their market ? Are they in a defensible position in their 
market or are they attempting to follow the leader hoping to gain market share through a low cost strategy ? Are they competing in a market which they can control ? The most defensible position for the high technology start-up is to be the leader in a sufficiently narrow market with a unique product that is not easily copiable.

4. The high technology start-up firm which has received venture capital funding is more likely to go public than the unfunded firm. This particular finding substantiates earlier research by Goslin and Kiehl (Goslin and Kiehl, 1988). Based on those earlier results and these current findings, one can conclude that the unfunded firm does not make a public stock offering for much the same reason that it does not seek venture capital financing independence. Management wants to maintain control of the firm. Public stock offerings, like venture capital infusions, result in the entrepreneur having "a smaller piece of a larger pie". However, with the potential of greater gain comes the loss of control and independence.

5. Business planning is practiced by the majority of all high technology start-up firms, although the funded firms do so to a greater extent. Not only do virtually all funded firms prepare business plans, but the plans themselves appear to be more extensive. Additionally, the primary purpose for which the funded firm prepares the plan is for venture capital acquisition. It is unknown if the 
business plan also serves as a working document for the management of the firm.

On the other hand, the unfunded firms perform business plan preparation to a lesser extent, but do so because of operating necessity. In this latter case, it can be concluded that the business plan is used in an ongoing fashion for the management of the firm.

These findings have implications particularly for the unfunded firm which may seek venture capital funding in the future - a comprehensive business plan is a must.

6. Evaluation of the perceptions regarding the importance of the various business plan components substantiates the aforementioned findings regarding a market driven strategy. Market analysis, strategy and definition are perceived as the most important business plan components. These components are also perceived as $21 / 2$ times as important as product definition and approximately four times as important as product $R$ \& D. It follows that the high technology start-up firms, as a group, also perceive themselves as more market driven than technology driven.

Additionally the findings regarding quality of the top management team appear to relate to the perceptions of the importance of the management team and technological competency components. The funded firms, with the higher quality top management teams perceive these two business 
plan components to be twice as important as the former's unfunded counterpart.

RECOMMENDATIONS FOR FURTHER RESEARCH

The review of the literature revealed a scarcity of empirical studies in this particular area. It is this researcher's hope that this study will be a step toward more research on the topic of high technology start-up firms.

There are several additional studies that need to be conducted, and they include the following:

1. The present study should be replicated using an index of annual sales growth as a means to measure the success of the firm. Utilizing this measure would give additional insight into the impact of the practices of both the funded and unfunded firms to the extent that comparisons could then be tied to a tangible index of success.

2. The present study should be replicated using a variable to ascertain whether or not the unfunded firm had ever sought venture capital funding and was subsequently refused. The findings of such a study, particularly where significant differences occurred, would provide useful, empirically based insights to the "refused funding" firms regarding how they differ from their funded counterparts.

3. Additional research should be conducted into the definition of the high technology start-up's market. The present study may not have used an adequate number of 
descriptors when trying to ascertain whether or not the start-up focuses narrowly on a niche. As such, the present study could not necessarily substantiate or vigorously refute the niche focus proposed in the current business literature. Additional descriptors should be used to the extent that a more exact description of how the firm competes can be determined.

4. The present study should be replicated using a variable to define the particular industry segment within which the high technology firms compete. Findings could then be compared across industry segments. Given statistically significant differences between segments, attributes of the start-up firm could be effectively differentiated based on segment. Given statistically insignificant differences, support would be given to the generalizability of the findings of the present study.

5. Additional research into the organizational climate of the high technology firm should be undertaken. The population in this endeavor would include a wider range regarding age. The intent would be to ascertain how the organizational climate might change and what that change is related to.

6. Additional research into geographic clustering should be undertaken. While the present study is limited to factors which are internal to the firm, the findings do indicate significant geographic clustering. The current 
business literature lends a great deal of support to the notion that geographic clustering does contribute to the success of the high technology start-up firm. Future research regarding the external factors which contribute to the success of the start-up would have value toward the end of building a more complete profile of the significant components in the formula for success.

In singular or together, these results provide a better picture of success and a clearer understanding of what factors generally support its achievement. The results have implications for the nascent entrepreneur in the high technology arena toward the end of contributing to a more complete understanding of some of the critical components essential to the success of a start-up. Understanding the characteristics of the successful start-up firm is fundamental to the successful founding and management of a high technology start-up. 


\section{REFERENCES}

Aggarwal, Vimla and Sumer C. Aggarwal. 1984. "High Technology: Economic Hope or Hoax?" Business Horizons, Vol 27, No $1,47-51$.

Allaby, Ian. 1984. "The Not So Hallowed Halls of Higher Learning," Canadian Business, Vol 57, No 9, 85-89.

Anderson, Michael A. "Portland Software Firms Face Long Odds," The Business Journal, 14 October, 1985: 13-18.

Andrews, Edmund I. 1986. "Running Out of Money," Venture, Vol 8 , No $1,32-35$.

Bellack, Dan. 1985. "Shattering The Marketing Myths of Silicon Valley start-Ups," Business Marketing, Vol 70, No $11,78-84$.

Black, Pamela. 1985. "How To Make Them Sit Up and Notice," Venture, Vol 7, No 9, 52-54.

Black, Sena H. 1986. "Different Strokes," Business and Economic Review, Vol 32, No 4, 9-12.

Bleicher, Knut, Frank Bleicher and Herbert Paul. 1983. "Managerial Frameworks for Innovative Responses in High-Tech Organizations," Business Horizons, Vol 26, No $6,69-78$.

Boland, John C. 1985. "Staking Out the High-Tech Winners," Einancial World, Vol 54, No 16, 90-93.

Bott, Robert. 1985. "High-Tech Scramble: Calgary Entrepreneurs Make a Play in the US Telephone Industry," Vol 58, No 3, 27-28.

Bruce, Robert V. 1973. Bell. Boston: Little Brown \& Co.

Burns, Tom and G. M. Stalker. 1980. "Mechanistic and Organic Systems," in organizations: Structure and Behavior, New York: John Wiley \& Sons.

Burstein, Daniel. 1983. "The Creative Chaos of Tomorrow's World," International Management, Vol 38, No 9, 77-81. 
Davidow, William H. 1986. Marketing High Technology, New York: The Free Press.

Dewar, Stephen. 1982. "High Tech's Brightest Hopes," Canadian Business, Vol 55, No 4, 76-87.

Drucker, Peter F. 1985. Innovation \& Entrepreneurship, New York: Harper \& Row.

Emory, C. William. 1980. Business Research Methods, Homewood: Richard D. Irwin.

Farrel1, Larry. 1986. "Building Entrepreneurship: A Global Perspective," Training, Vol 23, No $7,42-50$.

Gartner, William B. 1985. "A Conceptual Framework for Describing The Phenomenon of New Venture Creation," Academy of Management Review, Vol 10, No 4, 696-707.

Geneen, Harold. 1985. "Why Intrapreneurship Doesn't Work," Venture, vol 7, No 1, 46-52.

Gephardt, Richard A. 1985. "Congress is Committed to High Technology," Management Review, Vol 74, No 5, 15-16.

Goldman, Marshal I., Howard A Stafford, and Mark Templer. 1984. "The Business of Attracting Industry," Technology Review, Vol 87, No 4, 6-10, 74 .

Gomez-Mejia, Luis R. and David B. Balkin. 1985. "Managing a High-Tech Venture," Personnel, Vol 62, No 12, 31-36.

Gordon, Mitchell. 1983. "Tomorrow's Hot Issues: Brentwood Associates Has an Eye for High-Tech Winners," Barron's, Vol 63, No 1, 13, 21-22.

Goslin, L.N. and Kiehl, S.J. (in press) "Characteristics Influencing High Technology Start-Up Success," Frontiers of Entrepreneurship Research.

Greene, Michael. 1985. "A Profile of Seed Capital Funds," Business, Vol 35, No 4, 57-58.

Haavind, Robert. 1986. "Hong Kong: The Chinese Connection," High Technology, Vol 6, No 11, 28-31.

Hartman, Curtis. 1983. "Who's Running America's Fastest Growing Companies?" Inc., Vol 5, No 8, 41-47.

Henz, Donald J. 1986. "In Search of Excellence - The Lesson for Small Businesses," SAM Advanced Management Journal, Vol 51, No $3,29-35$. 
Horton, Thomas R. 1985. "The Challenge of High Technology," Management Review, Vol 74, No 5, 3-4.

Howell, James M. 1982. "High-Tech and Risk-Taking Are Bringing the Northeast Back," ABA Banking, Vol 74, No 12 , 60-71.

Howell, James M. 1985. "Formula for Growth: The New England Experience," Business and Economic Review, Vol 31, No 2, 17-24.

Johnson, Bob. 1982. "Capital Abounds for 'Right' Projects: Survey," Computerworld, Vol 16, No 32,78 .

Joseph, Johnathan. 1985. "Cracking the Japanese Market From the Inside," Business Week, No 2896, 138-142.

Josephson, Matthew. 1959. Edison, New York: McGraw-Hill.

Juillard, Marie-Jeanne. 1986. "I Get an Equity Kicker out of You," Venture, Vol 8, No 8, 90-92.

Kane, Sid. 1985. "Your Company or Yourself," Venture, Vol 7 , No $6,98-100$.

Kozmetsky, George, Michael D. Gill Jr. and Raymond W. Smilor. 1985. Financing and Managing Fast-Growth Companies, Lexington: Lexington Books.

Krishna, E.M. and C.P. Rao. 1986. "Is US High Technology High Enough?" Columbia Journal of World Business, Vol 21 , No $2,47-54$.

Larson, Erik, 1987. "The Best-Laid Plans," Inc., Vol 9, No $2,60-64$.

Levy, Robert, Niles Howard and Thomas J. Murray. 1982. "The High Priests of Hi Tech," Dun's Business Month, Vol 119, No 3, 47-57.

Liles, Patrick R. 1974. "Venture Capital: What It Is and How To Raise It," in New Business Ventures and The Entrepreneur, Homewood: Richard D. Irwin.

Lipton, Susan Lytle. 1982. "High Technology Acquisitions / Venture Capital in High Tech Acquisitions," Mergers \& Acquisitions, Vol 17, No 3, 30-40.

Logan, William Bryant. 1986. "Finding Your Angel," Venture, Vol 8, No $3,38-44$. 
Lorriman, John. 1983. "There's an Urgent Need for 'High Tech Humanism'," Canadian Insurance, Vol 88, No 10, 89.

Madlin, Nancy. 1985. "Probing the Entrepreneurial Psyche," Venture, Vol 7, No 5, 24 .

Maidique, Modesto A. and Robert H. Hayes. 1984. "Models for Management: Following the Leaders," Computerworld, Vol 18, No $22,49-63$.

Maidique, Modesto A. and Robert H. Hayes. 1984. "The Art of High-Technology Management," Sloan Management Review, Vol 25 , No $2,17-31$.

"Making New Ventures Go: A Bankroll and a High-Tech Idea Aren't Enough." 1984. Chemical Week, Vol 134, No 15, $44-48$.

Mancuso, Joseph. 1983. How To Prepare and Present a Business Plan, Englewood Cliffs: Prentice-Hall.

Mark, Ken. 1983. "The Entrepreneurial Explosion," Canadian Business, Vol 56, No 11, 86-93.

Marshall, Brian and Robert Forbes. 1983. "Venture Capital Financing of New Technologies," Business Quarterly, Vol 48, No 4, 105-109.

McGuire, Maureen. 1986. "Route 128's Outspoken Man: Napa Valley's Baron of Bubbly," Management Review, Vol 75, No $8,116-18$.

McKenna, Regis. 1985. "Market Positioning in High Technology," California Management Review, Vol 27, No $3,82-108$.

McQueen, Rod. 1984. "The Glory That Could Be Crowntek," Canadian Business, Vol 57, No 9, 108-112.

Michaels, Julie. 1986. "New England: Region Stages an Economic Revival," Advertising Age, Vol 57, No 32, 5153.

Miller, Roger and Marcel Cote. 1985. "Growing the Next Silicon Valley," Harvard Business Review, Vol 63, No $4,114-123$.

Morris, Gay. 1986. "Going Beyond the Product," Venture, Vol 8, No 7, 28-30. 
Moser, Thomas S. 1984. "The Great High-Tech Treasure Hunt," Management Focus, Vol 31, No 5, 16-21.

"Part 2: The Valley." 1985. Inc., Vol 7, No 7, 53-58.

Patterson, William Pat. 1983. "Paying Those High-Tech Dues," Industry Week, Vol 219, No 5, 61-62.

Patterson, William Pat. 1985. "High-Tech 'Chess'," Industry Week, Vol 225, No 2, 50-53.

Pearsen, Gordon. 1986. "Business Strategy Should Not Be Bureaucratic," Accountancy, Vol 97, No 1112, 109-111.

Petre, Peter. 1986. "America's Most Successful Entrepreneur," Fortune, Vol 114, No 9, 24-32.

Pratt, Stanley. 1982. How To Raise Venture Capital, New York: Charles Scribner \& Sons.

Radding, Alan. 1986. "High-Tech Industry Harvests Area's Resources," Advertising Age, Vol 57, No 32, 84.

Rich, Stanley R. and David E. Gumpert. 1985. "Business Plans That Win $\$ \$$ : Lessons From The MIT Enterprise Forum," Venture, Vol 7, No 6, 61-74.

Rosenfeld, Stuart A. 1986. "Let the Chips Fall Where They May," Business and Economic Review, Vol 32, No 4, 3-8.

Rozen, Miriam. 1985. "State Programs Lure High Tech Companies," Dun's Business Month, Vol 125, No 3, 93.

Rubinger, Bruce F. 1986. "Windows on Japan," High Technology, Vol 6 No $8,12-13$.

Rutigliano, Anthony J. 1986. "Managing the New," Management Review, Vol 75, No 1, 38-41.

Sabin, Russell. 1984. "Being Your Own Boss in America," Venture, Vol 6, No 5, 40-52.

Sabin, Russell. 1984. "Private Placements - How Much Are You Willing To Give Up?" Venture, Vol 6, No 7, 106.

Schendel, Dan and Charles Hofer. 1979. Strategic Management: A New View of Business Policy and Planning, Boston: Little Brown \& Company.

Schlitit, W. Keith. 1986. "Guidelines for Entrepreneurial Success," SAM Advanced Management Journal, Vol 51, No $3,44-48$. 
Schoch, Susan. 1985. "The Rarified Path of a Successful Business Plan: Marketing the Business Plan Through the Venture Capital In-Crowd," Venture, Vol 7, No 6, 7883.

Schoner, Bertram and Kenneth P. Uhl. 1975. Marketing Research, New York: John Wiley \& Sons.

Seddon, Norman. 1984. "Raising Venture Capital: The AllImportant Business Plan," The Accountant, Vol 191, No $5700,3-5$.

Shapero, Albert. 1982. "Developing a High-Tech Complex Through Small Business Formations," Survey of Business, Vol 18, No 1, 16-20.

Stacey, Tony. 1986. "How to succeed With a Start-Up," Accountancy, Vol 97, No 1114, 158-160.

Stevenson, Howard H. and Jose Carlos Jarrillo-Mossi. 1986. "Preserving Entrepreneurship as Companies Grow," The Journal of Business Strategy, Vol 7, No 1, 10-23.

Thurston, Philip H. 1983. "Should Smaller Companies Make Eormal Plans?" Harvard Business Review, Vol 61, No 5 , 162-188.

"Two Lessons in Failure from Silicon Valley." 1984. Business Week, No 2859, 78-83.

TulI, Donald S. and Del I. Hawkins. 1984. Marketing Research: Measurement and Method, New York: Macmillan.

Vesper, Karl H. 1980. New Venture Strategies, Englewood Cliffs: Prentice Hall.

Von Furstenburg, George M. 1986. "High-Tech Industries and Economic Growth," Business Economics, Vol 21, No 3, 43-45.

Walker, Ernset W. and J. William Petty II. 1986. Financial Management of the Small Firm, Englewood Cliffs: Pentice-Hall.

Wartik, Nancy. 1984. "When It Pays To Go It Alone," Venture, Vol 6, No 6, 154-156.

Webre, Philip and David Bodde. 1986. "High Technology's Stake In Tax Reform," Technology Review, Vol 89, No 5, 26-34. 
Williams, Bob. 1986. "Try to Understand the Forces of Motivation," Accountancy, Vol 97, No 1113, 90-91.

Willis, Rod. 1986. "Mavericks in Brokerage and Insurance," Management Review, Vol 75, No 9, 17-20.

Yeager, Robert L. 1985. "Engineering the Customer-oriented Marketing Strategy," Business Marketing, Vol 70, No $11,60-76$.

Yeskey, Dennis. 1986. "Strategic Marketing: Industrial Companies Face a Critical Challenge," Management Review, Vol 75, No 4, 20-24.

Zachary, G. Pascal. 1985. "High Tech's New Reality," Willamette Week, Vol 11 , No $50,1-12$.

Zalud, Bill. 1985. "High Tech In The Heartland," Datamation, Vol 31, No $13,90-96$. 
APPENDIX A

QUESTIONNAIRE

TOP MANAGEMENT TEAM

This section on management team experience deals with understanding the previous primary experience (strongest experience) of each of your principal top management team members. For you as $\mathrm{CEO}$ and for the other members of your team, indicated as $B, C$, and $D$, please provide:

- his/her prior primary Experience,

- Years of experience

- Level of organizational responsibility (as an example, CEO = "1", VP of a functional area = "3", Departmental manager $=" 5 "$, and Group Supervisor = "7".

- Sales volume (in millions of dollars) of firm in which experience was gained.

The following EXAMPLE provides some guideline.

CEO

O John Doe, CEO has had 5 years of experience in marketing.

- Place a "5" in the "Y" column under the "CEO" in the "Marketing/Sales" row.

- John's level of organizational responsibility was vice president of marketing.

- Place a "3" in the "I" column under the "CEO" in the "Marketing/Sales" row.

- The annual sales volume at the firm where John gained the experience was $\$ 4.3$ million.

- Place a "4.3" in the "S" column under the "CEO" in the "Marketing/Sales" row.

TEAM MEMBER B

- Pat May, team member B, has had 7 years experience in finance.

- Place a "7" in the "Y" column under the " $B$ " in the "Finance/Accounting" row. 
- Pat's level of organizational responsibility was department manager.

- Place a " 5 " in the " $L$ " column under the " $B$ " in the "Finance/Accounting" row.

- The annual sales volume at the firm where Pat gained the experience was $\$ 50$ million.

- Place a "50" in the "S" column under the " $B$ " in the "Finance/Accounting" row.

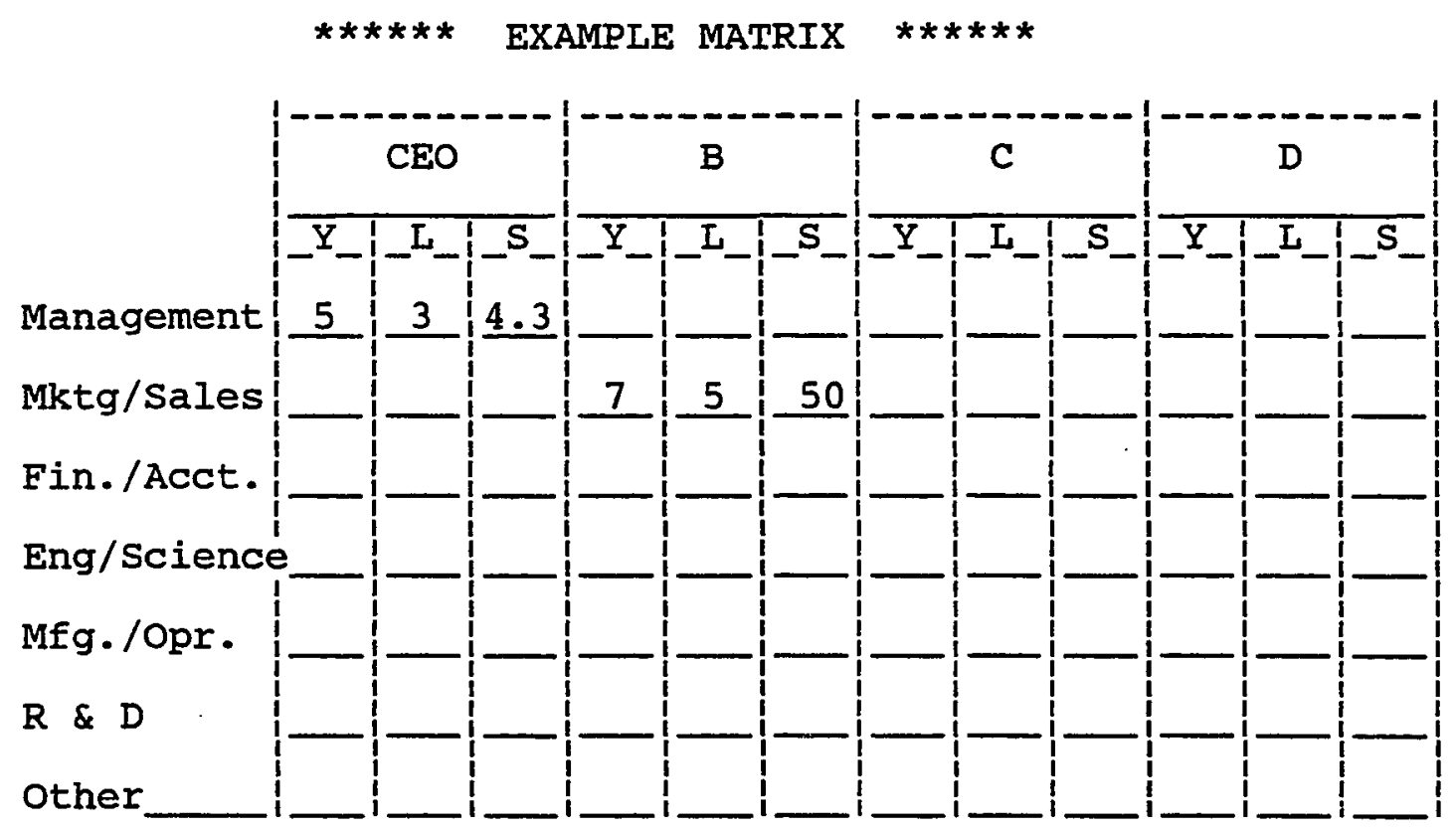

*** PLEASE FILI IN THE MATRIX BELOW FOR YOUR FIRM ***

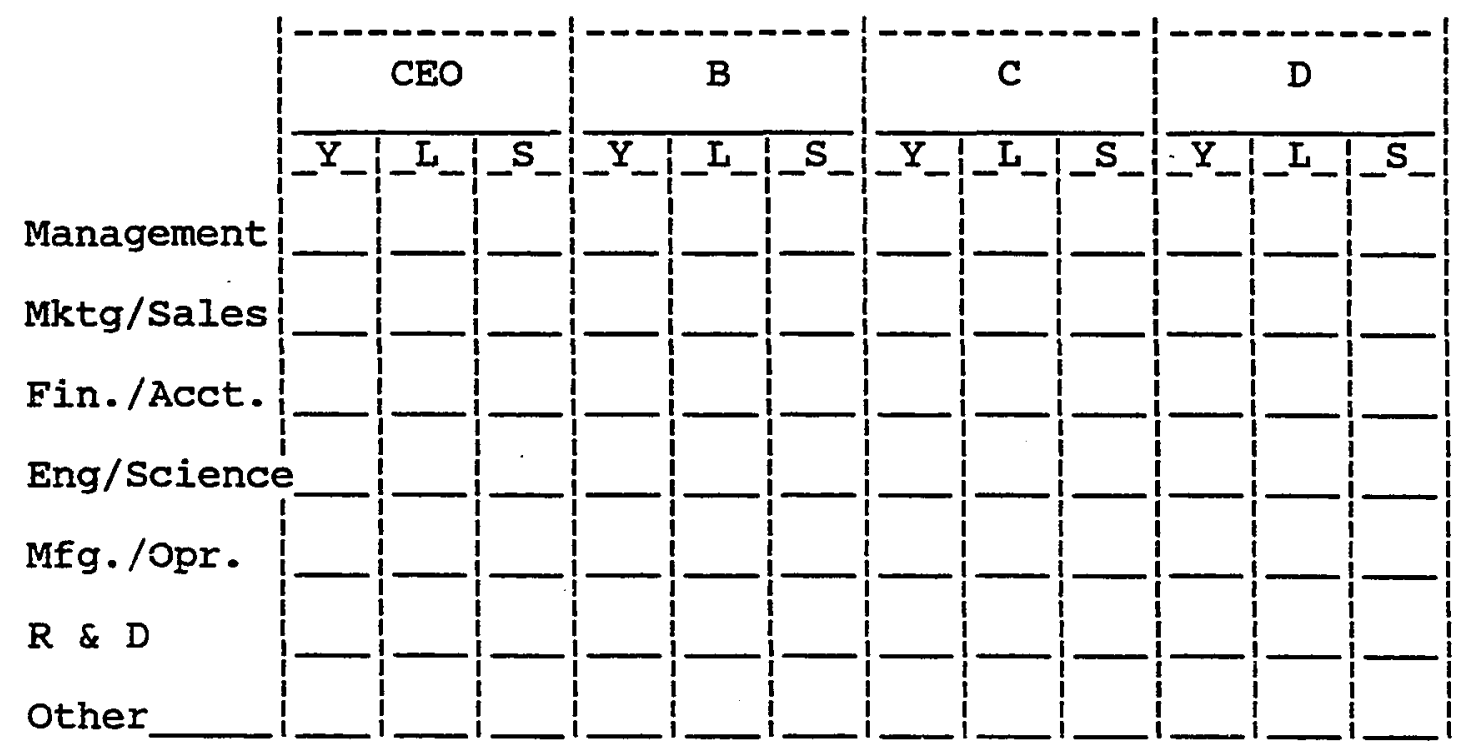


1. Please specify those members of your top management team who now serve in the same or a similar functional capacity as that specified above. (please circle the appropriate team member/s.)

$\begin{array}{llll}\text { CEO } & \mathrm{B} & \mathrm{C} & \mathrm{D}\end{array}$

2. Please specify those members of your top management team whose previous experience (as defined in the matrix above) was in a firm utilizing or producing the technology that supports your product. (please circle the appropriate team member/s.)
CEO
B
C
D

\section{FINANCE}

3. How many years has it been since your firm was founded?

\section{YEARS}

4. How many rounds of venture capital (equity from a formal venture capital company) has your firm had ? (please circle the appropriate number.)

$$
\begin{array}{llllll}
0 & 1 & 2 & 3 & 4 & 5
\end{array}
$$

5. What percent of your business (percent of equity) did you have to give up to get each round of venture funding?
ROUND
DOLLARS OBTAINED
$\div$ GIVEN UP

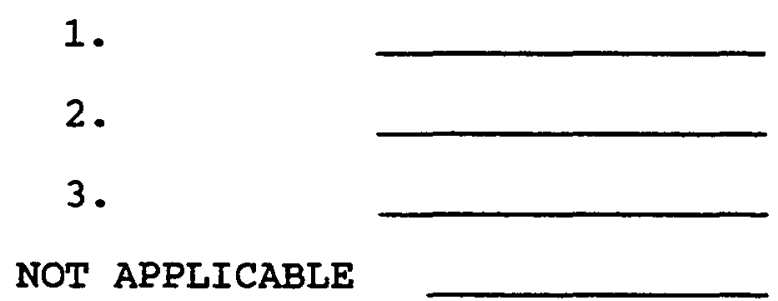


6. What is the probability of your firm going public in the next two years? (please circle the appropriate choice.)

$\begin{array}{ccccc}1 & 2 & 3 & 4 & 5 \\ \text { Definitely } & \text { Probably } & \text { Not } & \text { Probably } & \text { Definitely } \\ \text { Will Not } & \text { Will Not } & \text { Sure } & \text { Will } & \text { Will }\end{array}$

7. We expect to go public within years of founding. (please circle the appropriate number.)

$$
\begin{array}{llllll}
1 & 2 & 3 & 4 & 5 & \mathrm{~N} / \mathrm{A}
\end{array}
$$

\section{BUSINESS PLANNING}

8. How many $81 / 2 \times 11$ pages are there in your business plan?

$$
\text { PAGES }
$$

9. For what primary purpose did you develop your business plan?

(please circle the number to the left of the purpose.)

1. Operating necessity

2. Venture capital requirement

3. Market strategy and definition

4. Other (please specify)

10. Which component of your business plan do you consider to be the most important ? (please circle the number to the left of the "most important".)

1. Product definition

2. Market analysis (customers and competiticn)

3. Marketing strategy (pricing, promotion, distribution, etc.)

4. Product $R \& D$

5. Manufacturing (if applicable)

6. Profit and cashflow projections

7. Management team

8. Market size / share

9. Technological competency 
11. Which component of your business plan do you consider to be the least important? (please circle the number to the left of the "least important".)

1. Product definition

2. Market analysis (customers and competition)

3. Marketing strategy (pricing, promotion, distribution, etc.)

4. Product R\&D

5. Manufacturing (if applicable)

6. Profit and cashflow projections

7. Management team

8. Market size / share

9. Technological competency

12. Please divide 10 points among three of the business plan components listed below so that the division will reflect the three most important to you. (Assign the most points to the most important and the fewest points to the third most important.)

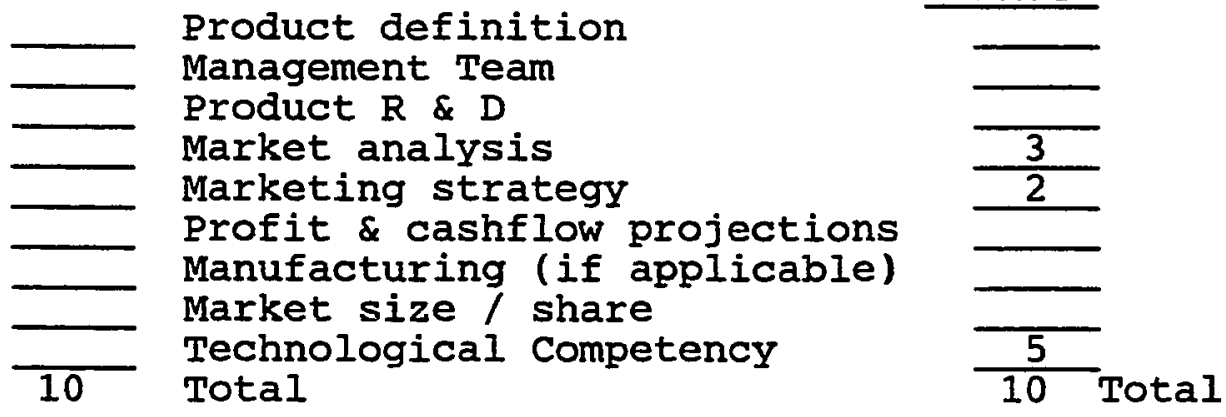

$\star * * * *$ Please indicate the extent to which you agree $* * * * *$ with the following statements about your firm.

Management Style

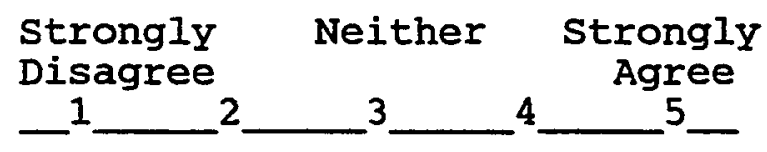

13. Open communication flow, both horizontal and vertical, is never encouraged.

1

1

$\begin{array}{lllll}2 & 3 & 4 & 5\end{array}$
is very participatory. 


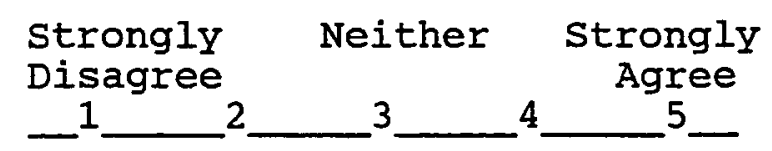

15. Our culture does not include

a tolerance of failure as

$\begin{array}{lllllll}\text { a part of learning. } & 1 & 2 & 3 & 4 & 5\end{array}$

16. Our policies (e.g. ethics, profit sharing, integrity) are very consistent with corporate goals.

1

2

3

4

5

17. Profit is much more important than integrity.

1

2

34

5

\section{MARKETING}

18. Our product is so good that it will sell itself.

19. Customer feedback is not essential to our product development.

\section{1}

2

3

4

5

20. Our firm is extremely krowledgeable about competitor activities.

21. We compete directly with very large companies.

1

22. Our employees are very customer focused.

23. We do not believe that market demand is primary to technological sophistication.

1

2

3

4

5

24. Our firm is intimately knowledgeable about our customers' business.

\section{1}

25. We strive to be low cost producer in our market.

26. Uniqueness of our product deters entry by others.

1

1

3

4

5

$\begin{array}{llll}2 & 3 & 4 & 5\end{array}$




Strongly
Disagree
1

27. Our product appeals to a broad commodity market.

1

2

3

4

5

28. Our firm's focus is on sharp unique market segmentation.

29. Our market has needs or characteristics that differ from the larger market as a whole.

23

4

5 


\author{
APPENDIX B \\ HYPOTHESIS TEST RESULTS \\ EXPECTED VERSUS ACTUAL
}

Expected Actual

\title{
Management Depth
}

HI: Funded firm's organizational climate more organic

H2: Funded firm's top management team higher quality

Marketing Skill

H3: Funded firm more market driven

$+$

H4: Funded firm more solutions oriented

$+$

H5: Funded firm focuses more narrowly on a niche

\section{Financial Control}

H6: Funded firm more likely to go public + +

H7: Funded firm more likely to have prepared a formal business plan 
APPENDIX C

DEMOGRAPHICS - ENTIRE SAMPLE

Variable

Location of Firm:

AL

AZ

$\mathrm{CA}$

$\mathrm{CO}$

CT

FL

GA

IL

KS

KY

MA

MD

MI

MN

MO

NC

$\mathrm{NH}$

NJ

NM

NY

$\mathrm{OH}$

OR

PA

RI

SC

TN

TX

VA

VT

WA

WI

WV
Number of Percentage of

Responses Total Responses

$\begin{array}{rr}1 & .4 \\ 4 & 1.8 \\ 56 & 24.8 \\ 3 & 1.3 \\ 7 & 3.1 \\ 7 & 3.1 \\ 4 & 1.8 \\ 5 & 2.2 \\ 1 & .4 \\ 1 & .4 \\ 25 & 11.1 \\ 7 & 3.1 \\ 3 & 1.3 \\ 8 & 3.5 \\ 1 & .4 \\ 2 & .9 \\ 2 & .9 \\ 6 & 2.7 \\ 1 & .4 \\ 4 & 1.8 \\ 2 & .9 \\ 24 & 10.6 \\ 11 & 4.9 \\ 1 & .4 \\ 2 & .9 \\ 2 & .9 \\ 12 & 5.3 \\ 5 & 2.2 \\ 4 & 1.8 \\ 10 & 4.4 \\ 4 & 1.8 \\ 1 & .4\end{array}$


Variable

Firm Age:

1 year

2 years

3 years

4 years

5 years

Venture Capital Funding: Unfunded

Funded
Number of Percentage of

Responses Total Responses

21

30

41

66

68

142

84

63.1

36.9
9.3

13.3

18.1

29.2

30.0 


\section{APPENDIX D}

\section{DEMOGRAPHICS - UNFUNDED FIRMS}

\section{Variable}

\section{Location of Firm:}

AI

AZ

$\mathrm{CA}$

CO

CT

FI

GA

IL

KY

KS

MA

MD

MI

MN

MO

NC

NH

NJ

NM

NY

$\mathrm{OH}$

OR

PA

RI

SC

TN

TX

VA

VT

WA

WI

WV

\section{Number of Percentage of \\ Responses Total Responses}

$\begin{array}{rr}1 & .7 \\ 4 & 2.8 \\ 34 & 23.9 \\ 3 & 2.1 \\ 4 & 2.8 \\ 5 & 3.5 \\ 4 & 2.8 \\ 3 & 2.1 \\ 1 & .7 \\ 0 & .0 \\ 12 & 8.5 \\ 3 & 2.1 \\ 2 & 1.4 \\ 5 & 3.5 \\ 1 & .7 \\ 2 & 1.4 \\ 2 & 1.4 \\ 2 & 1.4 \\ 1 & .7 \\ 1 & .7 \\ 1 & .7 \\ 16 & 11.3 \\ 8 & 5.6 \\ 1 & .7 \\ 2 & 1.4 \\ 1 & .7 \\ 5 & 3.5 \\ 3 & 2.1 \\ 2 & 1.4 \\ 9 & 6.3 \\ 3 & 2.1 \\ 1 & .7\end{array}$


Variable

Firm Age:

1 year

2 years

3 years

4 years

5 years
Number of Percentage of

Responses Total Responses

$\begin{array}{ll}16 & 11.3 \\ 20 & 14.1 \\ 23 & 16.2 \\ 39 & 27.4 \\ 44 & 40.0\end{array}$


APPENDIX E

DEMOGRAPHICS - FUNDED FIRMS

\section{Variable}

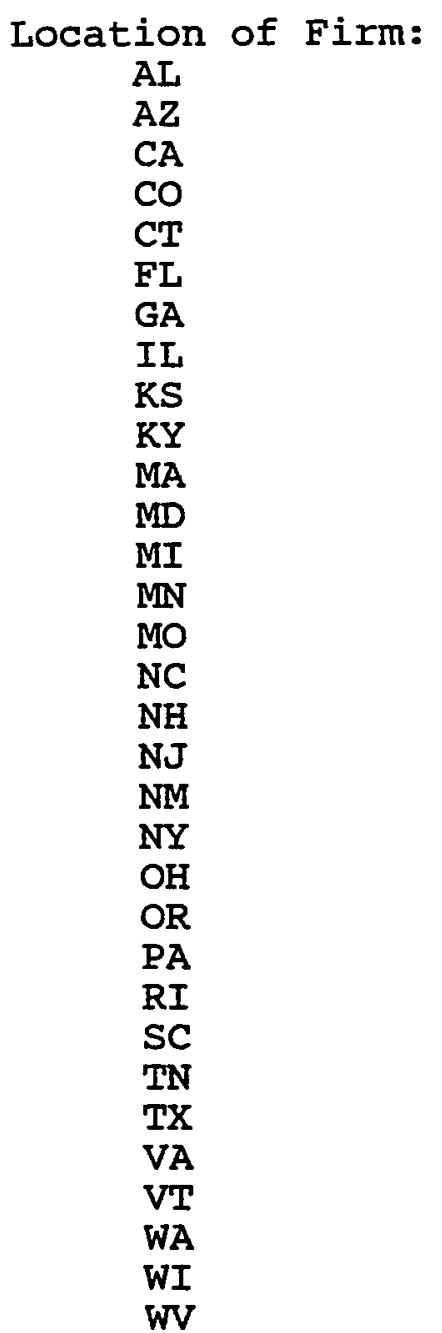

Number of Percentage of

Responses Total Responses

$\begin{array}{rr}0 & .0 \\ 0 & .0 \\ 22 & 26.5 \\ 0 & .0 \\ 3 & 3.6 \\ 2 & 2.4 \\ 0 & .0 \\ 2 & 2.4 \\ 1 & 1.2 \\ 0 & .0 \\ 13 & 15.7 \\ 4 & 4.8 \\ 1 & 1.2 \\ 3 & 3.6 \\ 0 & .0 \\ 0 & .0 \\ 0 & .0 \\ 3 & 3.6 \\ 0 & .0 \\ 3 & 3.6 \\ 1 & 1.2 \\ 8 & 9.6 \\ 3 & 3.6 \\ 0 & .0 \\ 0 & .0 \\ 1 & 1.2 \\ 7 & 8.4 \\ 2 & 2.4 \\ 2 & 2.4 \\ 1 & 1.2 \\ 1 & 1.2 \\ 0 & .0\end{array}$


Variable

Firm Age:



Rounds of Venture Capital:

1
2
3
4
5
7

Round 1 Dollars:

$$
\begin{aligned}
& <1 \text { million } \\
& 1-1.99 \text { million } \\
& 2-2.99 \text { million } \\
& 3-3.99 \text { million } \\
& 4-4.99 \text { million } \\
& 5-5.99 \text { million } \\
& 6-6.99 \text { million } \\
& 7-7.99 \text { million } \\
& 9-9.99 \text { million } \\
& 10 \text { million } \\
& 25 \text { million }
\end{aligned}
$$

Round 1 Equity \% Given Up:

$$
\begin{array}{r}
0-10 \\
11-20 \\
21=30 \\
31-40 \\
41-50 \\
51=60 \\
61-70 \\
75 \\
80 \\
90
\end{array}
$$

Number of Percentage of

Responses Total Responses

$\begin{array}{rr}5 & 6.0 \\ 10 & 12.0 \\ 18 & 21.7 \\ 26 & 31.3 \\ 24 & 28.9\end{array}$

32.5

31.3

24.1

7.2

3.6

1.2

1

26

18

11

3

3

4

2

2

1

1

1

36.1

25.0

15.3

4.2

4.2

5.6

2.8

2.8

1.4

1.4

1.4

$\begin{array}{rr}7 & 9.9 \\ 7 & 9.9 \\ 14 & 19.7 \\ 10 & 14.1 \\ 16 & 22.6 \\ 8 & 11.2 \\ 2 & 2.8 \\ 3 & 4.2 \\ 2 & 2.8 \\ 2 & 2.8\end{array}$


Variable

Round 2 Dollars:

$<1$ million

1 - 1.99 million

2 - 2.99 million

3 - 3.99 million

4 - 4.99 million

5 - 5.99 miliion

6 - 6.99 million

7 - 7.99 million

8 - 8.88 million

12 million

21 million

Round 2 Equity \& Given Up:
Number of Percentage of

Responses Total Responses

$$
\begin{array}{r}
0-10 \\
11-20 \\
21-30 \\
31-40 \\
41-50 \\
51-60 \\
61-70 \\
75 \\
80 \\
83
\end{array}
$$

$\begin{array}{rr}11 & 25.0 \\ 7 & 15.9 \\ 11 & 20.5 \\ 7 & 15.9 \\ 1 & 2.3 \\ 4 & 4.8 \\ 1 & 2.3 \\ 1 & 2.3 \\ 1 & 2.3 \\ 1 & 2.3 \\ 1 & 2.3\end{array}$

Round 3 Dollars:

$<1$ million

1 - 1.99 million

2 - 2.99 million

3 - 3.99 million

4 - 4.99 million

5 - 5.99 million

6 - 6.99 million

7 - 7.99 million

8 - 8.88 million

9 million

18.2 million
6
16
14
2
4
1
2
2
1
1

13.3

35.6

32.2

4.4

8.8

2.2

4.4

4.4

2.2

2.2

5.0

25.0

25.0

20.0

. 0

15.0

.0

.0

.0

5.0 
Variable

Round 3 Equity $\%$ Given Up:

$0-10$
$11=20$
$21=30$
$31-40$
$41-50$
$51=60$
$61-70$
75
80
83

Equity Cost / \$ 1 million Ist Round 2nd Round 3rd Round
Number of Percentage of

Responses Total Responses

$\begin{array}{rr}9 & 42.9 \\ 8 & 38.1 \\ 1 & 4.8 \\ 1 & 4.8 \\ 1 & 4.8 \\ 0 & .0 \\ 0 & .0 \\ 0 & .0 \\ 1 & 4.8 \\ 1 & 2.2\end{array}$

$36.4 \%$

10.5

5.8 
APPENDIX F

ORGANIZATIONAL CLIMATE PROFILES

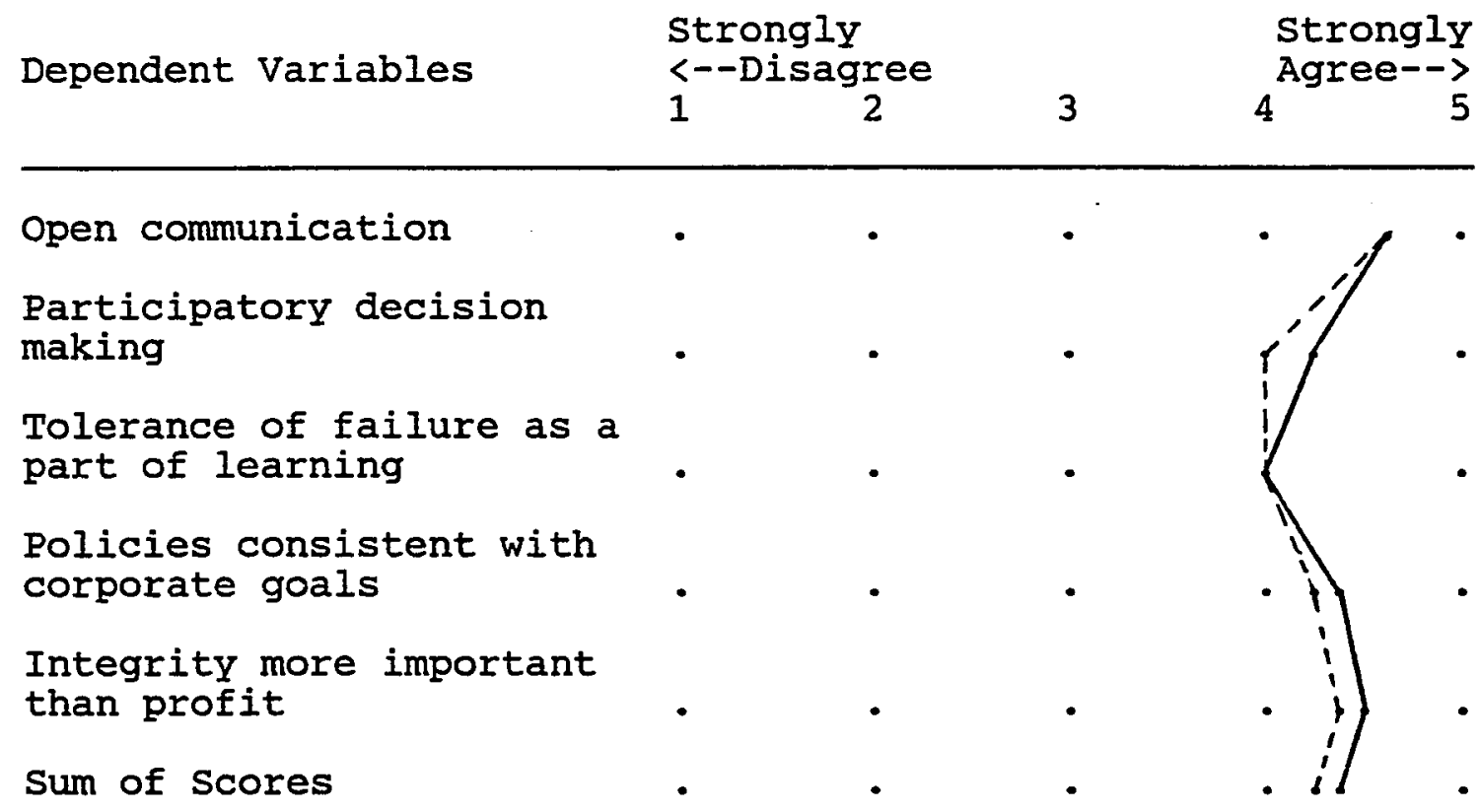

----- Mean Venture Capital Funded Rating

- Mean Unfunded Rating 
APPENDIX G

STRATEGY PROFILES

\begin{tabular}{|c|c|c|c|}
\hline Dependent Variables & $\begin{array}{l}\text { Strongly } \\
<--D i s a g r e e\end{array}$ & & $\begin{array}{l}\text { Strongly } \\
\text { Agree--> }\end{array}$ \\
\hline & $1 \quad 2$ & 3 & 5 \\
\hline
\end{tabular}

Product does not sell itself

Knowledgeable about competitor activities

Employees very customer focused

Market demand is primary to technology

Sum of scores

to

------ Mean Venture Capital Funded Rating Mean Unfunded Rating 
APPENDIX $\mathrm{H}$

SOLUTIONS ORIENTATION PROFILES

\begin{tabular}{|c|c|c|c|}
\hline Dependent Variables & $\begin{array}{l}\text { Strongly } \\
<--D i s a g r e e\end{array}$ & & $\begin{array}{l}\text { Strongly } \\
\text { Agree--> }\end{array}$ \\
\hline & $1 \quad 2$ & 3 & 4 \\
\hline
\end{tabular}

Customer feedback essential

to product development

Employees very customer focused

Intimately knowledgeable about customers' business

Focus on sharp unique market segmentation

sum of scores

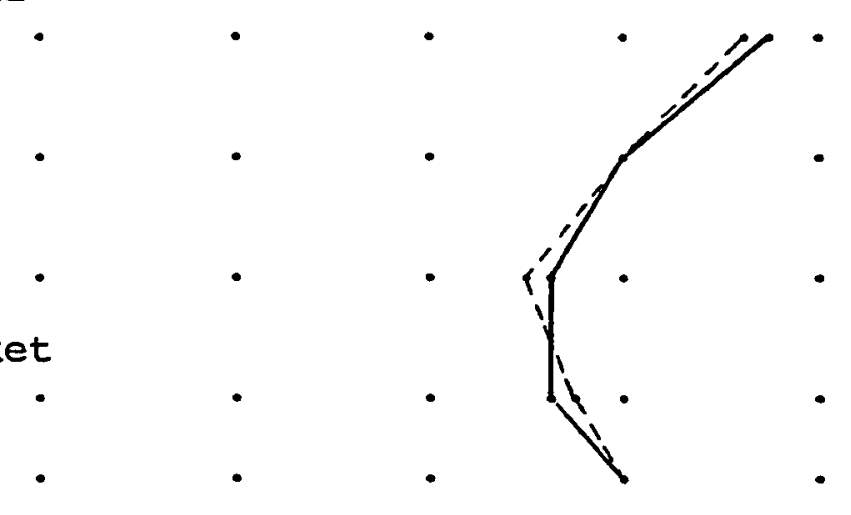

----- Mean Venture Capital Funded Rating Mean Unfunded Rating 


\section{APPENDIX I}

MARKET NICHE STRATEGY PROFILES

\begin{tabular}{llllr} 
Dependent Variables & $\begin{array}{l}\text { Strongly } \\
<--D i s a g r e e\end{array}$ & 3 & 4 & $\begin{array}{r}\text { Strongly } \\
\text { Agree--> }\end{array}$ \\
\hline
\end{tabular}

Do not compete directly with very large companies

Do not strive to be low cost producer

Uniqueness of product deters entry

Product does not appeal to broad commodity market

Focus on sharp unique market segmentation

Market differs from larger market as a whole

Sum of Scores

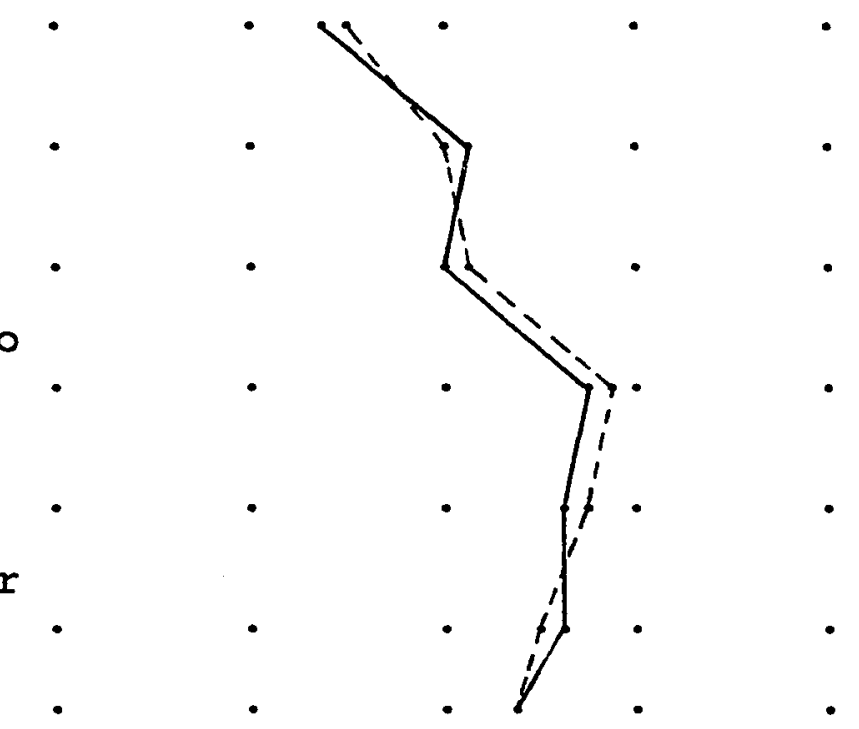

Mean Venture Capital Funded Rating

Mean Unfunded Rating 
APPENDIX J

BUSINESS PLAN COMPONENT WEIGHTING PROFILES

Component

Least

Most

$<-$-Important

$0 \quad 1$

2

Important-->

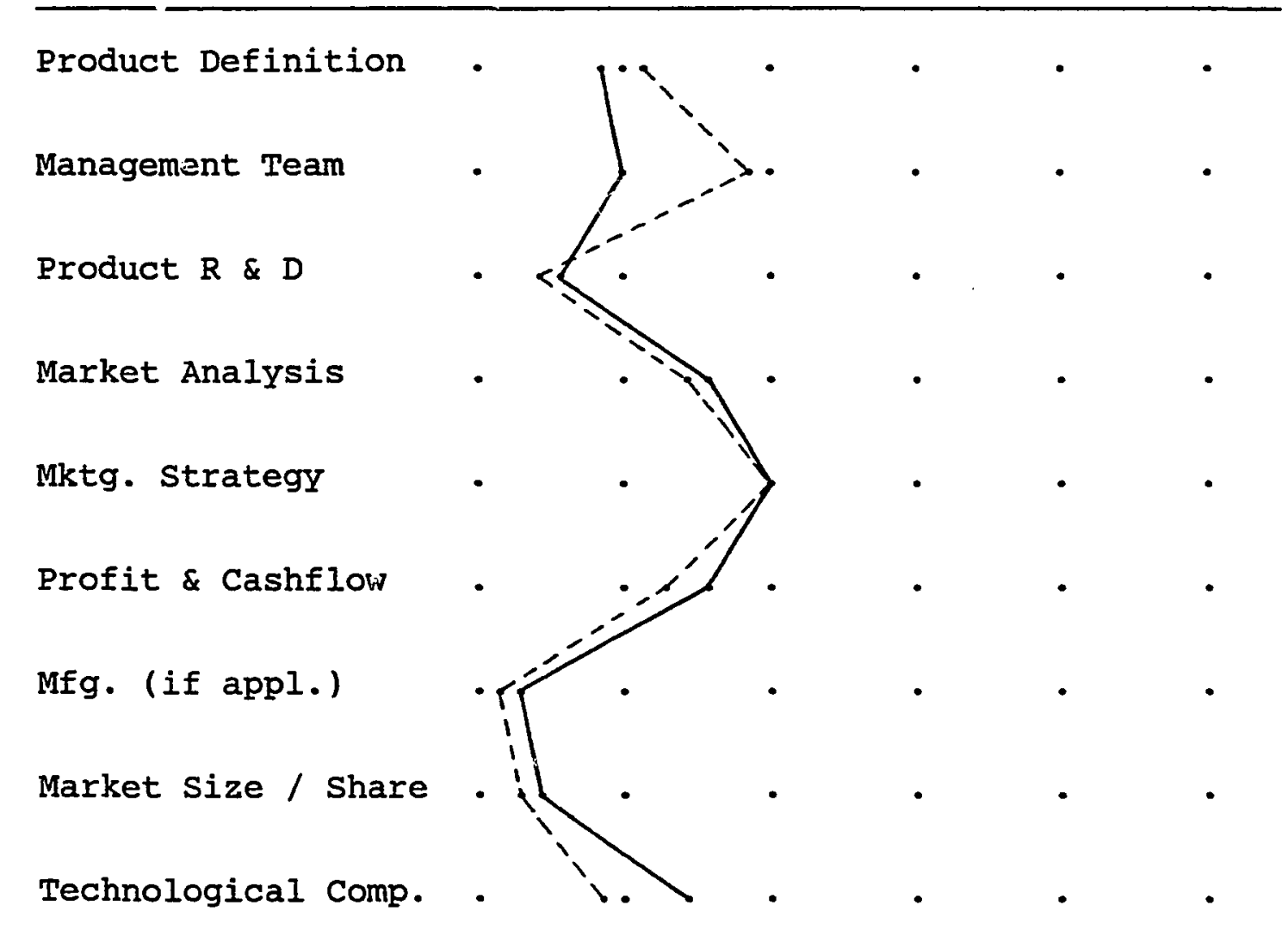

- - Mean Venture Capital Funded Rating

Mean Unfunded Rating 
APPENDIX K

\section{HYPOTHESIS 1 - ORGANIZATIONAL CLIMATE CORRELATION MATRIX}

\begin{tabular}{|c|c|c|c|c|c|}
\hline & $\mathrm{v} 1.1$ & v1. 2 & v1.3 & $\mathrm{v} 1.4$ & $v 1.5$ \\
\hline v1.1 & 1.00 & $\begin{array}{l}.2264 \\
\mathrm{p}=.00\end{array}$ & $\begin{array}{l}.0959 \\
p=.08\end{array}$ & $\begin{array}{l}.2551 \\
\mathrm{p}=.00\end{array}$ & $\begin{array}{l}.0689 \\
p=.07\end{array}$ \\
\hline $\mathrm{v} 1.2$ & & 1.00 & $\begin{array}{l}.2978 \\
\mathrm{p}=.00\end{array}$ & $\begin{array}{l}.4550 \\
p=.00\end{array}$ & $\begin{array}{l}.1393 \\
\mathrm{p}=.02\end{array}$ \\
\hline $\mathrm{v} 1.3$ & & & 1.00 & $\begin{array}{l}.3337 \\
\mathrm{p}=.00\end{array}$ & $\begin{array}{l}.2997 \\
\mathrm{p}=.00\end{array}$ \\
\hline $\mathrm{v} 1.4$ & & & & 1.00 & $\begin{array}{l}.2795 \\
p=.00\end{array}$ \\
\hline$v 1.5$ & & & & & 1.00 \\
\hline
\end{tabular}

Legend:

v1.1 = Open communication flow

v1.2 = Participatory decision making

v1.3 = Tolerance of failure

v1.4 = Policies consistent with corporate goals

$\mathrm{v} 1.5$ = Integrity more important than profit 


\section{HYPOTHESIS 2 - TOP MANAGEMENT TEAM QUALITY CORRELATION MATRIX}

\begin{tabular}{|c|c|c|c|c|c|c|c|}
\hline & $\mathrm{v} 2.2$ & $v 2.3$ & $\mathrm{v} 2.4$ & v2. 5 & $v 2.6$ & $v 2.7$ & $v 2.8$ \\
\hline $\mathrm{v} 2.2$ & 1.00 & $\begin{array}{l}.5070 \\
\dot{p}=.00\end{array}$ & $\begin{array}{l}.1779 \\
\mathrm{p}=.00\end{array}$ & $\begin{array}{l}.4366 \\
\dot{p}=.00\end{array}$ & $\begin{array}{l}.2972 \\
\dot{p}=.00\end{array}$ & $\begin{array}{l}.4695 \\
p=.00\end{array}$ & $\begin{array}{l}5190 \\
p=.00\end{array}$ \\
\hline$v 2.3$ & & 1.00 & $\begin{array}{l}.2624 \\
p=.00\end{array}$ & $\begin{array}{l}.3377 \\
\mathrm{p}=.00\end{array}$ & $\begin{array}{l}.3397 \\
\mathrm{p}=.00\end{array}$ & $\begin{array}{l}.4261 \\
\dot{p}=.00\end{array}$ & $\begin{array}{l}.5484 \\
\mathrm{p}=.00\end{array}$ \\
\hline$v 2.4$ & & & 1.00 & $\begin{array}{l}.0188 \\
\mathrm{p}=.39\end{array}$ & $\begin{array}{r}-.0092 \\
p=.45\end{array}$ & $\begin{array}{l}.1815 \\
\mathrm{p}=.00\end{array}$ & $\begin{array}{l}.0734 \\
\mathrm{p}=.14\end{array}$ \\
\hline$v 2.5$ & & & & 1.00 & $\begin{array}{l}.4570 \\
\mathrm{p}=.00\end{array}$ & $\begin{array}{l}.5525 \\
\dot{p}=.00\end{array}$ & $\begin{array}{l}.3858 \\
\mathrm{p}=.00\end{array}$ \\
\hline$v 2.6$ & & & & & 1.00 & $\begin{array}{l}.4335 \\
\dot{p}=.00\end{array}$ & $\begin{array}{l}.1725 \\
\mathrm{p}=.01\end{array}$ \\
\hline v2.7 & & & & & & 1.00 & $\begin{array}{l}.5141 \\
\mathrm{p}=.00\end{array}$ \\
\hline$v 2.8$ & & & & & & & 1.00 \\
\hline
\end{tabular}

Legend:

v2.2 = Aggregate years

v2.3 = Aggregate level of responsibility

v2.4 = Aggregate annual sales volume

v2.5 = Members serving in same functional capacity

v2.6 = Members having experience with same technology

v2.7 = Number of team members

v2.8 = Number of functional areas represented by prior experience 
HYPOTHESIS 3 - MARKET DRIVEN STRATEGY CORRELATION MATRIX

\begin{tabular}{|c|c|c|c|c|}
\hline & v3.1 & v3.2 & v3.3 & v3.4 \\
\hline v3.1 & 1.00 & $\begin{array}{r}-.0430 \\
\mathrm{p}=.26\end{array}$ & $\begin{array}{r}-.1169 \\
\mathrm{p}=.04\end{array}$ & $\begin{array}{l}.1819 \\
\mathrm{p}=.00\end{array}$ \\
\hline v3.2 & & 1.00 & $\begin{array}{l}.1806 \\
p=.00\end{array}$ & $\begin{array}{l}.0717 \\
\mathrm{p}=.15\end{array}$ \\
\hline v3.3 & & & 1.00 & $\begin{array}{l}.0435 \\
\mathrm{p}=.27\end{array}$ \\
\hline v3.4 & & & & 1.00 \\
\hline
\end{tabular}

Legend:

v3.1 = Product does not sell itself

v3.2 = Knowledgeable about competitor activities

v3.3 = Employees are customer focused

v3.4 = Market demand is primary to technological sophistication 


\section{HYPOTHESIS 4 - SOLUTIONS ORIENTATION CORRELATION MATRIX}

$\begin{array}{lrrrr} & v 4.1 & \mathrm{v} 4.2 & \mathrm{v} 4.3 & \mathrm{v} 4.4 \\ \mathrm{v} 4.1 & 1.00 & .1663 & .0903 & .1019 \\ \mathrm{v} 4.2 & & \mathrm{p}=.00 & \mathrm{p}=.09 & \mathrm{p}=.07 \\ \mathrm{v} 4.3 & 1.00 & .3064 & .1492 \\ \mathrm{v} 4.4 & & & \mathrm{p}=.00 & \mathrm{p}=.01 \\ & & & 1.00 & .0679 \\ & & & & \mathrm{p}=.16 \\ & & & & 1.00\end{array}$

Legend:

v4.1 = Customer feedback essential to new product development

v4.2 = Employees customer focused

v4.3 = Intimately knowledgeable about customers' business v4.4 = Focus on sharp unique market segmentation 


\section{HYPOTHESIS 5 - FOCUS ON MARKET NICHE CORRELATION MATRIX}

\begin{tabular}{|c|c|c|c|c|c|c|}
\hline & v5.1 & $\mathrm{v} 5.2$ & v5.3 & v5.4 & $v 5.5$ & $\mathrm{v} 5.6$ \\
\hline v5.1 & 1.00 & $\begin{array}{l}.2048 \\
p=.00\end{array}$ & $\begin{array}{l}.1318 \\
p=.03\end{array}$ & $\begin{array}{l}.0267 \\
\mathrm{p}=.35\end{array}$ & $\begin{array}{l}.0080 \\
p=.45\end{array}$ & $\begin{array}{r}-.0559 \\
p=.21\end{array}$ \\
\hline v5. 2 & & 1.00 & $\begin{array}{l}.0250 \\
p=.36\end{array}$ & $\begin{array}{r}.1819 \\
\mathrm{p}=.00\end{array}$ & $\begin{array}{l}.0679 \\
p=.16\end{array}$ & $\begin{array}{r}-.0338 \\
\mathrm{p}=.31\end{array}$ \\
\hline v5.3 & & & 1.00 & $\begin{array}{l}.0272 \\
p=.35\end{array}$ & $\begin{array}{l}.0824 \\
\mathrm{p}=.11\end{array}$ & $\begin{array}{l}.1412 \\
\mathrm{p}=.02\end{array}$ \\
\hline v5. 4 & & & & 1.00 & $\begin{array}{l}.3195 \\
\mathrm{p}=.00\end{array}$ & $\begin{array}{l}.3304 \\
\mathrm{p}=.00\end{array}$ \\
\hline v5.5 & & & & & 1.00 & $\begin{array}{l}.3016 \\
\mathrm{p}=.00\end{array}$ \\
\hline $\mathrm{v} 5.6$ & & & & & & 1.00 \\
\hline
\end{tabular}

Legend :

v5.1 = Do not compete directly with very large companies v5.2 = Do not strive to be low cost producer

v5.3 = Uniqueness of product deters entry

v5.4 = Product does not appeal to broad commodity market

v5.5 = Focus on sharp unique market segmentation

v5.6 = our market differs from the larger market as a whole 


\section{HYPOTHESIS 6 - PLAN ON GOING PUBLIC CORRELATION MATRIX}

$\begin{array}{lrr} & \text { v6.1 } & \text { v6.2 } \\ \text { v6.1 } & 1.00 & .1068 \\ \text { v6.2 } & & \mathrm{p}=.07 \\ & & 1.00\end{array}$

Legend:

v6.1 = Probability of going public in two years or less v6.2 = Years elapsed between founding and going public 